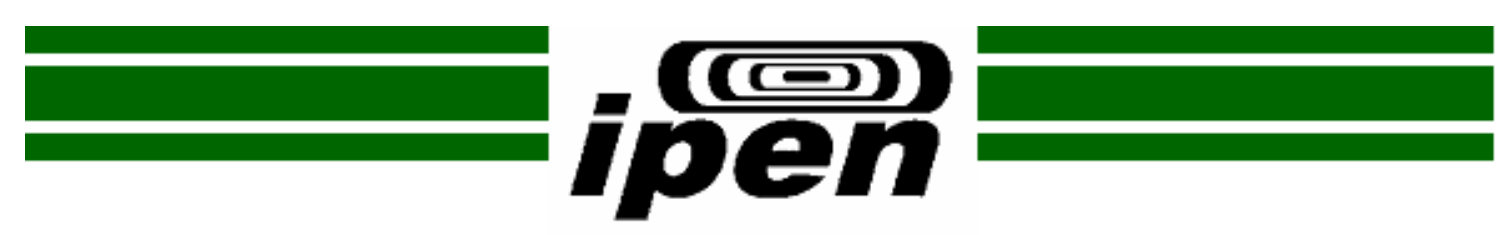

Autarquia associada à Universidade de São Paulo

\title{
PADRONIZAÇÃO DO MÉTODO DE DOSIMETRIA FRICKE GEL E AVALIAÇÃO TRIDIMENSIONAL DE DOSE EMPREGANDO A TÉCNICA DE IMAGEAMENTO POR RESSONÂNCIA MAGNÉTICA
}

CHRISTIANNE COBELLO CAVINATO

Dissertação apresentada como parte dos requisitos para obtenção do Grau de Mestre em Ciências na Área de Tecnologia Nuclear - Aplicações.

Orientadora:

Drª . Letícia Lucente Campos Rodrigues

SÃO PAULO 
INSTITUTO DE PESQUISAS ENERGÉTICAS E NUCLEARES

Autarquia associada à Universidade de São Paulo

\section{PADRONIZAÇÃO DO MÉTODO DE DOSIMETRIA FRICKE GEL E AVALIAÇÃO TRIDIMENSIONAL DE DOSE EMPREGANDO A TÉCNICA DE IMAGEAMENTO POR RESSONÂNCIA MAGNÉTICA}

CHRISTIANNE COBELLO CAVINATO

Dissertação apresentada como parte dos requisitos para obtenção do Grau de Mestre em Ciências na Área de Tecnologia Nuclear - Aplicações.

Orientadora:

Drà. Letícia Lucente Campos Rodrigues 
Aos meus queridos pais, meus tesouros eternos... Ao meu querido noivo, amigo fiel e incentivador. 


\section{AGRADECIMENTOS}

À minha orientadora, Dr ${ }^{a}$. Letícia Lucente Campos Rodrigues, pela orientação, paciência, compreensão, confiança e credibilidade, por tudo o que me ensinou, pelas valiosas sugestões e amizade.

Ao Instituto de Pesquisas Energéticas e Nucleares - Comissão Nacional de Energia Nuclear de São Paulo (IPEN-CNEN/SP), na pessoa do Superintendente Dr. Nilson Dias Vieira Junior, pela oportunidade de realizar e concluir o curso de pós-graduação.

À Comissão Nacional de Energia Nuclear (CNEN), à Fundação de Amparo à Pesquisa do Estado de São Paulo (FAPESP), ao Conselho Nacional de Desenvolvimento Científico e Tecnológico (CNPq) e à Coordenação de Aperfeiçoamento de Pessoal de Nível Superior (CAPES), pelo apoio financeiro.

À Drª . Linda Viola Ehlin Caldas, chefe da Gerência de Metrologia das Radiações (GMR) do IPEN, pela hospitalidade, paciência e amizade, pelos ensinamentos transmitidos e por ter sido, sempre, tão prestativa e gentil.

À Dra . Ana Maria Sisti Galante, grande exemplo de pesquisadora, pela amizade e paciência, pelo esclarecimento de dúvidas relacionadas às partes teórica e experimental do projeto, e, também, por todas as valiosas dicas e sugestões que contribuíram de maneira significativa na confecção desta dissertação. Também a agradeço por ter cedido as amostras de gelatina para que eu pudesse realizar este trabalho. Devo a ela esta conquista, por não ter medido esforços para me ajudar.

À Drạ. Felícia Delgallo Rocha, pelas valiosas sugestões dadas no dia da apresentação do Seminário Geral de Área, por todo auxílio prestado e pela amizade. 
Ao Dr. Orlando Rodrigues Junior, pela reconstrução das imagens tridimensionais do simulador desenvolvido neste trabalho, por ter me auxiliado sempre que precisei e pela amizade.

Ao Dr. Alberto Saburo Todo, por tudo o que me ensinou, pelas dicas, por ter me auxiliado no momento que mais precisei e pela amizade.

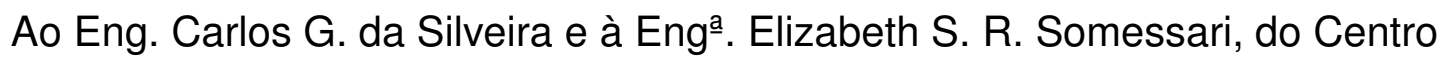
de Tecnologia das Radiações (CTR) do IPEN, pelas irradiações das amostras nos irradiadores com fonte de ${ }^{60} \mathrm{Co}$ do Laboratório de Fontes Intensas de Radiação (LFIR) do IPEN, pelo esclarecimento de dúvidas e pela amizade. Também agradeço ao Sr. Hélio Antônio Paes, do LFIR, por ter perfurado o bloco de chumbo utilizado para acomodar uma amostra contida no capilar de vidro que foi parcialmente irradiado na fonte Panorâmica e pela amizade.

À Drá. Maria da Penha Albuquerque Potiens e ao Dr. Vitor Vivolo, pelas irradiações das amostras nos sistemas de radiação $X$ de energias baixas do Laboratório de Calibração de Instrumentos (LCI) do IPEN, pelo esclarecimento de dúvidas e pela amizade.

Ao MSc. Gelson P. dos Santos, pelas irradiações das amostras no sistema de teleterapia com fonte de ${ }^{60} \mathrm{Co}$ do LCI do IPEN.

Ao físico Marcelo Ribeiro Picioli, pelas irradiações das amostras no acelerador de fótons, da Divisão de Oncologia do Instituto de Radiologia (InRad) do Hospital das Clínicas (HC) da Faculdade de Medicina da Universidade de São Paulo (FM-USP), pela gentileza e amizade.

Ao Instituto de Radiocirurgia Neurológica (IRN) do Hospital Santa Paula (HSP) de São Paulo, pela irradiação do simulador esférico no sistema radiocirúrgico Leksell Gamma Knife ${ }^{\circledR}$. 
Ao Dr. Said Rahanamaye Rabbani, ao Dr. Hernán Joel Cervantes Rodríguez e ao Dr. Antonio C. Bloise Junior, do Laboratório de Ressonância Magnética Nuclear (LRMN) do Instituto de Física (IF) da USP, pelas medições de Ressonância Magnética (RM) realizadas neste laboratório, pelas sugestões, auxílio e amizade.

À Drª . Brigitte R. S. Pecequilo, por ter fornecido amostras de gelatina para os testes preliminares, por tudo o que me ensinou, pelas valiosas sugestões, pelo incentivo e pela amizade.

Ao MSc. David Tadashi Fukumori, por ter permitido o uso do negatoscópio do Laboratório de Materiais Dosimétricos (LMD) do IPEN, pelo incentivo e amizade.

Ao MSc. Flávio Betti, ao Sr. Claudinei Tadeu Cescon e ao Sr. Antônio Cornélio de Souza, por todas às vezes que me auxiliaram na solução de problemas técnicos do laboratório onde foi desenvolvido o projeto.

À Sr . Donata Celicea de O. Zanin, pelo apoio, auxílio, incentivo, amizade, preocupação e por ter me proporcionado muitos momentos de alegria.

Ao Sr. José Luiz Bruçó, do Instituto de Física (IF) da USP de Ribeirão Preto, São Paulo, e diretor da empresa MRA Indústria de Equipamentos Eletrônicos Ltda., pelo apoio financeiro que permitiu a minha participação na $5^{\text {th }}$ International Conference on Radiotherapy Gel Dosimetry, realizada em Hersonissos, Creta, Grécia, no período de 29 de setembro a 3 de outubro de 2008. 
Às minhas inseparáveis amigas pós-graduandas, Maíra Tiemi Yoshizumi, Patrícia de Lara Antonio e Priscilla Roberta Tavares L. Camargo, por estarem sempre presentes principalmente nos momentos mais difíceis, por serem grandes responsáveis pelo meu crescimento pessoal e profissional, pelas sugestões, por tudo o que me ensinaram, por tudo o que fizeram para me auxiliar, pela paciência, pelos inúmeros momentos de alegria, pela amizade fiel e por serem tão importantes para mim. Também agradeço à minha querida amiga Fernanda Beatrice Conceição Nonato, pós-graduanda, que chegou recentemente, mas me ajudou muito.

À minha querida amiga pós-graduanda, Margareth Lika Onishi Tongu, por ter me ensinado a ser forte nas adversidades, pelo companheirismo e pela amizade.

À minha querida amiga Lúcia Helena da Silva Santos, aluna de Iniciação Científica, pela gentileza, pelo incentivo, amizade e por todas as palavras de apoio.

Ao meu amigo pós-graduando, MSc. Eduardo Heredia, por ter me auxiliado nos cálculos estatísticos juntamente com o Dr. Orlando Rodrigues Junior, pela paciência e amizade.

A todos os membros da GMR do IPEN, pelo incentivo e amizade.

Ao professor e amigo, Dr. Afonso Rodrigues de Aquino, pela realização do Curso de Boas Práticas de Laboratório (BPL) na GMR do IPEN, pelo constante incentivo e pela amizade.

A todos os professores, amigos e colegas da pós-graduação, por todo o conhecimento transmitido, incentivo, companheirismo e amizade.

A toda a equipe da Gerência de Ensino (GE) do IPEN, na pessoa do Presidente da Comissão de Pós-graduação (CPG), Dr. José Carlos Bressiani, pelos serviços prestados, pela gentileza e amizade. 
A toda a equipe da Biblioteca do IPEN, "Terezine Arantes Ferraz", por sempre ter sido tão prestativa.

À minha querida amiga, professora MSc. Telma Vinhas Cardoso, da Faculdade de Tecnologia de Sorocaba (FATEC-SO), por ter me incentivado desde o início e por toda confiança e credibilidade.

Aos meus queridos pais, Mário e Batistina, por serem meus verdadeiros anjos da guarda, por acreditarem em mim, pelo amor, confiança, paciência, auxílio, preocupação, cuidados, incentivo e por não terem medido esforços para que eu pudesse concluir uma etapa tão importante da minha vida.

Aos meus queridos irmãos, Danielle e Mário Fernando, pelo amor, incentivo e por tudo o que fizeram em meu favor.

Ao meu querido noivo e fiel amigo, Gladston, por todo amor, paciência e compreensão e por ter me incentivado de modo a não permitir que eu desistisse dos meus objetivos em momento algum. Sem dúvida, meus agradecimentos se estendem a toda a sua família, que muito me ajudou e incentivou.

A todos os meus verdadeiros amigos que estiveram presentes durante todo o tempo, por terem aliviado os momentos de tensão com palavras ternas e de encorajamento.

Enfim, a todos que de alguma maneira contribuíram para que eu atingisse $o$ meu objetivo. 
"Minha vida se resume em duas partes: Antes da pesquisa e hoje, durante a pesquisa... Antes, eu tinha sonhos... Hoje, eu realizo esses sonhos!" 


\title{
PADRONIZAÇÃO DO MÉTODO DE DOSIMETRIA FRICKE GEL E AVALIAÇÃO TRIDIMENSIONAL DE DOSE EMPREGANDO A TÉCNICA DE IMAGEAMENTO POR RESSONÂNCIA MAGNÉTICA
}

\author{
Christianne Cobello Cavinato
}

\section{RESUMO}

Neste trabalho foi padronizado o método de obtenção da solução Fricke gel desenvolvida no IPEN. Foram comparados os resultados obtidos para diferentes qualidades do gel utilizado na preparação das soluções e a influência da concentração de gelatina na resposta das soluções dosimétricas. Testes de desempenho tais como: resposta em função da dose, limites mínimo e máximo de detecção, reprodutibilidade da resposta, entre outros, foram realizados utilizando diferentes tipos de radiação e empregando as técnicas de espectrofotometria de Absorção Óptica (AO) e Ressonância Magnética (RM). Os intervalos de dose determinados para radiação gama do ${ }^{60} \mathrm{Co}$ e fótons de $6 \mathrm{MeV}$ estão entre $0,4 \mathrm{e}$ 30,0 Gy e entre 0,5 e 100,0 Gy, empregando as técnicas de AO e RM, respectivamente. Um estudo de difusão dos íons férricos na solução foi realizado para a determinação do intervalo de tempo ótimo entre a irradiação e a avaliação das amostras; as imagens por RM podem ser obtidas com boa nitidez até 2,5 horas após a irradiação. Também foi desenvolvido um simulador esférico constituído de solução Fricke gel preparada com $5 \%$ de gelatina 270 Bloom (qualidade nacional), para a avaliação tridimensional de dose empregando a técnica de Imageamento por Ressonância Magnética (IRM). A solução Fricke gel preparada com gelatina 270 Bloom, que, além do baixo custo, pode ser adquirida facilmente no mercado nacional, apresenta resultados satisfatórios quanto à facilidade de manuseio, sensibilidade, reprodutibilidade da resposta e consistência. Os resultados obtidos confirmam sua aplicabilidade na dosimetria tridimensional pela técnica de IRM. 


\title{
STANDARDIZATION OF THE FRICKE GEL DOSIMETRY METHOD AND TRIDIMENSIONAL DOSE EVALUATION USING THE MAGNETIC RESONANCE IMAGING TECHNIQUE
}

\author{
Christianne Cobello Cavinato
}

\begin{abstract}
This study standardized the method for obtaining the Fricke gel solution developed at IPEN. The results for different gel qualities used in the preparation of solutions and the influence of the gelatin concentration in the response of dosimetric solutions were compared. Type tests such as: dose response dependence, minimum and maximum detection limits, response reproducibility, among others, were carried out using different radiation types and the Optical Absorption (OA) spectrophotometry and Magnetic Resonance (MR) techniques. The useful dose ranges for ${ }^{60} \mathrm{Co}$ gamma radiation and $6 \mathrm{MeV}$ photons are 0,4 to $30,0 \mathrm{~Gy}$ and 0,5 to $100,0 \mathrm{~Gy}$, using OA and MR techniques, respectively. A study of ferric ions diffusion in solution was performed to determine the optimum time interval between irradiation and samples evaluation; until 2,5 hours after irradiation to obtain sharp MR images. A spherical simulator consisting of Fricke gel solution prepared with $5 \%$ by weight 270 Bloom gelatine (national quality) was developed to be used to three-dimensional dose assessment using the Magnetic Resonance Imaging (MRI) technique. The Fricke gel solution prepared with 270 Bloom gelatine, that, in addition to low cost, can be easily acquired on the national market, presents satisfactory results on the ease of handling, sensitivity, response reproducibility and consistency. The results confirm their applicability in the threedimensional dosimetry using MRI technique.
\end{abstract}




\section{SUMÁRIO}

Página

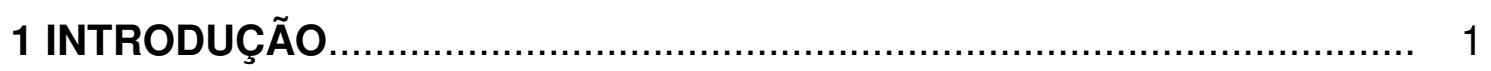

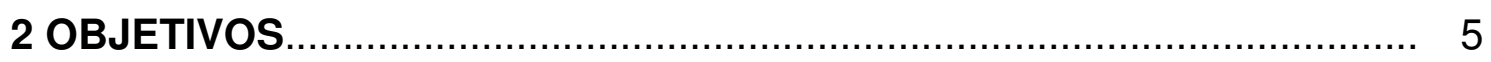

2.1 Gerais................................................................................ 5

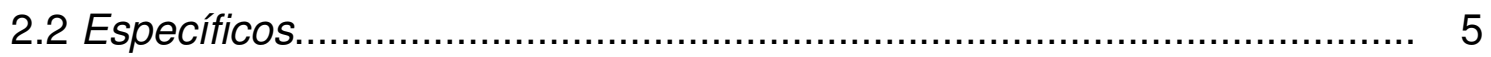

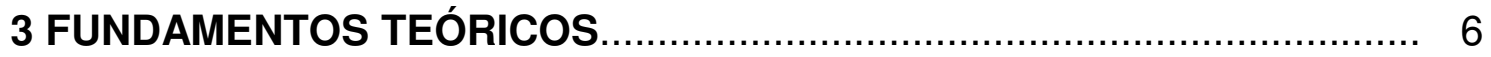

3.1 Classificação da radiação.......................................................... 6

3.2 Interações de fótons com a matéria.............................................. 7

3.2.1 Fótons indiretamente ionizantes.............................................. 7

3.2.1.1 Efeito fotoelétrico.................................................................. 7

3.2.1.2 Efeito Compton........................................................................... 8

3.2.1.3 Produção de pares................................................................... 9

3.2.1.4 Espalhamento Rayleigh...................................................... 9

3.2.1.5 Reações fotonucleares...................................................... 10

3.2.1.6 Predominâncias relativas de efeitos individuais............................. 10

3.3 Dosimetria das radiações............................................................ 11

3.3.1 Dosímetros......................................................................... 11

3.3.2 Classes de dosímetros................................................................. 13

3.3.3 Propriedades dos dosímetros.................................................... 14

3.3.3.1 Precisão e exatidão...................................................................... 14

3.3.3.2 Linearidade..................................................................... 14

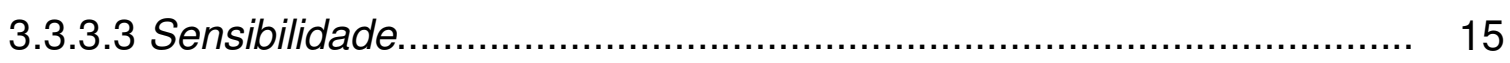

3.3.3.4 Limites inferior e superior de detecção........................................ 15

3.3.3.4.1 Limite inferior do intervalo de dose............................................ 15

3.3.3.4.2 Limite superior do intervalo de dose......................................... 16 


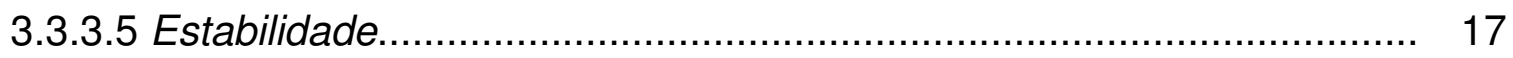

3.3.3.5.1 Antes da irradiação............................................................... 17

3.3.3.5.2 Depois da irradiação............................................................. 17

3.3.3.6 Dependência com a taxa de dose.................................................. 17

3.3.3.7 Dependência energética............................................................ 17

3.3.3.8 Dependência direcional ou angular................................................... 18

3.3.3.9 Resolução espacial................................................................... 18

3.3.3.10 Condição de uso................................................................ 18

3.3.3.11 Homogeneidade do lote.............................................................. 19

3.3.3.12 Fatores de influência.............................................................. 19

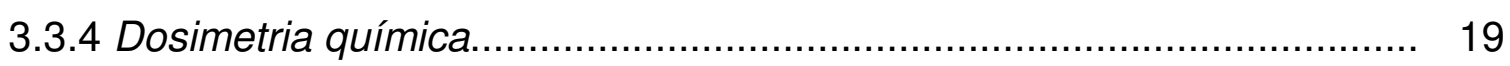

3.3.5 Dosimetria gel.................................................................... 20

3.3.5.1 Agente gelificante.............................................................. 21

3.3.5.2 Dosimetria Fricke gel............................................................... 22

3.4 Objetos simuladores.................................................................... 24

3.5 Curvas de isodose......................................................................... 24

3.6 Técnicas de avaliação................................................................. 25

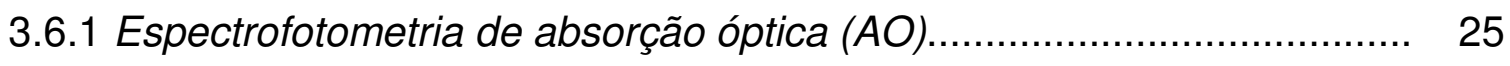

3.6.2 Ressonância magnética (RM)......................................................... 25

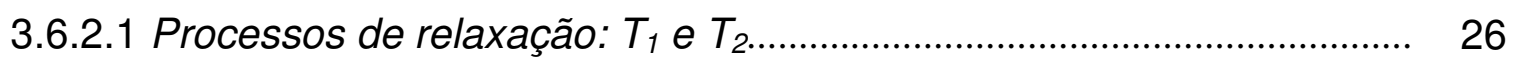

3.6.2.2 Imageamento por ressonância magnética (IRM)............................... 27

3.6.2.3 Espectroscopia por ressonância magnética (ERM)............................ 27

3.6.2.4 Espectroscopia localizada (EL).................................................... 27

3.7 Procedimentos e técnicas especiais em radioterapia.............................. 28

3.7.1 Irradiação estereotáxica................................................................... 28

3.7.1.1 Doenças tratadas com irradiação estereotáxica................................ 29

3.7.1.2 Técnicas radiocirúrgicas: Gamma Knife ${ }^{\circledR}$ e IMRT.............................. 29

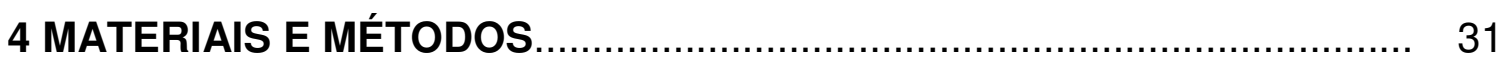

4.1 Reagentes e vidrarias.................................................................. 31

4.2 Equipamentos de medição.............................................................. 31

4.3 Sistemas de irradiação................................................................... 33

4.4 Programas computacionais.............................................................. 37 
4.5 Preparação da solução Fricke gel..................................................... 38

4.6 Irradiação das amostras................................................................... 39

4.7 Preparação, irradiação e avaliação do simulador esférico......................... 40

4.8 Medições de absorção óptica (AO)...................................................... 41

4.9 Imageamento por ressonância magnética (IRM)................................... 41

4.10 Espectroscopia por ressonância magnética (ERM).............................. 41

4.11 Apresentação dos resultados............................................................... 43

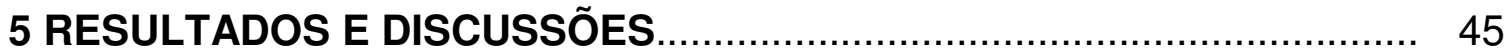

5.1 Padronização do método de obtenção da solução Fricke gel................... 45

5.1.1 Influência da concentração da gelatina............................................... $\quad 45$

5.1.2 Influência da qualidade da gelatina................................................... 47

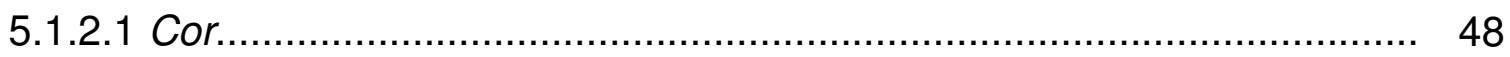

5.1.2.2 Consistência.................................................................... 48

5.1.2.3 Potencial de hidrogênio $-\mathrm{pH}$.................................................. 49

5.1.2.4 Espectros de absorção óptica..................................................... 49

5.1.2.5 Estabilidade da resposta......................................................... 51

5.1.2.6 Resposta em função da dose.................................................... 55

5.1.2.7 Limites mínimo e máximo de detecção para radiação gama do ${ }^{60} \mathrm{Co}$.. 57

5.2 Caracterização da resposta da solução Fricke gel para diferentes tipos de radiação.................................................................................. 58

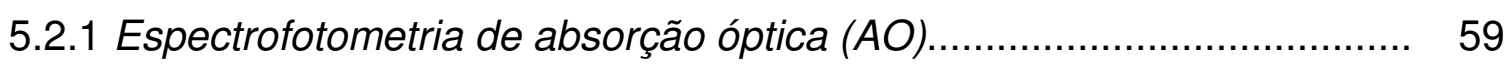

5.2.1.1 Repetitividade e reprodutibilidade................................................ 59

5.2.1.2 Resposta para radiação gama do ${ }^{60} \mathrm{Co}$ e fótons de $6 \mathrm{MeV}$............... 60

5.2.1.2.1 Dependência com a taxa de dose............................................... 60

5.2.1.2.2 Estabilidade da resposta para fótons de $6 \mathrm{MeV}$........................... 61

5.2.1.2.3 Resposta em função da dose para fótons de $6 \mathrm{MeV}$..................... 62

5.2.1.3 Resposta para radiação $X$ de energias entre 13,93 e 40,75 keV ........ 63

5.2.1.3.1 Dependência energética da resposta............................................ 63

5.2.1.3.2 Dependência angular da resposta............................................... 64

5.2.1.3.3 Resposta em função da dose para radiação X.............................. 65

5.2.2 Resposta da solução Fricke gel avaliada por imageamento por RM e tempo de relaxação........................................................................ 67 
5.2.2.1 Influência da concentração da gelatina......................................... 67

5.2.2.2 Difusão de íons férricos $\left(\mathrm{Fe}^{3+}\right)$ na solução Fricke gel........................ 68

5.2.2.3 Dependência com a taxa de dose............................................. 70

5.2.2.4 Estabilidade da resposta..................................................... 71

5.3 Irradiação do simulador esférico no sistema Leksell Gamma Knife ${ }^{\circledR}$......... 72

5.3.1 Resposta em função da imagem................................................. 72

5.3.2 Imagens dos cortes do simulador esférico.................................... 74

5.3.3 Reconstrução da imagem em 3D........................................... 76

5.3.4 Determinação das curvas de isodose............................................ 78

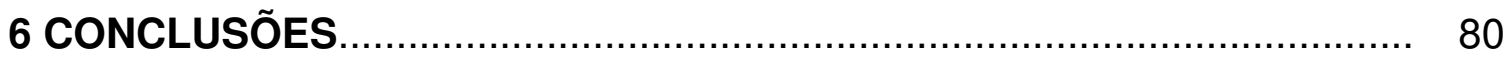

APÊNDICE A - Avaliação de incertezas de medições.......................... 82

APÊNDICE B - Equipamentos de medição e sistema radiocirúrgico

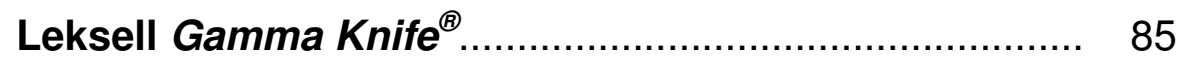

APÊNDICE C - Parâmetros utilizados para a avaliação da resposta da solução Fricke gel por IRM e tempo de relaxação........... 89

ANEXO A - Certificados de análise das gelatinas 270 e 300 Bloom........ 93

REFERÊNCIAS BIBLIOGRÁFICAS ................................................. 97 


\section{LISTA DE TABELAS}

TABELA 1 - Sistemas dosimétricos e exemplos de dosímetros utilizados

TABELA 2 - Classificação do número Bloom e pesos moleculares médios correspondentes

TABELA 3 - Parâmetros operacionais do espectrofotômetro marca SHIMADZU ${ }^{\circledR}$

TABELA 4 - Parâmetros operacionais do espectrômetro de RM marca VARIAN ${ }^{\circledR}$.....

TABELA 5 - Parâmetros de irradiação do sistema de radiação X marca PANTAK-SEIFERT ${ }^{\circledR}$...

TABELA 6 - Parâmetros de irradiação do sistema de radiação $X$ marca RIGAKU-DENKI ${ }^{\circledR}$

TABELA 7 - Parâmetros de irradiação do acelerador de fótons marca VARIAN $^{\circledR}$

TABELA 8 - Parâmetros de irradiação do sistema radiocirúrgico Leksell Gamma Knife ${ }^{\circledR}$ marca Elekta ${ }^{\circledR}$

TABELA 9 - Limites mínimos e máximos de detecção das soluções Fricke gel preparadas com gelatinas 270 e 300 Bloom para radiação gama do ${ }^{60} \mathrm{Co}$

TABELA 10 - Parâmetros operacionais utilizados para a avaliação da influência da concentração da gelatina na resposta da solução Fricke gel por IRM.

TABELA 11 - Parâmetros operacionais utilizados para a avaliação da influência da taxa de dose na resposta da solução Fricke gel por tempo de relaxação.

TABELA 12 - Parâmetros operacionais utilizados para a avaliação da estabilidade da resposta da solução Fricke gel por tempo de relaxação.

TABELA 13 - Parâmetros operacionais utilizados para a avaliação da resposta em função da imagem da solução Fricke gel por IRM 
TABELA 14 - Parâmetros operacionais utilizados para a avaliação das imagens do simulador esférico por IRM............................. 92

TABELA 15 - Especificações da gelatina alimentícia suína - 270P/8_..... 94

TABELA 16 - Especificações da gelatina alimentícia suína -273P/8....... 95

TABELA 17 - Especificações da gelatina pró-análise suína 300 Bloom 


\section{LISTA DE FIGURAS}

FIGURA 1 - Representação do efeito fotoelétrico.................................. 8

FIGURA 2 - Representação do efeito Compton.................................... 8

FIGURA 3 - Representação da produção de pares............................... 9

FIGURA 4 - Regiões de predominância relativa das três principais formas de interação de fótons com a matéria..................... 11

FIGURA 5 - Respostas características de dois sistemas dosimétricos diferentes.......................................................... 15

FIGURA 6 - Ilustração de uma função dose-resposta duplamente estimada resultante de uma diminuição na sensibilidade de um dosímetro em doses altas.

FIGURA 7 - Simulador esférico contendo solução Fricke gel preparada com $5 \%$ de gelatina 270 Bloom não irradiada e cubeta de leitura contendo a mesma solução, para melhor visualização da cor da solução não irradiada e controle da irradiação.

FIGURA 8 - Amostras da solução Fricke gel preparada com $5 \%$ de gelatina 270 Bloom não irradiadas (a), totalmente (b) e parcialmente (c) irradiadas com radiação gama do ${ }^{60} \mathrm{Co} \ldots$.

FIGURA 9 - Arranjo experimental para a irradiação parcial da amostra da solução Fricke gel (5\% de gelatina 270 Bloom) na fonte de ${ }^{60} \mathrm{Co}$ Panorâmica (a); tijolo de chumbo perfurado para acomodação do capilar de vidro contendo a solução Fricke gel para a irradiação parcial da amostra (b) e solução Fricke gel parcialmente irradiada (c).

FIGURA 10 - Resposta espectrofotométrica das soluções Fricke gel preparadas com gelatina 270 Bloom em função da concentração da gelatina.

FIGURA 11 - Intervalo de cores apresentado pela solução Fricke gel (5\% de gelatina 270 Bloom) não irradiada e irradiada com radiação gama do ${ }^{60} \mathrm{Co}$ com doses entre $0,5 \mathrm{e}$ 100,0 Gy

FIGURA 12 - Espectros de absorção óptica das soluções Fricke gel preparadas com gelatinas 270 (a) e 300 (b) Bloom não irradiadas e irradiadas com radiação gama do ${ }^{60} \mathrm{Co}$ 
FIGURA 13 - Espectros de absorção óptica das soluções Fricke gel preparadas com gelatinas 270 e 300 Bloom não irradiadas.

FIGURA 14 - Estabilidade da resposta espectrofotométrica da solução Fricke gel preparada com $5 \%$ de gelatina 270 Bloom não irradiada em função do tempo em horas (a) e em dias (b)..

FIGURA 15 - Estabilidade da resposta espectrofotométrica da solução Fricke gel preparada com $5 \%$ de gelatina 270 Bloom irradiada com radiação gama do ${ }^{60} \mathrm{Co}$ em função do tempo em horas (a) e em dias (b).

FIGURA 16 - Estabilidade da resposta espectrofotométrica da solução Fricke gel preparada com $5 \%$ de gelatina 300 Bloom não irradiada em função do tempo em horas (a) e em dias (b)..

FIGURA 17 - Estabilidade da resposta espectrofotométrica da solução Fricke gel preparada com 5\% de gelatina 300 Bloom irradiada com radiação gama do ${ }^{60} \mathrm{Co}$ em função do tempo em horas (a) e em dias (b).

FIGURA 18 - Resposta espectrofotométrica da solução Fricke gel preparada com $5 \%$ de gelatina 270 Bloom em função da dose.

FIGURA 19 - Resposta espectrofotométrica da solução Fricke gel preparada com $5 \%$ de gelatina 300 Bloom em função da dose.

FIGURA 20 - Comparação entre as curvas de resposta com a dose das soluções Fricke gel preparadas com gelatinas $270 \mathrm{e}$ 300 Bloom

FIGURA 21 - Reprodutibilidade da resposta espectrofotométrica da solução Fricke gel preparada com $5 \%$ de gelatina 270 Bloom não irradiada (a) e irradiada (b) em função de diferentes lotes.

FIGURA 22 - Resposta espectrofotométrica relativa ao valor de absorvância médio das soluções Fricke gel preparadas com 5\% de gelatina 270 Bloom e irradiadas com diferentes taxas de dose nas fontes de radiação gama do ${ }^{60} \mathrm{Co}$ Panorâmica e Gammacell e no acelerador CLINAC 6EX 
FIGURA 23 - Estabilidade da resposta espectrofotométrica da solução Fricke gel preparada com 5\% de gelatina 270 Bloom irradiada com fótons de $6 \mathrm{MeV}$ em função do tempo em horas (a) e em dias (b).

FIGURA 24 - Resposta espectrofotométrica da solução Fricke gel preparada com $5 \%$ de gelatina 270 Bloom em função da dose.

FIGURA 25 - Dependência energética da resposta espectrofotométrica da solução Fricke gel preparada com $5 \%$ de gelatina 270 Bloom

FIGURA 26 - Dependência angular relativa da resposta espectrofotométrica da solução Fricke gel preparada com $5 \%$ de gelatina 270 Bloom.

FIGURA 27 - Resposta espectrofotométrica da solução Fricke gel preparada com $5 \%$ de gelatina 270 Bloom em função da dose para radiação $X$

FIGURA 28 - Intensidade de sinal de RM das soluções Fricke gel preparadas com gelatina 270 Bloom em função da concentração de gelatina

FIGURA 29 - Perfis espectrais da evolução dos íons $\mathrm{Fe}^{3+}$ (a) e $\mathrm{Fe}^{2+}$ (b) na solução Fricke gel preparada com $5 \%$ de gelatina 270 Bloom parcialmente irradiada com radiação gama do ${ }^{60} \mathrm{Co}$, em função do tempo.

FIGURA 30 - Resposta relativa ao valor médio de $R_{1}$ da solução Fricke gel preparada com $5 \%$ de gelatina 270 Bloom e irradiada com radiação gama do ${ }^{60} \mathrm{Co}$ em função da taxa de dose...

FIGURA 31 - Estabilidade da taxa de relaxação $T_{1}\left(R_{1}\right)$ da solução Fricke gel preparada com $5 \%$ de gelatina 270 Bloom não irradiada (a) e irradiada (b) em função do tempo

FIGURA 32 - Imagens por RM das cubetas de PMMA contendo a solução Fricke gel (5\% de gelatina 270 Bloom) não irradiada e irradiada com radiação gama do ${ }^{60} \mathrm{Co}$

FIGURA 33 - Intensidade de sinal de RM da solução Fricke gel preparada com $5 \%$ de gelatina 270 Bloom e irradiada com radiação gama do ${ }^{60} \mathrm{Co}$ em função da dose. 
FIGURA 34 - Taxa de relaxação $\left(R_{1}\right)$ da solução Fricke gel preparada com $5 \%$ de gelatina 270 Bloom e irradiada com radiação gama do ${ }^{60} \mathrm{Co}$ em função da dose [49]. A curva em escala logarítmica (b) é apresentada para melhor visualização dos valores de $R_{1}$ correspondentes às doses de $0,5 \mathrm{e}$ 1,0 Gy

FIGURA 35 - Imagens dos cortes do simulador esférico produzido com solução Fricke gel (5\% de gelatina 270 Bloom) e irradiado no sistema Leksell Gamma Knife ${ }^{\circledR}$ obtidas pela técnica de IRM (a); ilustração para auxílio da orientação das imagens: coronal, sagital e axial (b)

FIGURA 36 - Fatias em $z$ da imagem do simulador esférico irradiado, selecionadas, obtidas pela técnica de IRM.

FIGURA 37 - Representação do simulador esférico em 3D com a orientação das fatias obtidas pela técnica de IRM. Corte na fatia $x=130$

FIGURA 38 - Reconstrução da imagem do simulador esférico em 3D. Corte na fatia $y=50$ para destacar o centro do volume irradiado.

FIGURA 39 - Reconstrução da imagem do simulador esférico em 3D. Cortes nas fatias $y=60$ e $x=120$ mostrando a projeção do cone irradiado.

FIGURA 40 - Representação dos dois voxels dos quais foram obtidos os valores de $T_{1}$ utilizados para a determinação das curvas de isodose. Imagem da fatia 14, apresentada na FIG. 36 .

FIGURA 41 - Porcentagem de distribuição de dose absorvida na fatia 14 (FIG. 36) baseada nas curvas apresentadas nas FIG. 33 e 34

FIGURA 42 - Espectrofotômetro marca SHIMADZU ${ }^{\circledR}$ (a) e seus compartimentos de referência e amostra (b)

FIGURA 43 - Tomógrafo de corpo inteiro marca PHILIPS ${ }^{\circledR}$...................... 86

FIGURA 44 - Espectrômetro de RM de alta resolução marca VARIAN ${ }^{\circledR}$.. 86 
FIGURA 45 - Sistema Leksell Gamma Knife ${ }^{\circledR}$ marca Elekta ${ }^{\circledR}$ modelo B (Instituto de Radiocirurgia Neurológica - Hospital Santa Paula) (a); vista da parte posterior do capacete colimador de feixes de radiação gama do ${ }^{60} \mathrm{Co}(\mathrm{b})$; simulação dos feixes (em azul) colimados (c) e demonstração do capacete colimador encaixado na unidade Gamma Knife $^{\circledR}(\mathrm{d})$

FIGURA 46 - Dispositivo estereotáxico (a), encaixado na cabeça de um paciente (b) e, então, encaixado dentro do capacete colimador (c) 


\section{INTRODUÇÃO}

Em novembro de 1895, o físico alemão Wilhelm Konrad von Röntgen (18451923) descobriu, acidentalmente, os raios $X$ (ou radiação $X$ ), assim denominados por serem de natureza desconhecida, os quais eram capazes de penetrar diversos materiais e ser registrados em chapas fotográficas [1-4]. No ano seguinte, o físico francês Antoine Henry Becquerel (1852-1908) descobriu que os sais de urânio emitiam espontaneamente um tipo de radiação análoga aos raios $X$ que ele chamou de raios Becquerel [2,4]. Mas, Becquerel limitou-se ao relato desse fenômeno e nada mais publicou até o final de 1897 [5].

No entanto, a matemática, física e química polonesa Marie Sklodowska Curie (1867-1934), em busca de um tema para sua tese de doutorado, explorou os raios Becquerel juntamente com seu esposo Pierre Curie (1859-1906), físico francês. Em Paris, no ano de 1898, madame Curie descobriu que, entre os elementos conhecidos, o tório apresentava as características radioativas do urânio. O célebre casal Curie passou a quantificar a radiação pelo efeito de ionização que ela produzia no ar e, desta forma, descobriu vários elementos químicos radioativos. Em 18 de julho de 1898, Marie e Pierre divulgaram a descoberta do polônio, elemento que recebeu este nome em homenagem à pátria de Marie Curie. Em 26 de dezembro daquele mesmo ano, com a ajuda de Gustave Bémont (1857-1932), químico francês, descobriram mais um elemento radioativo: o rádio $[2,4,5]$.

Em 1899, o físico neozelandês Ernest Rutherford (1871-1937) investigou a natureza da radiação emitida pelos materiais radioativos e descobriu que as emissões radioativas continham, no mínimo, dois tipos de radiação, alfa e beta (conhecidas hoje como partículas alfa e beta e representadas pelas letras gregas $\alpha$ e $\beta$, respectivamente) [5]. Em 1900, a radiação gama (representada pela 
letra grega $\gamma$ ) foi identificada pelo físico francês Paul Ulrich Villard (1860-1934) como uma terceira forma de radiação $[4,6]$.

Em 1902, Rutherford e o químico britânico Frederick Soddy (1877-1956) formularam as leis exponenciais que regem o decaimento e a produção de substâncias radioativas. Estas leis foram aperfeiçoadas por Harry Bateman (18821946), matemático inglês, em 1910 [7].

Rutherford continuou explorando o núcleo atômico e, em 1919, produziu a primeira desintegração artificial, bombardeando átomos de nitrogênio com partículas alfa. Desta maneira, ele descobriu o próton e levantou a hipótese da existência de outra partícula neutra (com massa semelhante à do próton): o nêutron, descoberto treze anos mais tarde pelo seu colaborador, o físico britânico James Chadwick (1891-1974) [5].

Desde então, as radiações ionizantes têm sido amplamente utilizadas e suas aplicações estão crescendo na indústria, na agricultura, na medicina e em muitos outros campos da indústria e da pesquisa, beneficiando a humanidade [7,8]. As radiações ionizantes também têm sido utilizadas para fins não pacíficos, como por exemplo, na obtenção de explosivos nucleares.

A irradiação tem sido mundialmente empregada para preservar gêneros alimentícios e reduzir desperdícios. Na agricultura, técnicas de esterilização têm servido para erradicar doenças eliminando insetos e pestes. A radiografia industrial está sendo usada rotineiramente, por exemplo, para verificar soldas, revelar rupturas e ajudar a prevenir falha de estruturas projetadas. Fontes de radiação ionizante são essenciais ao atual cuidado com a saúde: a esterilização de materiais médicos descartáveis utilizando fonte de radiação intensa tem sido fundamental ao combate de doenças, a radiologia e a medicina nuclear são ferramentas diagnósticas muito importantes e, a radioterapia é um dos três principais métodos de tratamento de doença maligna (câncer); os outros dois são cirurgia e quimioterapia. Em comparação com outras especialidades médicas, a radioterapia, por fazer uso da radiação ionizante no tratamento de câncer ou desordens funcionais, conta rigorosamente com a colaboração de vários profissionais qualificados e com tecnologia moderna, a fim de obter sucesso nos resultados dos tratamentos [7].

Avanços atuais em oncologia são conduzidos principalmente pelo desenvolvimento tecnológico de equipamentos para procedimentos e 
imageamento em radioterapia [7]. Também é de fundamental importância a realização do planejamento do tratamento com radiação para que sejam obtidos resultados satisfatórios e para que os tecidos sadios adjacentes à região a ser tratada não sejam comprometidos. Para isto, são empregadas diferentes técnicas com a finalidade de definir com precisão o volume a ser irradiado, a dose a ser administrada, a qualidade da radiação e o tipo de equipamento a ser utilizado. Atualmente, a região e o tamanho do campo de irradiação são definidos em simulações com equipamentos sofisticados e aplicativos computacionais excelentes para tratamento de imagens, como Tomografia Computadorizada (TC) e Ressonância Magnética (RM), que muito auxiliam nesta tarefa [9].

A dosimetria é uma técnica utilizada com a finalidade de determinar a dose empregada em um processamento com radiação. Vários são os materiais dosimétricos e as técnicas que podem ser empregadas, sendo que os materiais podem ser sólidos, líquidos ou gasosos. A escolha depende de vários fatores como: intervalo de dose de utilização, resposta independente da energia da radiação incidente, características de absorção equivalente ao material que será irradiado, relação linear entre a dose e o efeito produzido no detector, resolução espacial e simplicidade de preparo e uso $[9,10]$.

Dosímetros convencionais, tais como câmaras de ionização, dosímetros termoluminescentes (TLDs), diodos e filmes radiocrômicos são os mais empregados, mas dificultam o uso na avaliação tridimensional da distribuição de dose, que é de extrema importância no planejamento dos tratamentos de doenças empregando radiações ionizantes, por serem limitados a medições em duas dimensões (2D). No entanto, se forem utilizados dosímetros na forma gel, a informação de dose pode ser obtida em três dimensões (3D) com alta resolução espacial $[7,8]$; por isso esses dosímetros tridimensionais são tão atrativos na área médica.

Atualmente, novas técnicas têm sido desenvolvidas para a determinação da dose utilizando objetos simuladores constituídos de diferentes materiais equivalentes ao tecido e materiais dosimétricos, como, por exemplo, o dosímetro Fricke na forma gel, que emprega a solução Fricke modificada com a adição de um agente gelificante [11-13].

A dosimetria gel ainda é considerada um projeto de pesquisa e a introdução dessa ferramenta no uso clínico está sendo feita lentamente porque até agora há 
pouca aceitação deste método de dosimetria, principalmente por causa de objetivos por ora não atingidos (ainda existem algumas dificuldades na preparação e utilização de alguns géis). Os membros da comunidade de física das radiações ainda não estão convencidos das vantagens da dosimetria gel sobre os métodos de dosimetria convencionais. Cabe aos pesquisadores que trabalham com dosímetros géis incentivar a utilização clínica mais generalizada desse vantajoso método dosimétrico, aproveitando todas as oportunidades para apresentar os bons resultados que vêm sendo obtidos [14].

O dosímetro Fricke gel atende às exigências de aplicação em dosimetria tridimensional, muito útil em radioterapia e radiocirurgia. As características do dosímetro Fricke gel devem ser muito bem avaliadas e todas as variáveis relacionadas ao seu desempenho devem ser determinadas, para a precisão e exatidão da sua resposta.

A relevância deste trabalho está no fato de contribuir para a aplicação do dosímetro Fricke gel na dosimetria clínica em 3D empregando as técnicas de espectrofotometria de Absorção Óptica ( $A O)$ e Ressonância Magnética (RM), bem como no desenvolvimento de objetos simuladores empregando a gelatina, material equivalente ao tecido e de mesmas características do material dosimétrico. 


\section{OBJETIVOS}

\subsection{Gerais}

Padronização do método de obtenção da solução Fricke gel desenvolvida no IPEN e o desenvolvimento de um objeto simulador para avaliação tridimensional da distribuição de dose espacial por meio da técnica de Imageamento por Ressonância Magnética (IRM), para o controle de qualidade em radioterapia.

\subsection{Específicos}

- Padronização do método de obtenção da solução Fricke gel desenvolvida no IPEN, empregando gelatinas de diferentes qualidades, nacional e importada, com a finalidade de verificar a eficácia da gelatina nacional e de tornar viável o uso clínico dessa solução como dosímetro no Brasil;

- Caracterização da resposta da solução Fricke gel obtida para radiação gama do cobalto-60 $\left({ }^{60} \mathrm{Co}\right)$, radiação $\mathrm{X}$ de energias baixas e fótons de energia alta, empregando as técnicas de espectrofotometria de Absorção Óptica (AO) e Imageamento por Ressonância Magnética (IRM);

- Estudo da difusão de íons férricos $\left(\mathrm{Fe}^{3+}\right)$ na solução Fricke gel empregando a técnica de Espectroscopia por Ressonância Magnética (ERM);

- Desenvolvimento de um objeto simulador esférico (cérebro) para irradiação no sistema radiocirúrgico Leksell Gamma Knife ${ }^{\circledR}$ para avaliação tridimensional da distribuição de dose empregando a técnica de IRM;

- Obtenção das curvas de isodose correspondentes à distribuição de dose no volume alvo irradiado no simulador esférico. 


\section{FUNDAMENTOS TEÓRICOS}

\subsection{Classificação da radiação}

A radiação é classificada em duas categorias principais, não ionizante (ondas de rádio, por exemplo) e ionizante. A radiação ionizante pode ionizar a matéria de forma direta ou indireta, dependendo da sua capacidade de ionizar a matéria. O potencial de ionização dos átomos (isto é, a energia mínima necessária para ionizar um átomo) varia de poucos elétrons-volt $(\mathrm{eV})$ para elementos alcalinos a 24,5 $\mathrm{eV}$ para o hélio (gás nobre) [7].

A radiação diretamente ionizante compreende as partículas carregadas como elétrons, prótons, partículas alfa e íons pesados. Estas partículas depositam energia no meio por intermédio de interações Coulombianas diretas entre a partícula carregada diretamente ionizante e os elétrons orbitais dos átomos do meio.

A radiação indiretamente ionizante compreende as partículas neutras (nêutrons) e os fótons (raios $X$ e radiação gama). Os fótons ou nêutrons depositam energia no meio em duas etapas:

- Na primeira etapa, a partícula carregada é liberada no meio (os fótons liberam elétrons ou pósitrons e os nêutrons liberam prótons ou íons pesados);

- Na segunda etapa, as partículas carregadas liberadas depositam energia no meio por intermédio de interações Coulombianas diretas com elétrons orbitais dos átomos do meio.

Ambas as radiações, direta e indiretamente ionizantes, são utilizadas no tratamento de doenças, principalmente, mas não exclusivamente, para doenças malignas [7]. Pterígio, neurinomas, meningiomas, paragangliomas e adenomas hipofisários são exemplos de doenças benignas tratáveis com radiação ionizante $[15,16]$. 


\subsection{Interações de fótons com a matéria}

São descritas nesta subseção somente as interações dos fótons com a matéria, pois neste trabalho foram realizadas, unicamente, irradiações com fótons.

\subsubsection{Fótons indiretamente ionizantes}

Dependendo de sua origem, os fótons indiretamente ionizantes atendem a uma das quatro categorias seguintes:

- Bremsstrahlung ou raios $X$ de freamento (raios $X$ contínuos), emitidos por meio de interações elétron-núcleo;

- Raios X característicos (discretos), emitidos durante as transições de elétrons para as camadas mais internas de um átomo;

- Radiação gama (discreta), emitida por meio de transições nucleares em decaimento gama;

- Radiação de aniquilação (discreta, normalmente $0,511 \mathrm{MeV}$ ), emitida por meio de aniquilação pósitron-elétron $[7,17,18]$.

Os fótons podem sofrer diversas interações possíveis com os átomos de um atenuador; a probabilidade para cada interação depende da energia do fóton, $h v$, e do número atômico, $Z$, do material atenuador.

Durante a interação o fóton pode desaparecer completamente (efeito fotoelétrico, produção de par) ou pode ser coerente ou incoerentemente espalhado (espalhamento Rayleigh e efeito Compton, respectivamente) [7].

Nas próximas subseções são descritas, sucintamente, os tipos de interações de fótons (radiação $X$ e gama) com a matéria.

\subsubsection{Efeito fotoelétrico}

No efeito fotoelétrico (às vezes mencionado como fotoefeito) o fóton interage com um elétron orbital firmemente ligado de um atenuador e desaparece, enquanto o elétron orbital é ejetado do átomo como um fotoelétron (FIG. 1) com uma energia cinética, $E_{C}$, dada na EQ. 1 :

$$
E_{C}=h v-E_{e}
$$


onde $h v$ é a energia do fóton incidente e $E_{e}$ é a energia de ligação do elétron $[7,19,20]$.

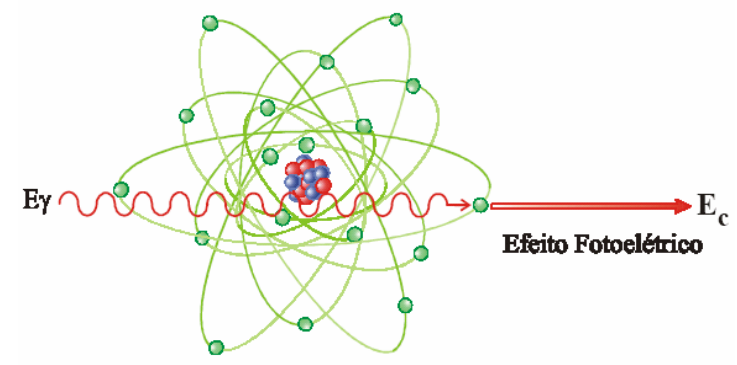

FIGURA 1 - Representação do efeito fotoelétrico [17].

O efeito fotoelétrico pode ocorrer sob energias de até $0,5 \mathrm{MeV}$ e a probabilidade de ocorrência diminui com o aumento da energia. $O$ fotoefeito é dependente de $Z^{5}$, aproximadamente [21].

\subsubsection{Efeito Compton}

O efeito Compton (espalhamento incoerente) representa uma interação de fótons com um elétron orbital essencialmente "livre e estacionário". A energia do fóton incidente, $h v$, é muito maior que a energia de ligação do elétron orbital. $\mathrm{O}$ fóton perde parte de sua energia ao elétron recuado (Compton) e é espalhado como fóton, $h v^{\prime}$, por um ângulo de espalhamento, $\theta$, como apresentado esquematicamente na FIG. 2. O ângulo $\theta$ representa o ângulo entre a direção do fóton incidente e a direção do elétron recuado $[7,19,20]$.

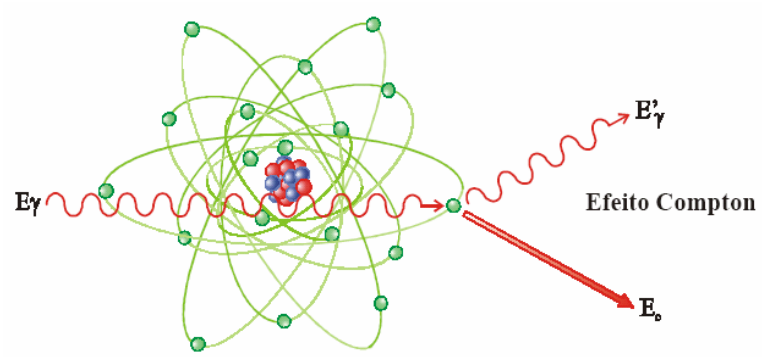

FIGURA 2 - Representação do efeito Compton [17]. 
O efeito Compton pode ocorrer sob energias de $\cong 1 \mathrm{MeV}$, com diminuição da probabilidade de ocorrência em função do aumento da energia, e é dependente de $Z$, aproximadamente [21].

\subsubsection{Produção de pares}

$\mathrm{Na}$ produção de pares o fóton desaparece e um par elétron-pósitron com uma energia cinética combinada igual a $h v-2 m_{e} c^{2}$ é produzido no campo nuclear Coulombiano (FIG. 3).

Já que a massa é produzida totalmente da energia do fóton na forma de um par elétron-pósitron, a produção de pares tem uma energia limiar (energia do fóton mínima necessária para 0 efeito acontecer) de $2 m_{e} c^{2}=1,02 \mathrm{MeV}[7,19,20]$.

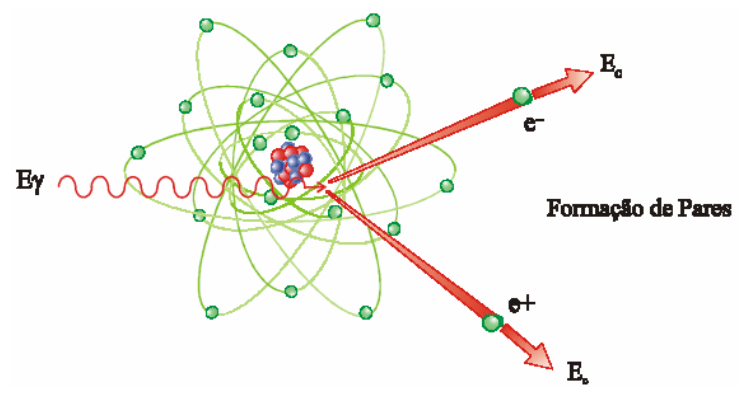

FIGURA 3 - Representação da produção de pares [17].

A produção de pares pode ocorrer sob energias maiores que $1 \mathrm{MeV}$, principalmente no intervalo de energia entre 5 e $10 \mathrm{MeV}$ e é dependente de $Z^{2}$, aproximadamente [21].

\subsubsection{Espalhamento Rayleigh}

No espalhamento Rayleigh (coerente) o fóton interage com um elétron orbital ligado (isto é, com a ação combinada do átomo inteiro). O evento é elástico no sentido do fóton não perder essencialmente energia alguma e de ser espalhado por um único ângulo pequeno. Já que não ocorre transferência de energia dos fótons às partículas carregadas, o espalhamento Rayleigh não desempenha nenhum papel no coeficiente de transferência de energia; entretanto, contribui com o coeficiente de atenuação. 
Em tecidos e em materiais equivalentes ao tecido a importância relativa do espalhamento Rayleigh é pequena em comparação com outras interações dos fótons com a matéria, quando contribui somente um pouco por cento ou menos ao coeficiente de atenuação total $[7,20]$.

$\mathrm{O}$ espalhamento Rayleigh pode ocorrer sob energias menores que $1 \mathrm{MeV}$ e é dependente de $Z^{2}$ (ângulos pequenos) e $Z^{3}$ (ângulos grandes), aproximadamente [21].

\subsubsection{Reações fotonucleares}

Reações fotonucleares (também conhecidas como reações de fotodesintegração) ocorrem quando um fóton de energia alta é absorvido pelo núcleo de um átomo, resultando em uma emissão de um nêutron [reação $(x, n)$ ] ou de um próton [reação $(x, p)$ ] e uma transformação do núcleo em um produto da reação radioativo.

O limiar para uma reação fotonuclear particular depende da reação e do núcleo e é da ordem de $10 \mathrm{MeV}$ ou superior para a maioria dos núcleos (com exceção dos núcleos atômicos do deutério $\left({ }^{2} \mathrm{H}\right)$ e do berílio $\left({ }^{9} \mathrm{Be}\right)$, para os quais o limiar é da ordem de $2 \mathrm{MeV})[7,21]$.

\subsubsection{Predominâncias relativas de efeitos individuais}

Geralmente, o efeito fotoelétrico predomina em energias baixas, o efeito Compton predomina em energias intermediárias e a produção de pares, em energias altas.

Na FIG. 4 são apresentadas as regiões de predominância relativa individual dos três mais importantes efeitos adotando $h v$ e $Z$ como parâmetros. A curva do lado esquerdo representa a região onde os coeficientes atômicos para o efeito fotoelétrico e para o efeito Compton são iguais e a curva do lado direito representa a região onde o coeficiente atômico Compton é igual ao coeficiente atômico da produção de pares $[7,22]$. 


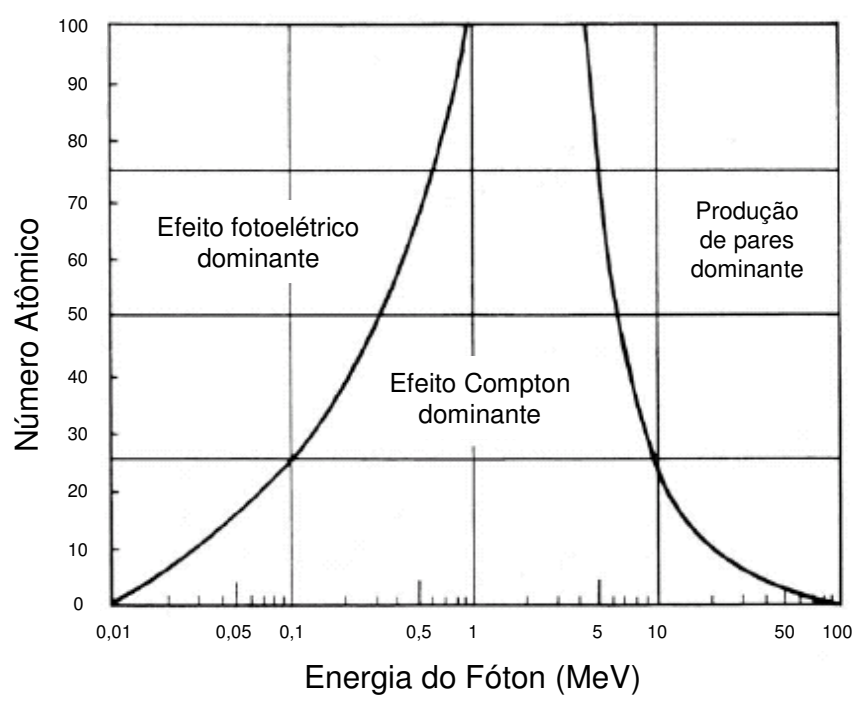

FIGURA 4 - Regiões de predominância relativa das três principais formas de interação de fótons com a matéria [7,22].

\subsection{Dosimetria das radiações}

A dosimetria das radiações (ou simplesmente "dosimetria") trata, exatamente, da medição da dose absorvida ou da taxa de dose resultante da interação da radiação ionizante com a matéria. Mais claramente, refere-se à determinação (por medição ou estimativa) dessas grandezas, assim como de algumas das outras grandezas radiologicamente relevantes tais como, por exemplo, exposição e kerma [10,23].

\subsubsection{Dosímetros}

Um dosímetro é um dispositivo, instrumento ou sistema que mede ou avalia, direta ou indiretamente, as grandezas exposição, kerma, dose absorvida ou dose equivalente, ou suas derivadas do tempo (taxas), ou outras grandezas de radiação ionizante relacionadas [24].

Os dosímetros podem ser físicos ou químicos; estes últimos podendo ser sólidos, líquidos ou gasosos. Na TAB. 1 são apresentados exemplos dos tipos de dosímetros existentes [10,25-28]. 
TABELA 1 - Sistemas dosimétricos e exemplos de dosímetros
utilizados $[10,25-28]$.

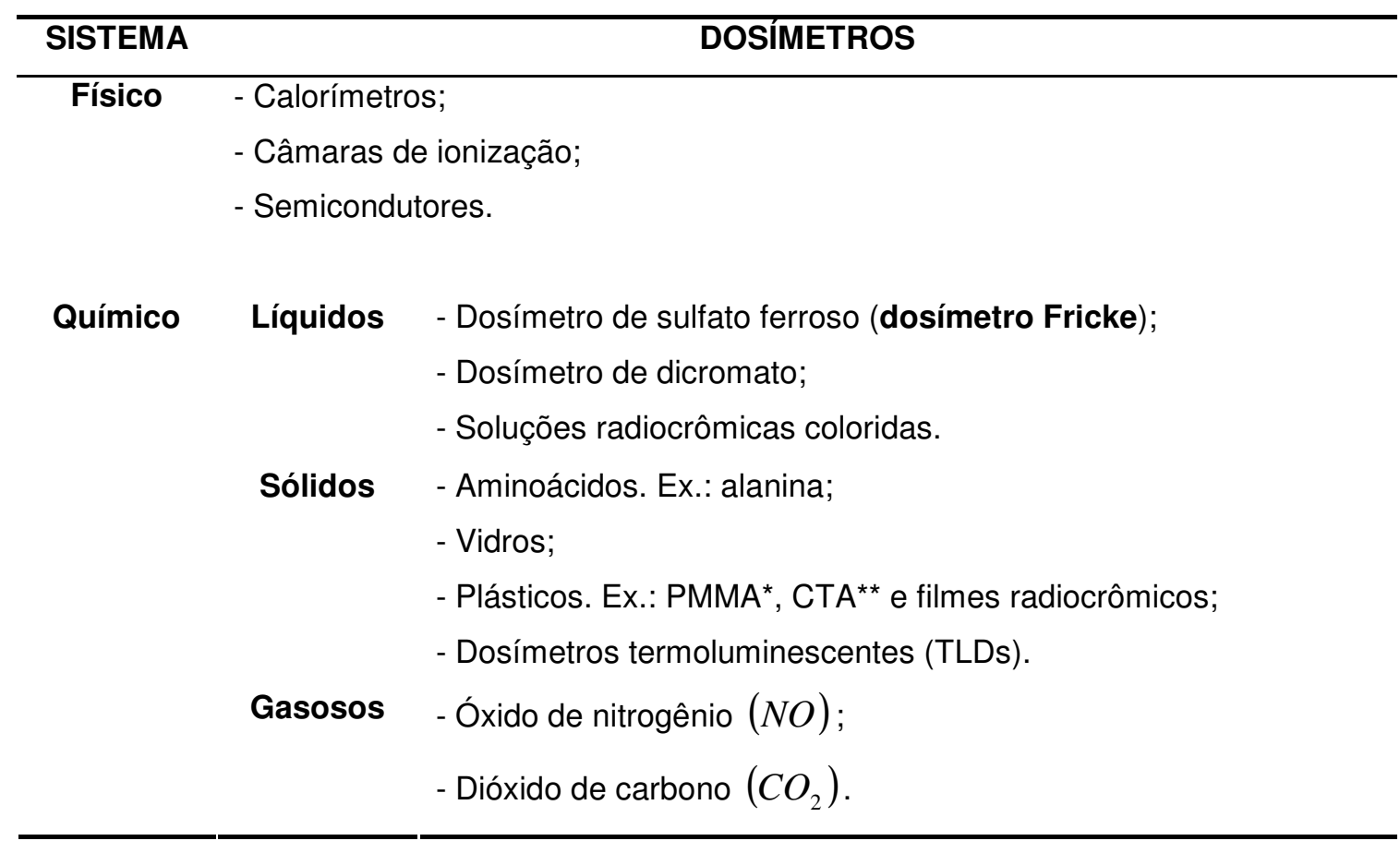

* Polimetilmetacrilato.

** Triacetato de celulose.

A medição da dose absorvida envolve o uso de um sistema dosimétrico o qual consiste não somente de dosímetros físicos e químicos bem estabelecidos, mas também do instrumento que mede o efeito relevante induzido pela radiação ionizante no dosímetro (por exemplo, espectrofotômetros e espectrômetros de Ressonância Paramagnética Eletrônica-RPE) e seus padrões de referência associados (tais como comprimento de onda e absorvância) e o procedimento para utilizar o sistema. $O$ instrumento de medição deve ser bem caracterizado, de maneira que forneça resultados reprodutíveis e precisos. Algum efeito induzido pela radiação (também chamado de resposta do dosímetro) o qual é reprodutível e mensurável pode, em princípio, ser utilizado para dosimetria [29].

Para ser definido como um dosímetro, o material deve possuir pelo menos uma propriedade física que seja uma função da grandeza dosimétrica medida e que possa ser utilizada para dosimetria da radiação com calibração própria.

Para que sejam úteis, os dosímetros de radiação devem apresentar várias características desejáveis. Por exemplo, em radioterapia, o conhecimento exato da dose absorvida na água em um ponto específico e sua distribuição espacial 
são de grande importância, assim como a possibilidade de obter a dose em um órgão de interesse no paciente [24]. Para diagnósticos e tratamentos de doenças as doses de radiação empregadas variam na ordem de poucos $G y$ [9].

\subsubsection{Classes de dosímetros}

Os sistemas dosimétricos podem ser classificados com base na sua acurácia intrínseca e nas suas aplicações. Existem quatro classes de dosímetros:

- Dosímetros padrões primários;

- Dosímetros padrões de referência;

- Dosímetros padrões de transferência;

- Dosímetros de rotina.

Por meio do uso de dosímetros padrões primários é possível obter uma medição absoluta da dose absorvida a ser feita com referência somente a unidades fundamentais do Sistema Internacional de Unidades (SI) (massa, comprimento, tempo, corrente elétrica, etc.) e constantes físicas essenciais. Eles não precisam ser calibrados. Há dois tipos de dosímetros padrões primários: câmaras de ionização e calorímetros.

Os dosímetros padrões de referência são dosímetros de qualidade metrológica alta que podem ser utilizados para calibrar outros dosímetros. No entanto, eles precisam ser calibrados em comparação com um padrão primário, geralmente pelo uso de um dosímetro padrão de transferência. Dosímetros de referência comumente utilizados são os dosímetros Fricke e de alanina.

Os dosímetros padrões de transferência são utilizados para transferir a informação de dose de laboratórios padrões internacionais ou oficialmente aceitos ou reconhecidos a uma instalação de irradiação a fim de estabelecer a rastreabilidade desses laboratórios padrões. Eles são normalmente dosímetros padrão de referência e, portanto, precisam ser calibrados.

Os dosímetros de rotina são utilizados em instalações de processamento com radiação para monitorar o processo e mapear a dose para o controle de qualidade. Eles devem ser frequentemente calibrados contra dosímetros de referência ou de transferência. Os dosímetros de rotina comumente utilizados são os dosímetros de PMMA e filmes radiocrômicos, os quais são empregados na dosimetria dos processos de radioesterilização de materiais, por exemplo [10,29]. 


\subsubsection{Propriedades dos dosímetros}

Os dosímetros devem apresentar propriedades desejáveis para que possam ser utilizados em processos que utilizam radiações ionizantes.

Obviamente, nem todos os dosímetros podem satisfazer todas as características descritas nas próximas subseções. A escolha de um dosímetro e de sua leitora deve então ser feita judiciosamente, considerando os requerimentos da situação de medição; por exemplo, em radioterapia as câmaras de ionização são recomendadas para calibração de feixes e os outros tipos de dosímetros (como os apresentados na TAB. 1) são apropriados para a avaliação da distribuição de dose (dosimetria relativa) ou verificação de dose [24,29,30].

\subsubsection{Precisão e exatidão}

$\mathrm{Na}$ dosimetria realizada em radioterapia a incerteza associada com a medição é frequentemente expressa em termos de exatidão e precisão. A precisão das medições em dosimetria especifica a reprodutibilidade destas sob condições similares e pode ser estimada a partir dos dados obtidos em medições repetidas. Alta precisão é associada com um pequeno desvio padrão da distribuição dos resultados da medição. A exatidão das medições dosimétricas é a proximidade de seu valor esperado ao "valor verdadeiro" da grandeza medida. Os resultados das medições não podem ser absolutamente exatos e a inexatidão destes resultados é caracterizada como "incerteza".

A incerteza é o parâmetro que descreve a dispersão do valor medido de uma grandeza; é avaliada por métodos estatísticos (tipo A) ou por outros métodos (tipo B). Estes métodos são descritos no APÊNDICE A.

O erro da medição é a diferença entre o valor medido de uma grandeza e o valor verdadeiro dessa grandeza. Tipicamente, os erros das medições não são exatamente conhecidos, mas eles são estimados da melhor maneira possível e, quando possível, correções de compensação são introduzidas [24,29,30].

\subsubsection{Linearidade}

O ideal seria que a leitura de um dosímetro fosse linearmente proporcional à grandeza dosimétrica. Entretanto, depois de um determinado intervalo de dose uma não linearidade se inicia. $O$ intervalo de linearidade e o comportamento de não linearidade dependem do tipo de dosímetro e de suas características. 
Dois exemplos típicos de respostas características de sistemas dosimétricos são apresentados na FIG. 5. A curva $A$ apresenta primeiramente linearidade com a dose, então, comportamento supralinear e finalmente, saturação. A curva $B$ apresenta, primeiramente, linearidade e então, saturação em doses altas $[24,29,30]$.

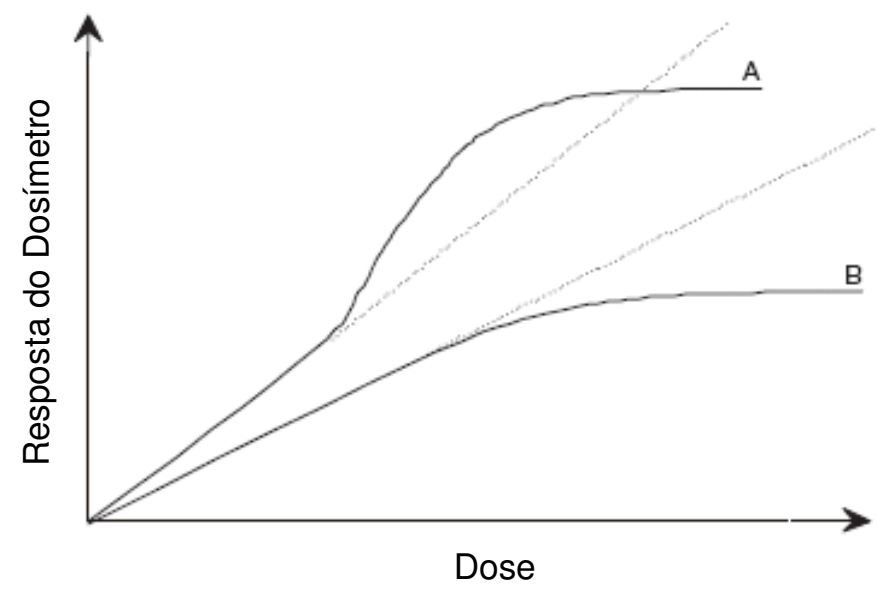

FIGURA 5-Respostas características de dois sistemas dosimétricos diferentes [24].

Em geral, um comportamento não linear deve ser corrigido [24].

\subsubsection{Sensibilidade}

Para ser útil, um dosímetro deve ter sensibilidade à dose adequada do começo ao fim do intervalo de dose a ser medido. Uma sensibilidade constante dentro deste intervalo fornece uma resposta linear (isto é, leitura versus dose média no meio $(g)$ contido no volume sensível do dosímetro, ou $r$ versus $\overline{D_{g}}$ ), que é desejável para a facilidade de calibração e interpretação $[23,29,30]$.

\subsubsection{Limites inferior e superior de detecção}

\subsection{Limite inferior do intervalo de dose}

O limite inferior do intervalo de dose útil pode ser adulterado pelo ruído instrumental e/ou pela radiação de fundo; por isso, essas interferências devem ser subtraídas da leitura do dosímetro. 
Se $\sigma^{\prime}$ é o desvio padrão da média de um grupo de leituras de um dosímetro irradiado, $\bar{r}$, e $\sigma_{0}^{\prime}$ é o desvio padrão da média de leituras da radiação de fundo, $\bar{r}_{0}$, então o desvio padrão da leitura do dosímetro adquirida, $r-r_{0}$, é dado pela EQ. 2 (estes desvios não são desvios padrões percentuais) $[23,29,30]$ :

$$
\sigma_{r-r_{0}}^{\prime}=\sqrt{\left(\sigma^{\prime}\right)^{2}+\left(\sigma_{0}^{\prime}\right)^{2}}
$$

\subsection{Limite superior do intervalo de dose}

O limite superior do intervalo de dose útil de um dosímetro pode ser imposto simplesmente pelas limitações instrumentais externas, tais como escala fora de leitura no último intervalo sensível de um eletrômetro. Alternativamente, alguma espécie de limite próprio pode ser imposto pelo dosímetro como, por exemplo, reações de competição por produtos da radiação em dosímetros químicos.

Usualmente, o limite superior do intervalo de doses é revelado por uma diminuição na sensibilidade a um valor inaceitável. A sensibilidade pode ser reduzida a zero, ou a um valor negativo, como apresentado na FIG. 6, estimando duplamente a função dose-resposta. É possível, em princípio, fazer uso da parte inclinada negativa de uma curva de resposta em função da dose, tal como apresentado na FIG. 6, para propósitos de dosimetria se for suficientemente reprodutível [23,29,30].

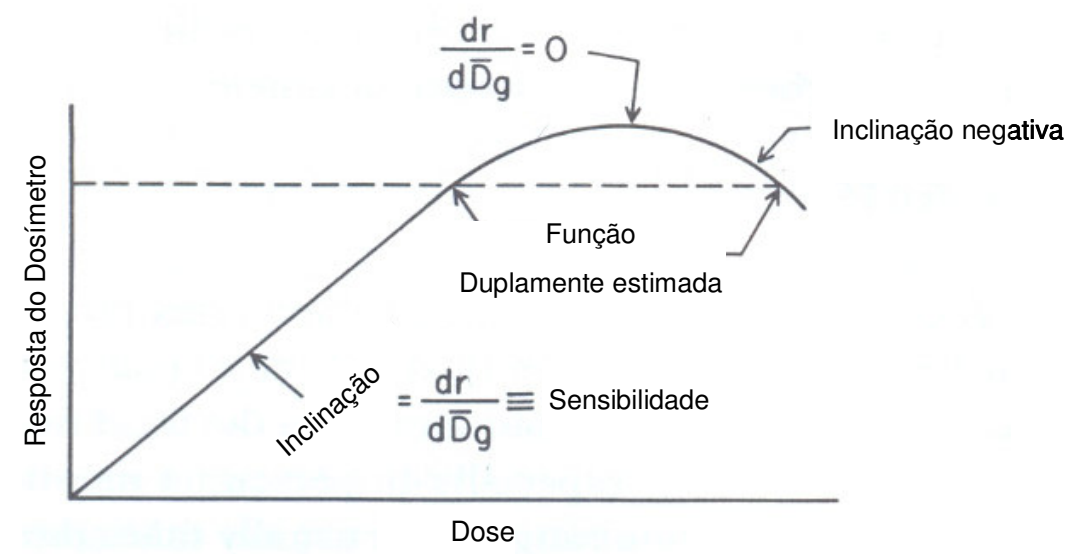

FIGURA 6 - llustração de uma função dose-resposta duplamente estimada resultante de uma diminuição na sensibilidade de um dosímetro em doses altas [23]. 


\subsubsection{Estabilidade}

\subsection{Antes da irradiação}

As características de um dosímetro devem ser estáveis com o tempo até ele ser utilizado. Efeitos da temperatura, oxigênio atmosférico ou umidade e luz, por exemplo, podem causar uma mudança gradual na sensibilidade à dose. Dosímetros fotográficos, químicos ou de estado sólido são geralmente mais suscetíveis a estas influências que câmaras de ionização e contadores $[23,29,30]$.

\subsection{Depois da irradiação}

A leitura latente em alguns tipos de dosímetros integradores (por exemplo, fotográficos, químicos e de estado sólido) pode ser inconstante em alguma extensão do dosímetro, sofrendo desvanecimento durante o intervalo de tempo entre a irradiação e a leitura. Novamente, condições ambientais desfavoráveis de temperatura ou umidade elevadas, luz solar direta ou iluminação fluorescente brilhante, por exemplo, podem agravar este efeito $[23,29,30]$.

\subsubsection{Dependência com a taxa de dose}

De maneira ideal, a resposta de um sistema dosimétrico a duas taxas de dose diferentes deve permanecer constante. Na realidade, a taxa de dose pode influenciar as leituras dos dosímetros e correções apropriadas são necessárias, por exemplo, correções de recombinação para câmaras de ionização em feixes pulsados $[24,29,30]$.

\subsubsection{Dependência energética}

A resposta de um sistema dosimétrico é geralmente uma função da qualidade do feixe de radiação (energia). Já que os sistemas dosimétricos são calibrados em uma qualidade (ou qualidades) de feixe de radiação específica e utilizados sobre um intervalo de energia muito extenso, a variação da resposta de um sistema dosimétrico com a qualidade da radiação (chamada de dependência energética) requer correção.

A resposta energética deve ser horizontal, isto é, o sistema de calibração deve ser independente da energia sobre um determinado intervalo de qualidade 
de radiação. A correção de energia tem que ser incluída na determinação da grandeza para a maior parte das situações de medição.

Em radioterapia, a grandeza de interesse é a dose na água (ou no tecido). Quando o dosímetro não é aquoso ou equivalente ao tecido para todas as qualidades do feixe de radiação, a dependência energética é uma característica importante de um sistema dosimétrico $[24,29,30]$.

\subsubsection{Dependência direcional ou angular}

A variação na resposta de um dosímetro com o ângulo de incidência da radiação é conhecida como dependência direcional ou angular do dosímetro. Comumente, os dosímetros apresentam dependência direcional, em virtude dos seus detalhes estruturais, tamanho físico e da energia da radiação incidente. A dependência direcional é importante em determinadas aplicações, por exemplo, em dosimetria in vivo, embora usando dosímetros semicondutores. Dosímetros empregados em terapia são geralmente utilizados na mesma geometria em que são calibrados [24,29,30].

\subsubsection{Resolução espacial}

Uma vez que a dose é uma grandeza pontual, o dosímetro deve permitir a determinação da dose em um volume muito pequeno. A posição espacial da dose determinada deve ser bem definida em um sistema de referência coordenado.

Os filmes dosimétricos apresentam resolução bidimensional e os géis apresentam resolução tridimensional excelentes, nos quais o ponto de medição é limitado somente pela resolução do sistema de avaliação $[24,29,30]$.

\subsubsection{Condição de uso}

As câmaras de ionização são reutilizáveis, com nenhuma ou pequena mudança na sensibilidade dentro de seu tempo de vida útil. Os dosímetros semicondutores são reutilizáveis, mas com uma perda gradual de sensibilidade dentro do seu tempo de vida útil; entretanto, alguns dosímetros não são reutilizáveis, pois medem a distribuição de dose em uma única exposição, como por exemplo, filmes, géis e alanina $[24,29,30]$. 


\subsubsection{Homogeneidade do lote}

É essencial determinar a extensão de variabilidade da resposta dos dosímetros de um dado lote. Para isto, 10 a 30 dosímetros são irradiados com a mesma dose sob as mesmas condições de irradiação. Estes dosímetros são então analisados sob condições similares pela mesma técnica durante um período de tempo curto. Isto é geralmente mencionado como condições de repetitividade. O desvio padrão da distribuição dos valores resultante é a medição da incerteza devida à não homogeneidade do lote de dosímetros [29].

Além da repetitividade, também é necessário verificar a reprodutibilidade do dosímetro, a qual é definida pelo grau de concordância dos resultados obtidos em diferentes condições de medição [17]. Para dosímetros químicos, é aceitável uma precisão entre $\pm 1 \%$ e $\pm 5 \%$ [31].

\subsubsection{Fatores de influência}

A resposta de quase todos os tipos de dosímetros é influenciada por parâmetros externos em uma proporção variada. Algumas das grandezas de influência comuns são: temperatura, umidade (volume de água no dosímetro), volume de oxigênio no dosímetro, taxa de dose e luz. $\mathrm{O}$ tipo de radiação (radiação gama ou elétrons), a energia da radiação e os fatores geométricos também podem afetar a resposta de um dosímetro; entretanto, em uma proporção menor. A resposta de um dosímetro pode variar completamente com o tempo após várias irradiações.

É importante que a influência destes efeitos seja considerada para reduzir qualquer incerteza na resposta do dosímetro $[29,30]$.

\subsubsection{Dosimetria química}

A dosimetria química é baseada na determinação da dose de radiação por meio da mudança química produzida em um meio (o volume sensível do dosímetro químico), já que a mudança química é relacionada à energia absorvida no meio exposto à radiação ionizante [24,31,32].

Se $G$ é definido como o número de moléculas do produto formado ou reagente destruído por $100 \mathrm{eV}$ de energia absorvida, a estimativa da dose em dosimetria química requer um conhecimento do valor $-G$ (também conhecido como rendimento químico da radiação) o qual é estabelecido pela comparação do 
sistema químico com um dosímetro físico absoluto, por exemplo, dosímetros calorimétricos ou câmaras de ionização. Os dosímetros químicos são, portanto, dosímetros secundários (ou de referência), como discutido anteriormente [10,31].

O padrão de dosimetria química mais amplamente utilizado é o dosímetro Fricke, proposto em 1927, por Fricke e Morse [33]. A solução Fricke é composta de $1 \mathrm{mM}$ de $\mathrm{FeSO}_{4}$ ou $\mathrm{Fe}\left(\mathrm{NH}_{4}\right)_{2}\left(\mathrm{SO}_{4}\right)_{2}, 0,8 \mathrm{~N}$ de $\mathrm{H}_{2} \mathrm{SO}_{4}$ em ar saturado e $1 \mathrm{mM}$ de $\mathrm{NaCl}$. A irradiação de uma solução Fricke oxida os íons ferrosos $\left(\mathrm{Fe}^{2+}\right)$ em íons férricos $\left(\mathrm{Fe}^{3+}\right)$; estes apresentam uma forte banda de absorção em um comprimento de onda (representado pela letra grega $\lambda$ ) de $304 \mathrm{~nm}$, ao passo que os íons $\mathrm{Fe}^{2+}$ não apresentam qualquer absorção neste comprimento de onda $[24,28]$.

A concentração de íons $\mathrm{Fe}^{3+}$ induzida pela radiação pode ser determinada utilizando a técnica de espectrofotometria de Absorção Óptica (AO), a qual mede a absorção (ou absorvância) da solução [24].

\subsubsection{Dosimetria gel}

A dosimetria gel é uma técnica de dosimetria relativa altamente promissora e útil para a verificação de dose em situações clínicas complexas (por exemplo, a Radioterapia por Intensidade Modulada (Intensity Modulated Radiotherapy-IMRT), em objetos simuladores de geometria totalmente tridimensional (anatomicamente formados) e para a avaliação de doses em braquiterapia, incluindo braquiterapia cardiovascular. Os géis são aproximadamente equivalentes ao tecido e podem ser moldados em qualquer forma desejada.

A dosimetria gel pode ser dividida em dois tipos:

- Fricke gel; baseada na bem estabelecida dosimetria Fricke;

- Gel polimérico.

A dosimetria Fricke gel é descrita na subseção 3.3.5.2.

Nos géis poliméricos, monômeros tais como acrilamida são distribuídos em uma matriz de gelatina ou agarose. Por meio da exposição à radiação, os monômeros sofrem uma reação de polimerização, resultando em uma matriz de polímero gel em três dimensões (3D), que pode ser avaliada usando as técnicas 
de Ressonância Magnética (RM), Tomografia Computadorizada (TC), tomografia óptica, espectroscopia vibracional ou ultrassom. Existe uma variedade de formulações de gel polimérico, incluindo géis poliacrilamida, geralmente apresentados como géis $P A G^{\circledR}$ (por exemplo, $B A N G^{\circledR}$ gel), e os novos géis normóxidos (por exemplo, MAGIC ${ }^{\circledR}$ gel); os últimos não são sensíveis à presença de oxigênio atmosférico.

Há uma relação semilinear entre a taxa de relaxação de $\mathrm{RM}$ e a dose absorvida em um ponto no dosímetro gel. Por esta razão, por mapeamento das taxas de relaxação usando um equipamento (scanner) de RM, o mapa de dose pode ser derivado por computação e por calibração própria [14,24].

\subsubsection{Agente gelificante}

Diferentes sistemas gel têm sido propostos para a dosimetria gel, mas agarose e gelatina são os géis normalmente escolhidos. Ambos produzem dosímetros estáveis e bem caracterizados.

A gelatina, gel escolhido para a preparação das soluções Fricke gel estudadas neste trabalho, é um gel relativamente fácil de utilizar, pois dissolve em água a aproximadamente $45^{\circ} \mathrm{C}$; temperatura inferior aos $90^{\circ} \mathrm{C}$ necessários para a dissolução de agarose no mesmo meio. Isso facilita a preparação e pode proporcionar géis mais reprodutíveis, já que a remoção de oxigênio da solução gel é menor em temperatura inferior. Também tem sido mostrado que a matriz agarose pode ser degradada em larga escala na solução ácida por causa da temperatura de preparação elevada [34].

A gelatina é uma mistura heterogênea de proteínas solúveis em água de altos pesos moleculares médios, presentes no colágeno. As proteínas são extraídas por ebulição de pele, tendões, ligamentos, ossos, etc., em água.

A gelatina pode ser de dois tipos, conforme o tratamento a que é submetida:

- Tipo A: a gelatina é derivada de tecido que sofreu tratamento ácido. Exemplo: gelatina de origem suína;

- Tipo B: a gelatina é derivada de tecido que sofreu tratamento básico. Exemplo: gelatina de origem bovina [35]. 
A consistência do gel é determinada pelo valor de Bloom e pela concentração da gelatina utilizada [36]. O número Bloom, como determinado pelo gelômetro Bloom , é uma indicação da dureza de um gel formado de uma solução de concentração conhecida. A unidade Bloom é uma medição da força (peso) requerida para abaixar (empurrando para baixo) uma dada área de gel da amostra a uma distância de $4 \mathrm{~mm}$. Quanto maior o número Bloom, mais resistente é o gel. O número Bloom é proporcional ao peso molecular médio, como apresentado na TAB. 2 [35].

TABELA 2 - Classificação do número Bloom e pesos moleculares médios correspondentes [35].

\begin{tabular}{ccc}
\hline \multirow{2}{*}{ NÚMERO } & Bloom & $\begin{array}{c}\text { PESO MOLECULAR MÉDIO } \\
(k D a)\end{array}$ \\
\hline $50-125$ & Baixo & $20-25$ \\
$175-225$ & Médio & $40-50$ \\
$225-325$ & Alto & $50-100$ \\
\hline
\end{tabular}

O tamanho dos grãos (expresso por mesh) não é uma propriedade direta da gelatina e nem influencia na sua qualidade. No entanto, sob as mesmas condições, gelatinas de mesh baixo são mais facilmente diluídas que gelatinas de mesh alto. Quanto maior o valor de mesh, menor o tamanho dos grãos [36].

\subsubsection{Dosimetria Fricke gel}

O dosímetro Fricke gel foi estabelecido por Gore [11], em 1984, quando reconheceu que o dosímetro Fricke [33] poderia ser avaliado pela técnica de RM além da bem estabelecida técnica de espectrofotometria de AO. O método foi descrito para determinar a distribuição espacial da dose de radiação em um simulador equivalente ao tecido utilizando a técnica de Imageamento por Ressonância Magnética (IRM), com resolução espacial alta e exatidão para doses de radiação moderadas (no intervalo entre 1 e 100 Gy) [11].

O dosímetro Fricke gel consiste da modificação do dosímetro Fricke convencional [33] por meio da adição de um agente gelatinoso na solução e, portanto, sua dosimetria se baseia no mesmo princípio convencional. Em pH 
baixo (aproximadamente 1,0; produzido pela dissolução do sal em 0,8 $N$ de ácido sulfúrico) as reações simplificadas são as seguintes [11]:

$$
\begin{gathered}
\mathrm{Fe}^{2+}+\mathrm{OH} \rightarrow \mathrm{Fe}^{3+}+\mathrm{OH}^{-} \\
\mathrm{H}+\mathrm{O}_{2} \rightarrow \mathrm{HO}_{2} \\
\mathrm{Fe}^{2+}+\mathrm{HO}_{2} \rightarrow \mathrm{Fe}^{3+}+\mathrm{HO}_{2}^{-} \\
\mathrm{HO}_{2}^{-}+\mathrm{H}^{+} \rightarrow \mathrm{H}_{2} \mathrm{O}_{2} \\
\mathrm{Fe}^{2+}+\mathrm{H}_{2} \mathrm{O}_{2} \rightarrow \mathrm{Fe}^{3+}+\mathrm{OH}+\mathrm{OH}^{-}
\end{gathered}
$$

Analogamente à medição da mudança resultante na concentração de íons $\mathrm{Fe}^{3+}$ pela técnica de espectrofotometria de $\mathrm{AO}$, o método de $\mathrm{RM}$ proposto determina a concentração de íons $\mathrm{Fe}^{3+}$ pela observação das mudanças nas propriedades magnéticas da solução que acompanham a mudança no estado de valência [11].

Nos dosímetros Fricke gel, os íons $\mathrm{Fe}^{2+}$ em soluções de sulfato ferroso são dispersos por toda a matriz gel [37], a qual restringe a difusão dos íons $\mathrm{Fe}^{2+}$ e $\mathrm{Fe}^{3+}$ de tal modo que se a imagem do gel é formada dentro de algumas horas após a irradiação, os íons $\mathrm{Fe}^{3+}$ permanecem próximos ao seu ponto de produção. O gel também contribui para a oxidação dos íons $F e^{2+}$ durante a irradiação, aumentando assim o rendimento químico dos íons $\mathrm{Fe}^{3+}$ na solução aquosa pura e aumentando a sensibilidade à dose do dosímetro [38]. A resposta em função da dose do dosímetro Fricke gel depende criticamente do gel usado na sua preparação [34].

Comparando o dosímetro Fricke gel com outros métodos de dosimetria, suas vantagens são as seguintes: fácil de preparar, moldável em qualquer forma e tamanho desejados, equivalência ao tecido em um amplo intervalo de energias de fótons, aplicável em imageamento tridimensional, não é tóxico e é completamente não destrutivo e não invasivo [39]. Este dosímetro também apresenta algumas desvantagens: a oxidação natural e contínua dos íons $F e^{2+}$ presentes na solução, a difusão dos íons $\mathrm{Fe}^{3+}$ na matriz gel a qual impede a obtenção de uma imagem com boa nitidez se passadas muitas horas após a irradiação da solução dosimétrica e o fato do dosímetro não ser reutilizável. 
Têm sido estudados os efeitos de vários parâmetros tais como: concentração de gel [38-41], condições ambientais [39,41,42], estabilidade da resposta [41,43-46], dependência energética [43] e com a taxa de dose [39,40,43], dose mínima detectável [39], difusão dos íons $F e^{3+}$ na matriz gel após a irradiação $[39,47,48]$, para a resposta espectrofotométrica e de RM dos dosímetros Fricke gel irradiados com radiação gama e fótons de energias altas e empregando técnicas radiocirúrgicas, como Gamma Knife ${ }^{\circledR}[39,49]$ e IMRT [50].

\subsection{Objetos simuladores}

Uma estrutura que contém um ou mais substitutos de tecido (ou materiais equivalentes ao tecido) e é usada para simular interações com a radiação ionizante no corpo é chamado de simulador (phantom). Um simulador pode simular um volume de tecido do corpo com relação às estruturas anatômicas tais como forma e distribuição espacial. Simuladores são amplamente utilizados em radioterapia, imageamento radiológico, medicina nuclear, proteção radiológica e radiobiologia [51,52].

\subsection{Curvas de isodose}

As curvas de isodose são linhas que ligam pontos de mesma dose. Elas oferecem uma representação planar da distribuição de dose (variação espacial da dose absorvida por toda parte do material irradiado, tendo a dose os valores mínimo, $D_{\min }$, e máximo, $D_{\max }$ [29]) e facilmente mostram o comportamento de um feixe ou uma combinação de feixes com diferentes blindagens, por exemplo. As curvas de isodose podem ser medidas diretamente na água ou podem ser calculadas. Um arranjo de curvas de isodose é válido para uma dada máquina de tratamento, energia do feixe, distância fonte-superfície (Source to Surface Distance - SSD) e tamanho do campo.

Embora as curvas de isodose possam ser obtidas para apresentar a dose em $G y$, é mais comum apresentá-las normalizadas a $100 \%$ em um ponto fixado. Duas dessas normalizações são as seguintes:

- Normalização a $100 \%$ na profundidade de dose máxima no eixo central;

- Normalização no isocentro [53,54]. 


\subsection{Técnicas de avaliação}

Nesta subseção são descritas de forma resumida, as técnicas de avaliação utilizadas neste trabalho: espectrofotometria de Absorção Óptica (AO), Imageamento por Ressonância Magnética (IMR), Espectroscopia por Ressonância Magnética (ERM) e Espectroscopia Localizada (EL).

\subsubsection{Espectrofotometria de absorção óptica (AO)}

Em análises químicas, a quantidade de luz absorvida pela substância, usualmente um soluto em uma solução, é medida pela espectrofotometria de $A O$, fornecendo informações quantitativas dos componentes do sistema em análise. A resposta espectrofotométrica (absorção ou absorvância) da solução analisada é adimensional.

A cubeta padrão comumente utilizada para a realização das medições espectrofotométricas tem caminho óptico de $1 \mathrm{~cm}$. O equipamento utilizado nessa técnica de avaliação é o espectrofotômetro (APÊNDICE B) $[31,55,56]$.

\subsubsection{Ressonância magnética (RM)}

O fenômeno da Ressonância Magnética (RM) descoberto por F. Block e E. Purcell, em 1946, tem se tornado uma técnica espectroscópica padrão em química e física. Mais adiante, a RM foi aplicada como uma técnica de imageamento desbravada por R. Damadian (1971), P. Lauterbur (1973) e P. Mansfield (1973) [3]. Ainda se utiliza o nome "Ressonância Magnética Nuclear" (RMN), no entanto, o termo "nuclear" não é o mais correto, uma vez que causa confusão com radioatividade e não há radiação ionizante nesse método.

A técnica de RM se fundamenta nas três etapas seguintes:

- Alinhamento: refere-se à propriedade magnética de núcleos de alguns átomos, que tendem a se orientar paralelamente a um campo magnético. O elemento utilizado para produzir imagens de seres biológicos é o núcleo de hidrogênio (próton), por razões físicas e pela abundância. Desta forma, para que esses átomos sejam orientados em uma certa direção, é necessário um campo magnético intenso;

- Excitação: cada núcleo de hidrogênio "vibra" numa determinada frequência proporcional ao campo magnético em que está localizado. Então, o equipamento de RM emite uma onda eletromagnética 
(radiofrequência - RF) nessa mesma frequência. Há uma transferência de energia da onda emitida pelo equipamento para os átomos de hidrogênio. Este fenômeno é conhecido como ressonância;

- Detecção de radiofrequência (RF): os núcleos de hidrogênio tornam-se instáveis ao receber a energia e emitem ondas eletromagnéticas (RF) na mesma frequência ao retornarem ao estado habitual. Assim, o equipamento detecta essas ondas e determina a posição no espaço e a intensidade da energia. Em Imageamento por Ressonância Magnética (IRM) essa intensidade é mostrada como "brilho" na imagem, sendo utilizada a nomenclatura "intensidade de sinal" [4,57].

\subsubsection{Processos de relaxação: $T_{1}$ e $T_{2}$}

Quando a onda de rádio é desligada, o sinal decai completamente. Este decaimento é o resultado do retorno dos prótons ao estado em que estes estavam antes da onda de rádio ser aplicada. Este retorno é chamado de relaxação dos prótons. Há dois processos de relaxação básicos em movimento na amostra. Ambos os processos consideram o decaimento do sinal de RM observado.

Um dos processos envolve o retorno dos prótons ao seu alinhamento original com o campo magnético estático. Este processo, chamado de relaxação longitudinal ou spin-rede, é caracterizado por uma constante de tempo $\mathrm{T}_{1}$.

O outro processo de relaxação é uma perda de sincronia de precessão entre os prótons. Antes da onda de rádio ser aplicada, a orientação precessional dos prótons é aleatória. A aplicação de uma onda de RF conduz os prótons em precessão sincrônica ou "em fase". Quando a onda de RF é desligada, os prótons começam a interagir com seus vizinhos e fornecem energia em colisões aleatórias. Então, eles revertem a um estado de fase aleatória. Como os prótons revertem à orientação aleatória, a magnitude do sinal diminui porque os momentos magnéticos tendem a se cancelar mutuamente. Esse processo é chamado de relaxação transversa ou spin-spin e é caracterizado por uma constante de tempo $T_{2}[4,58,59]$.

Nas duas próximas subseções são descritas duas aplicações da RM, as quais foram utilizadas neste trabalho. 


\subsubsection{Imageamento por ressonância magnética (IRM)}

Se os valores dos sinais de RM podem ser mapeados de acordo com suas posições espaciais e podem ser codificados como "brilho" (escala de cinza) em um monitor, então pode ser produzida uma imagem. Este é o método de Imageamento por Ressonância Magnética, abreviado por IRM no campo clínico, que apresenta as vantagens seguintes: capacidade de penetrar estruturas ósseas e preenchidas com ar com atenuação e artefatos desprezíveis, utiliza radiação não ionizante e é minimamente invasiva [3,4].

No APÊNDICE B é apresentado o tomógrafo de RM que é o equipamento utilizado em IRM.

\subsubsection{Espectroscopia por ressonância magnética (ERM)}

Aplicações espectroscópicas da RM podem ser efetuadas com alguns sistemas de imageamento. Se realizada em um aparelho de IRM, a técnica é habitualmente mencionada como Espectroscopia por Ressonância Magnética (ERM). Esta técnica tem sido utilizada em química analítica desde os anos da década de 1940. A ERM mede as diferenças nas frequências de ressonância entre os núcleos que ocupam diferentes posições nas moléculas [4,58].

Neste trabalho, o estudo da difusão de íons $\mathrm{Fe}^{3+}$ na solução Fricke gel foi realizado por meio da técnica de ERM utilizando um espectrômetro de RM (APÊNDICE B).

Imageamento e espectroscopia por RM requerem a aplicação de pulsos de RF em uma amostra de maneira que sinais coerentes podem ser obtidos de uma bobina receptora localizada ao redor da amostra. Estes pulsos são aplicados em sequências específicas para produzir sinais de RM que rendam informação a respeito da amostra. Exemplos de "sequências de pulso": InversãoRecuperação (Inversion-Recuperation - IR) e Eco de Spin (Spin-Echo - SE) [3,4].

\subsubsection{Espectroscopia localizada (EL)}

A técnica de Espectroscopia Localizada (EL), que combina as técnicas espectroscópicas e de imagens, consiste em relacionar a informação espectral 
com a informação espacial de forma que o sinal do espectro localizado provenha de uma região bem definida da região de interesse [60].

\subsection{Procedimentos e técnicas especiais em radioterapia}

A radioterapia se divide em duas categorias principais: radioterapia de feixe externo (ou teleterapia) e braquiterapia. Na primeira categoria, a fonte de radiação é posicionada a uma determinada distância do paciente e o alvo dentro do paciente é irradiado com um feixe de radiação externo. Em braquiterapia as fontes de radiação são colocadas diretamente no volume alvo (braquiterapia intracavitária ou intersticial) ou sobre um alvo (radioterapia intraoperatória) [52,53,61].

Além das técnicas de radioterapia convencionais utilizadas rotineiramente em departamentos e clínicas de radioterapia padrões, várias técnicas especializadas são conhecidas e utilizadas para procedimentos especiais, seja com dose distribuída ou localizada.

Dentre as técnicas radioterápicas especializadas, as principais técnicas radiocirúrgicas aplicadas no Brasil são a Gamma Knife ${ }^{\circledR}$, que trata de tumores menores e a IMRT, que trata de tumores maiores; essas técnicas são descritas sucintamente na subseção 3.7.1.2 [62].

\subsubsection{Irradiação estereotáxica}

De uma técnica de irradiação obscura experimentada nos anos das décadas de 1960 e 1970 em somente uns poucos centros especializados, a irradiação estereotáxica desenvolveu-se, durante os últimos 15 anos, em uma técnica radioterapêutica de tendência atual experimentada na maior parte dos principais centros de radioterapia por todo o mundo. Irradiação estereotáxica é o termo utilizado para descrever técnicas de irradiação focal que usam múltiplos feixes de fótons não coplanares e para distribuir uma dose prescrita de radiação ionizante a lesões pré-selecionadas e localizadas estereotaxicamente, principalmente no cérebro, apesar de procurar se estender às outras partes do corpo.

As características principais da irradiação estereotáxica são as seguintes:

- As doses totais prescritas são da ordem de 10 a 50 Gy e o delineamento dos alvos são pequenos, com volumes típicos variando de 1 a $35 \mathrm{~cm}^{3}$; 
- As exigências de exatidão posicional e numérica na dose distribuída são de $\pm 1 \mathrm{~mm}$ e $\pm 5 \%$, respectivamente;

- A dose em irradiação estereotáxica pode ser distribuída por uma implantação estereotáxica de fontes radioativas (braquiterapia estereotáxica) ou mais comumente, com uma ou várias fontes de radiação externa (irradiação estereotáxica com feixe externo);

- Quanto ao fracionamento de dose, a irradiação estereotáxica com feixe externo (Stereotactic External Beam Irradiation - SEBI), é dividida em duas categorias:

- Radiocirurgia estereotáxica: a dose total é distribuída em uma única sessão;

- Radioterapia estereotáxica: como em radioterapia padrão, a dose total é distribuída em múltiplas frações;

- De um ponto de vista técnico, essencialmente, não há diferença entre radiocirurgia e radioterapia estereotáxicas e muitas vezes o termo radiocirurgia é utilizado para descrever ambas as técnicas;

- Basicamente, qualquer feixe de radiação que tenha sido estabelecido como útil para radioterapia de feixe externo tem também sido útil em radiocirurgia (radiação gama do ${ }^{60} \mathrm{Co}$, raios $\mathrm{X}$ de megavoltagem, feixes de prótons e partículas carregadas pesadas e até feixes de nêutrons) [62].

\subsubsection{Doenças tratadas com irradiação estereotáxica}

As doenças tratadas com irradiação estereotáxica são as seguintes:

- Desordens funcionais;

- Lesões vasculares;

- Tumores benignos e malignos primários;

- Tumores metastáticos [62].

\subsubsection{Técnicas radiocirúrgicas: Gamma $K$ iffe ${ }^{\circledast}$ e IMRT}

A Gamma Knife ${ }^{\circledast}$ (também chamada de unidade gama) é um dispositivo radiocirúrgico que tem sido associado e dedicado à radiocirurgia por quatro décadas passadas. Apesar dos grandes avanços tecnológicos durante este 
tempo, o escopo e os princípios fundamentais da unidade gama não tem mudado muito desde que o neurocirurgião sueco, Lars Leksell, introduziu o protótipo da unidade gama nos últimos anos da década de 1960. Na unidade gama (APÊNDICE B) são incorporadas 201 fontes de ${ }^{60} \mathrm{Co}$ alojadas em sua parte principal (parte central). Por meio destas fontes são produzidos 201 feixes colimados diretos a um único ponto focal a uma distância fonte-foco de aproximadamente $40 \mathrm{~cm}$; desta forma, os tecidos saudáveis são preservados. A definição final do tamanho do campo de feixe circular é fornecido por um dos quatro capacetes (APÊNDICE B) distribuindo campos circulares com diâmetros nominais entre 4 e $18 \mathrm{~mm}$ ao ponto focal da máquina. Com a finalidade de obter alta precisão no posicionamento da cabeça do paciente, este é colocado, primeiramente, em um quadro rígido de referência denominado dispositivo estereotáxico (APÊNDICE B), que é ajustado dentro do capacete [62,63].

Além do campo configurado em radioterapia conformal em duas dimensões (2D), na qual os campos de radiação são irregularmente conformados, mas de intensidade uniforme, um colimador multifoliado (Multileaf Collimators - MLC), pode ser utilizado para conseguir modulação de intensidade do feixe para uso em radioterapia conformal em 3D. A técnica de IMRT é atualmente a principal forma avançada de radioterapia conformal e é considerada muito promissora para melhorar a radioterapia tanto pelo aumento da probabilidade do controle de tumores quanto pela diminuição da morbidez nos tratamentos, isto é, diminuição da probabilidade de complicação de tecido normal (Normal Tissue Complication Probability - NTCP) [62]. 


\section{MATERIAIS E MÉTODOS}

Os experimentos foram realizados no Laboratório de Doses Altas (LDA) Dosimetria Química e Absorção Óptica do IPEN.

\subsection{Reagentes e vidrarias}

- Ácido sulfúrico, $\mathrm{H}_{2} \mathrm{SO}_{4}$; pró-análise (P.A.) Merck ${ }^{\circledR}$;

- Cloreto de sódio, $\mathrm{NaCl}$; P.A. Merck ${ }^{\circledR}$;

- Sulfato ferroso amoniacal ou sal de Mohr, $\left[\mathrm{Fe}\left(\mathrm{NH}_{4}\right)_{2}\left(\mathrm{SO}_{4}\right)_{2} \cdot 6 \mathrm{H}_{2} \mathrm{O}\right]$; P.A. Merck ${ }^{\circledR}$;

- Alaranjado de xilenol, $\mathrm{C}_{31} \mathrm{H}_{28} \mathrm{~N}_{2} \mathrm{Na}_{4} \mathrm{O}_{13} \mathrm{~S}$; indicador de íons férricos; P.A. Merck ${ }^{\circledR}$;

- Água tri-destilada [64];

- Gelatinas suínas:

- 270 Bloom (alimentícia); Gelita ${ }^{\circledR}$, Brasil;

○ 300 Bloom (P.A.); Sigma-Aldrich ${ }^{\circledR}$, Alemanha.

No ANEXO A são apresentados os certificados de análise dessas gelatinas.

Para a preparação de todas as soluções dosimétricas foram utilizadas vidrarias da rotina de um laboratório de análises químicas [65].

\subsection{Equipamentos de medição}

- Preparação das soluções Fricke gel:

- Balança analítica eletrônica de alta resolução marca METTLER TOLEDO ${ }^{\circledR}$ modelo AB204-S;

- Tri-destilador de água marca MARCONI ${ }^{\circledR}$ modelo MA-079;

- Purificador de água marca ELGA ${ }^{\circledR}$ modelo PURELAB Option-Q DV 25; 
- Agitador magnético marca FISATOM ${ }^{\circledast}$ modelo 753A;

- Refrigerador compacto 80 marca CONSUL ${ }^{\circledR}$ modelo CRT08CBBNA;

- Estufa de secagem e esterilização marca FANEM $^{\circledR}$ modelo 315 SE.

- Determinação do $\mathrm{pH}$ das soluções dosimétricas:

- pH-metro de bancada marca PHTEK ${ }^{\circledR}$ modelo PHS-3B com eletrodo modelo E-900.

- Medições espectrofotométricas:

- Espectrofotômetro marca SHIMADZU ${ }^{\circledR}$ modelo UV-2101PC. Os parâmetros operacionais são apresentados na TAB. 3.

TABELA 3 - Parâmetros operacionais do espectrofotômetro marca SHIMADZU ${ }^{\circledR}$.

\begin{tabular}{cc}
\hline DESCRIÇÃO & PARÁMETROS \\
\hline Modo de aquisição dos dados & Espectros de absorção óptica \\
Modo medição & Absorvância \\
Intervalo de comprimento de onda $(\mathrm{nm})$ & $190-900$ \\
Velocidade de varredura & Rápida \\
Largura da fenda $(\mathrm{nm})$ & 2,0 \\
Intervalo de amostragem $(\mathrm{nm})$ & Automático \\
Linha de base & Ar \\
Material de referência & (nos compartimentos de amostra \\
\hline
\end{tabular}

- Medições de ressonância magnética (RM):

- Tomógrafo de Corpo Inteiro (TCl) marca PHILIPS ${ }^{\circledR}$ modelo GYROSCAN S15/ACS-II, de 1,5 T;

- Espectrômetro de RM de alta resolução marca VARIAN ${ }^{\circledR}$ modelo GEMINI 2000. Os parâmetros operacionais são apresentados na TAB. 4. 
Ambos os equipamentos de RM pertencem ao Laboratório de Ressonância Magnética Nuclear (LRMN) do Instituto de Física (IF) da Universidade de São Paulo (USP).

TABELA 4 - Parâmetros operacionais do espectrômetro de RM marca VARIAN ${ }^{\circledR}$.

\begin{tabular}{cc}
\hline DESCRIÇÃO & PARÂMETROS \\
\hline Sequência de pulso & IR \\
Frequência & $200 \mathrm{MHz}$ para prótons \\
$\mathbf{T}_{\mathbf{1}}$ para a amostra não irradiada & $868 \mathrm{~ms}$ \\
$\mathbf{T}_{\mathbf{1}}$ para a amostra totalmente irradiada & $404 \mathrm{~ms}$ \\
Tempo de inversão das sequências de pulso & $760 \mathrm{~ms}$ para $\mathrm{Fe}^{2+}$ \\
IR para a amostra parcialmente irradiada $(\tau)$ & $310 \mathrm{~ms}$ para $\mathrm{Fe}^{3+}$ \\
(diferentes intervalos entre os pulsos $\mathbf{1 8 0 ^ { \circ }} \mathbf{e ~ 9 0}^{\circ}$ ) & $5000 \mathrm{~ms}$ para $\mathrm{Fe}$ total \\
Gradiente para aquisição dos & Linear \\
espectros de RM & (paralelo ao campo principal) \\
Gradiente para codificação da & $\mathrm{z}_{1}$ \\
distribuição espacial &
\end{tabular}

- Auxílio da visualização das cores das soluções Fricke gel:

○ Negatoscópio marca E.M.B. ${ }^{\circledR}$ modelo Prendograv - Pat. no. 84063, pertencente ao Laboratório de Materiais Dosimétricos (LMD) do IPEN.

\subsection{Sistemas de irradiação}

- Radiação gama do cobalto-60 $\left({ }^{60} \mathrm{Co}\right)$ :

- Sistema de teleterapia com fonte de ${ }^{60} \mathrm{Co}$ :

- Marca: Keleket Barnes Flaxaray ${ }^{\circledR}$;

- Modelo: IS;

- Atividade (abril de 2009): $\mathbf{9 , 7} \times 10^{-2} \mathrm{TBq}$;

- Incerteza expandida apresentada no certificado de calibração emitido pelo Instituto de Radioproteção e Dosimetria (IRD), rastreado ao Physikalisch-Technische Bundesanstalt (PTB): $\pm 1 \%$, com um nível de confiança de $95 \%$;

pertencente ao Laboratório de Calibração de Instrumentos (LCI) do IPEN; - Irradiador do tipo Panorâmico (fonte Panorâmica): 
- Marca: Yoshizawa Kiko ${ }^{\circledR}$;

- Modelo: FIS 60-04;

- Atividade (abril de 2009): 18,1533 TBq;

- Taxas de dose sem atenuação (abril de 2009) para as distâncias calibradas pelo Programa Internacional de Garantia de Dose da Agência Internacional de Energia Atômica (International Dose Assurance Service - International Atomic Energy Agency - IDASIAEA), com os dosímetros Fricke e de alanina [66]:

> $10 \mathrm{~cm}: 1,99 \times 10^{-1} \mathrm{kGy} \cdot \mathrm{h}^{-1}$;

$>20 \mathrm{~cm}: 7,95 \times 10^{-2} \mathrm{kGy} \cdot \mathrm{h}^{-1}$;

$>40 \mathrm{~cm}: 2,78 \times 10^{-2} \mathrm{kGy} \cdot \mathrm{h}^{-1}$;

- Possibilita o uso de atenuador de chumbo (6\% de antimônio) que reduz a taxa de dose em $70 \%$ do valor inicial;

- Irradiador do tipo Gammacell (fonte Gammacell):

- Marca: Atomic Energy of Canada ${ }^{\circledR}$;

- Modelo: 220:

- Atividade (abril de 2009): 98,8615 TBq;

- Taxa de dose sem atenuação (abril de 2009) (IDAS-IAEA): 2,21 $k G y \cdot h^{-1}$;

- Possibilita o uso de atenuadores de chumbo (6\% de antimônio) que reduzem a taxa de dose em $50 \%, 70 \%$ e $90 \%$ do valor inicial;

ambos os irradiadores apresentam incerteza expandida na taxa de dose de $\pm 1,7 \%$, com um nível de confiança de 95\% (IDAS-IAEA) e pertencem ao Laboratório de Fontes Intensas de Radiação (LFIR) do IPEN.

- Radiação X:

- Sistema de radiação $X$ de energias baixas marca PANTAKSEIFERT $^{\circledR}$ modelo ISOVOLT 160 HS. Os parâmetros de irradiação são apresentados na TAB. 5. 
TABELA 5 - Parâmetros de irradiação do sistema de radiação $X$ marca PANTAK-SEIFERT ${ }^{\circledR}[67,68]$.

\begin{tabular}{|c|c|c|c|c|c|c|}
\hline \multirow{3}{*}{$\begin{array}{l}\text { QUALIDADE } \\
\text { DA } \\
\text { RADIAÇÃO }\end{array}$} & \multirow{3}{*}{$\begin{array}{c}\text { FILTRAÇÃO } \\
\text { ADICIONAL } \\
(m m A l)\end{array}$} & \multirow{3}{*}{$\begin{array}{l}\text { TENSÃO } \\
(k V)\end{array}$} & \multicolumn{2}{|c|}{ CAMADA } & \multirow{3}{*}{$\begin{array}{c}\text { TAXA DE } \\
\text { KERMA NO AR } \\
\left(m G y \cdot s^{-1}\right)\end{array}$} & \multirow{3}{*}{$\begin{array}{c}\text { ENERGIA } \\
\text { EFETIVA } \\
(k e V)\end{array}$} \\
\hline & & & \multicolumn{2}{|c|}{$\begin{array}{l}\text { SEMI-REDUTORA (CSR) } \\
(m m A l)\end{array}$} & & \\
\hline & & & $1^{\mathrm{a}}$ & $2^{a}$ & & \\
\hline $\mathrm{T}-25$ & 0,4 & 25 & 0,279 & 0,410 & 2,762 & 13,93 \\
\hline$T-50(b)$ & 1,0 & 50 & 1,079 & 1,690 & 4,027 & 22,08 \\
\hline$T-50(a)$ & 4,0 & 50 & 2,411 & 2,890 & 0,821 & 30,48 \\
\hline$\overline{\text { RQR7 }}$ & 2,5 & 90 & 2,950 & 4,620 & 4,960 & 33,05 \\
\hline RQR8 & 2,5 & 100 & 3,240 & 5,200 & 6,000 & 34,40 \\
\hline RQR9 & 2,5 & 120 & 3,840 & 6,310 & 8,120 & 37,05 \\
\hline RQR10 & 2,5 & 150 & 4,730 & 7,790 & 11,680 & 40,75 \\
\hline
\end{tabular}

As qualidades de radiação apresentadas na TAB. 5 são de níveis de radioterapia (inicial "T") e radiodiagnóstico (inicial " $R$ ").

A distância da fonte ao centro do volume da cubeta foi de $50 \mathrm{~cm}$ e a corrente utilizada foi de $10 \mathrm{~mA}$ para todas as energias efetivas apresentadas na TAB. 5.

- Sistema de radiação $X$ de energias baixas marca RIGAKU-DENKI ${ }^{\circledR}$ modelo GEIGERFLEX. Os parâmetros de irradiação são apresentados na TAB. 6.

TABELA 6 - Parâmetros de irradiação do sistema de radiação $X$ marca RIGAKU-DENKI ${ }^{\circledR}$.

\begin{tabular}{ccccc}
\hline $\begin{array}{c}\text { FILTRO } \\
(\mathrm{mm} A l)\end{array}$ & $\begin{array}{c}\text { TENSÃo } \\
(\mathrm{k} V)\end{array}$ & $\begin{array}{c}\text { CORRENTE } \\
(\mathrm{mA})\end{array}$ & $\begin{array}{c}\text { ENERGIA } \\
\text { EFETIVA } \\
(\mathrm{keV})\end{array}$ & $\begin{array}{c}\text { TAXA DE } \\
\text { EXPOSIÇÃo } \\
\left(\mathrm{mC} \cdot \mathrm{kg}^{-1} \cdot \mathrm{min}^{-1}\right)\end{array}$ \\
\hline 0,682 & 40 & 30 & 17,7 & 16,4 \\
\hline
\end{tabular}

A distância da fonte ao centro do volume da cubeta foi de $50 \mathrm{~cm}$ para a energia efetiva apresentada na TAB. 6. 
Os sistemas de radiação $X$ utilizados pertencem ao $\mathrm{LCl}$ do IPEN e apresentam incerteza expandida de $\pm 1,54 \%$, com um nível de confiança de 95\% (PTB).

\section{- Fótons de energia alta:}

- Acelerador de fótons marca VARIAN ${ }^{\circledR}$ modelo CLINAC 6EX. Os parâmetros de irradiação são apresentados na TAB. 7.

TABELA 7 - Parâmetros de irradiação do acelerador de fótons marca VARIAN $^{\circledR}[69]$.

\begin{tabular}{ccc}
\hline ENERGIA & PROFUNDIDADE & CAMPO DE \\
NOMINAL & DE & RADIAÇÃO \\
$(\mathrm{MeV})$ & MÁXIMA DOSE & $\left(\mathrm{cm}^{2}\right)$ \\
& $(\mathrm{cm})$ & \\
\hline 6 & 1,5 & $10 \times 10$ \\
\hline
\end{tabular}

pertencente à Divisão de Oncologia do Instituto de Radiologia (InRad) do Hospital das Clínicas (HC) da Faculdade de Medicina da USP (FM-USP). Este acelerador de fótons apresenta incerteza expandida de $\pm 3 \%$, com um nível de confiança de 95\% (ICRU 50 [70], ICRU 62 [71]).

Foram confeccionadas placas de polimetilmetacrilato (PMMA) $\left(30 \times 30 \times 1,8 \mathrm{~cm}^{3}\right)$ utilizadas juntamente com placas de água sólida RMI-457 $\left(30 \times 30 \mathrm{~cm}^{2}\right.$ e diferentes espessuras) como objeto simulador. Este foi usado apenas para posicionar a profundidade de máxima ionização no centro da cubeta.

\section{- Sistema Leksell Gamma Knife ${ }^{\circledR}$ :}

- Sistema radiocirúrgico Leksell Gamma Knife ${ }^{\circledR}$ marca Elekta ${ }^{\circledR}$ modelo B pertencente ao Instituto de Radiocirurgia Neurológica (IRN) do Hospital Santa Paula (HSP) de São Paulo. Os parâmetros de irradiação são apresentados na TAB. 8. 
TABELA 8 - Parâmetros de irradiação do sistema radiocirúrgico Leksell Gamma Knife ${ }^{\circledR}$ marca Elekta ${ }^{\circledR}$.

\begin{tabular}{cc}
\hline DESCRIÇÃO & PARÂMETROS \\
\hline Dose prescrita na isodose $(G y)$ & 40 \\
Dose no centro do alvo $(G y)$ & 80 \\
Isodose $(\%)$ & 50 \\
Tempo de irradiação (min) & 59,68 \\
\hline
\end{tabular}

No APÊNDICE B são apresentadas as ilustrações dos equipamentos de medição e do sistema radiocirúrgico Leksell Gamma Knife ${ }^{\circledast}$ utilizados neste trabalho.

\subsection{Programas computacionais}

- Programa de controle e aquisição de dados de radiação X, utilizando o software LabVIEW $^{\circledR}[72]$, para a irradiação realizada no sistema de radiação $X$ PANTAK-SEIFERT ${ }^{\circledR}$ com as qualidades de radiação apresentadas na TAB. 5 e com dose de $1 \mathrm{~Gy}$;

- Software PHILIPS ${ }^{\circledR}$ GYROSCAN MR/VMS versão 3.8.1., para a obtenção das intensidades de sinal de RM;

- Programa NMR desenvolvido em 1995, pelo Prof. Dr. Cláudio José Magon, do Instituto de Física (IF) da Universidade Federal de São Carlos (UFSCAR), utilizado para ajustar os valores de $T_{1}$;

- Software Leksell GammaPlan ${ }^{\circledR}$ (sistema de planejamento de dose do sistema Gamma Knife ${ }^{\circledast}$ modelo B), para calcular a distribuição de dose assumindo uma geometria cerebral;

- Software MRIcro ${ }^{\circledR}$ versão 1.40, para a conversão dos arquivos gerados no sistema de IRM em imagens;

- Software MATLAB ${ }^{\circledast}$ versão 7.0.4, para a reconstrução tridimensional do simulador esférico;

- Software Microsoft ${ }^{\circledR}$ Excel versão 2002, para a efetuação de todos os cálculos necessários para a obtenção dos resultados; 
- Software Microcal Origin ${ }^{\circledR}$ versão 7.5, para a confecção dos gráficos apresentados.

\subsection{Preparação da solução Fricke gel}

A solução Fricke gel consiste de [40]:

- $50 \mathrm{mM}$ de ácido sulfúrico, $\mathrm{H}_{2} \mathrm{SO}_{4}$;

- $1 \mathrm{mM}$ de cloreto de sódio, $\mathrm{NaCl}$;

- $1 \mathrm{mM}$ de sulfato ferroso amoniacal, $\left[\mathrm{Fe}\left(\mathrm{NH}_{4}\right)_{2}\left(\mathrm{SO}_{4}\right)_{2} \cdot 6 \mathrm{H}_{2} \mathrm{O}\right]$;

- $0,1 \mathrm{mM}$ de alaranjado de xilenol, $\mathrm{C}_{31} \mathrm{H}_{28} \mathrm{~N}_{2} \mathrm{Na}_{4} \mathrm{O}_{13} \mathrm{~S}$;

- Água tri-destilada [65];

- Gelatina suína:

- 270 Bloom; ou

- 300 Bloom .

A gelatina é dissolvida em $75 \%$ do volume total de água tri-destilada. Inicialmente, a gelatina é umedecida com um pouco de água fria. Depois da total absorção é adicionado o restante da água que é previamente aquecida a $45^{\circ} \mathrm{C}$. Esta solução é mantida sob agitação e aquecimento até a completa dissolução. Nos $25 \%$ de água restante são dissolvidos os demais compostos. Esta solução é adicionada à solução gelatinosa, a qual é previamente resfriada. A solução resultante é mantida sob agitação para completa homogeneização [40]. Foram preparadas soluções Fricke gel com concentrações de 1\%, 5\%, 10\% e 15\% de gelatina.

Todas as soluções dosimétricas estudadas foram preparadas com água produzida pelo tri-destilador (MARCONI ${ }^{\circledR}$ ) utilizado, exceto a solução Fricke gel (5\% de gelatina 270 Bloom) irradiada no sistema de radiação X PANTAKSEIFERT ${ }^{\circledR}$ com dose de $1 \mathrm{~Gy}$ e energias efetivas entre 13,93 e 40,75 keV (para a determinação da dependência energética da resposta espectrofotométrica), que foi preparada com água produzida no purificador de água $\left(E L G A^{\circledR}\right)$. Este purificador de água foi adquirido pelo laboratório no final da execução deste trabalho, então foi decidido preparar uma das soluções com essa qualidade de água a fim de compará-la com as soluções preparadas com água tri-destilada e 
verificar uma possível diferença. A solução dosimétrica não irradiada preparada com água do purificador apresenta o valor de absorvância de 0,1658 \pm 0,0034, enquanto a solução não irradiada preparada com água tri-destilada apresenta o valor de absorvância de 0,1899 \pm 0,0036, nas mesmas condições experimentais, indicando que a água produzida no purificador $\left(E L G A^{\circledR}\right)$ é de pureza maior que a produzida no tri-destilador $\left(\mathrm{MARCONI}^{\circledR}\right)$. É recomendável utilizar uma água de maior pureza na preparação das soluções Fricke gel, para que as incertezas nas medições possam ser reduzidas, mas isto não significa que a água tri-destilada não possa ser utilizada, já que também é de pureza alta.

As soluções Fricke gel preparadas foram acondicionadas em cubetas de PMMA, marca Sarstedt ${ }^{\circledR}$, de $4 \mathrm{~mL}$, com faces ópticas paralelas, dimensões de $10 \times 10 \times 45 \mathrm{~mm}^{3}$ e caminho óptico de $10 \mathrm{~mm}$, seladas com filme de policloreto de vinila (PVC), para a realização das medições espectrofotométricas e de IRM, e, em capilares de vidro (5 $\mathrm{mm}$ de diâmetro, $1 \mathrm{~mm}$ de espessura da parede do tubo e $200 \mathrm{~mm}$ de altura), para as medições de espectroscopia de RM.

\subsection{Irradiação das amostras}

As soluções a serem irradiadas foram mantidas sob refrigeração $\left((4 \pm 1)^{\circ} C\right)$ e ao abrigo da luz por aproximadamente 12 horas [40] e permaneceram por 30 minutos à temperatura ambiente e ao abrigo da luz antes da irradiação. As amostras de solução Fricke gel foram irradiadas na própria cubeta de leitura.

As irradiações foram sempre realizadas no ar e em condições de equilíbrio eletrônico para as irradiações realizadas com radiação gama do ${ }^{60} C o$ e no acelerador de fótons de $6 \mathrm{MeV}$.

Para alcançar as condições de equilíbrio eletrônico foram utilizadas:

- Placas de PMMA com $3 \mathrm{~mm}$ de espessura, para as irradiações nas fontes de ${ }^{60} \mathrm{Co}$;

- Placas de água sólida, posicionadas acima e abaixo do suporte de acrílico em que estavam as cubetas para garantir a profundidade de máxima dose $(1,5 \mathrm{~cm})$ e o retroespalhamento, respectivamente, para as irradiações no acelerador de fótons de $6 \mathrm{MeV}$. 


\subsection{Preparação, irradiação e avaliação do simulador esférico}

Para o desenvolvimento do simulador esférico, um balão volumétrico de fundo redondo de $1000 \mathrm{~mL}$ (aproximadamente $12,5 \mathrm{~cm}$ de diâmetro) foi preenchido com solução Fricke gel preparada com $5 \%$ de gelatina 270 Bloom (FIG. 7) e mantido sob refrigeração $\left((4 \pm 1)^{\circ} C\right)$ e ao abrigo da luz por cerca de 12 horas.

Antes da irradiação, o simulador permaneceu sob temperatura ambiente até alcançar equilíbrio térmico, foi posicionado em um dispositivo estereotáxico próprio do equipamento e introduzido no sistema radiocirúrgico Leksell Gamma $K$ nife ${ }^{\circledR}$. O tumor simulado foi irradiado ininterruptamente por 59,68 minutos; tempo correspondente à $80 G y$ no centro do alvo, com isodose prescrita de $50 \%$. Após a irradiação, o simulador foi transportado (em uma caixa de isopor com gelo) até a instalação de medição de IRM.

Em virtude da distância entre as instalações (Gamma Knife ${ }^{\circledR}$ e IRM), as imagens foram obtidas aproximadamente 2 horas depois da irradiação. Foram obtidas imagens do simulador não irradiado e irradiado (colocados na mesma posição dentro do magneto do tomógrafo de RM). As imagens do simulador irradiado foram utilizadas para reconstruir imagens em três dimensões (3D). As imagens do simulador não irradiado foram utilizadas como referência.

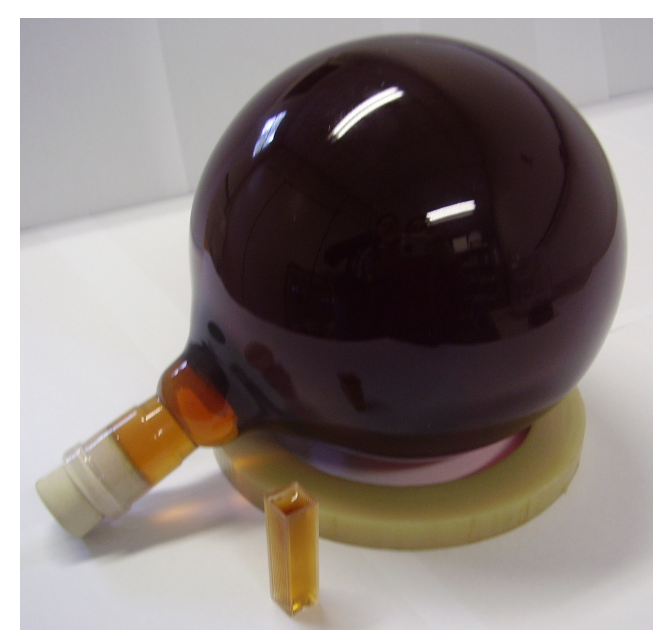

FIGURA 7 - Simulador esférico contendo solução Fricke gel preparada com $5 \%$ de gelatina 270 Bloom não irradiada e cubeta de leitura contendo a mesma solução, para melhor visualização da cor da solução não irradiada e controle da irradiação. 


\subsection{Medições de absorção óptica (AO)}

As medições de absorção óptica foram realizadas imediatamente após a preparação das soluções (soluções não irradiadas) e 30 minutos após a irradiação. Foi determinado o comprimento de onda dosimétrico para cada solução irradiada analisada. Esse comprimento de onda foi utilizado para a obtenção dos valores de absorvância das soluções irradiadas.

\subsection{Imageamento por ressonância magnética (IRM)}

As imagens por RM foram obtidas utilizando-se as sequências de pulso seguintes: Eco do Campo Turbo ponderado em $\mathrm{T}_{1}$ ( $T_{1}$-Weighted Turbo Field Echo - T1-TFE), Inversão-Recuperação (Inversion-Recovery - IR) e Eco de Spin Turbo com Inversão-Recuperação (Inversion-Recovery Turbo Spin Echo - IR-TSE). Das sequências utilizadas, a que proporcionou melhor contraste na imagem foi a sequência IR-TSE com Tempo de Repetição (TE) de $700 \mathrm{~ms}$ e Tempo de Eco (TE) de $11 \mathrm{~ms}$.

Foi utilizada a orientação coronal em todas as sequências de pulso. Todos os valores de intensidade de sinal de RM foram obtidos de fatias das imagens das amostras de orientação coronal.

Os parâmetros utilizados para a obtenção da resposta da solução Fricke gel avaliada por IRM e tempo de relaxação são apresentados no APÊNDICE C.

\subsection{Espectroscopia por ressonância magnética (ERM)}

Para estudar o processo de difusão de íons férricos $\left(\mathrm{Fe}^{3+}\right)$ na solução Fricke gel, foi preparada uma solução com $5 \%$ de gelatina 270 Bloom e foram adicionadas 2 gotas $\cdot m L^{-1}$ de água deuterada para estabelecer o sinal de deutério utilizado para fixar a frequência de ressonância do espectrômetro de RM (sistema de locking). Dois capilares de vidro foram parcialmente preenchidos com a solução dosimétrica até $40 \mathrm{~mm}$ de altura (FIG. 8a); ambos permaneceram sob refrigeração $\left((4 \pm 1)^{\circ} C\right)$ e ao abrigo da luz por aproximadamente 17 horas. Depois de uma hora sob temperatura ambiente, foi medido o tempo de relaxação $\mathrm{T}_{1}$ de um dos capilares de vidro com solução não irradiada. Esse mesmo capilar foi totalmente irradiado (FIG. 8b) e $\circ T_{1}$ da solução dosimétrica foi medido novamente. Após 40 horas, a outra amostra foi parcialmente irradiada (FIG. 8c) e, 
imediatamente depois, foram obtidos os espectros de RM da solução na presença de um gradiente linear na direção $z$, superposto ao campo magnético principal do espectrômetro. As duas amostras foram irradiadas com radiação gama do ${ }^{60} \mathrm{Co}$ com dose de 50 Gy [73].

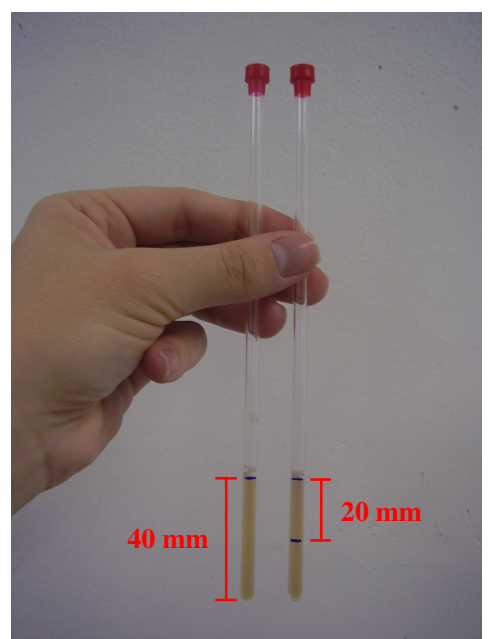

a

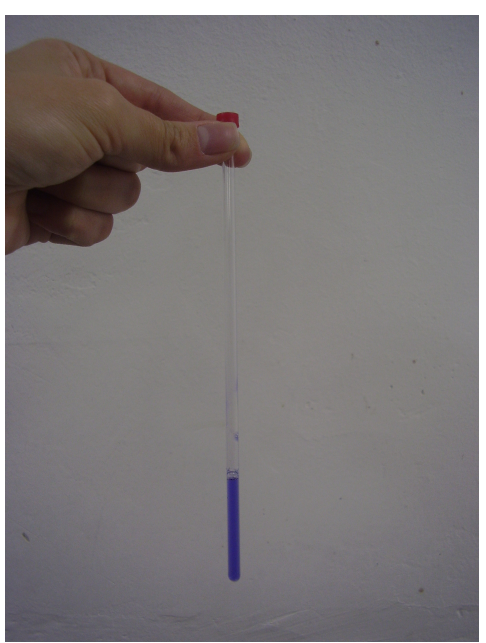

b

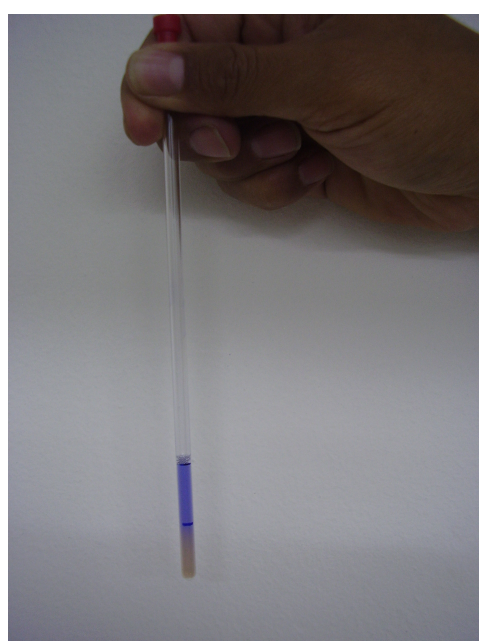

C

FIGURA 8 -Amostras da solução Fricke gel preparada com $5 \%$ de gelatina 270 Bloom não irradiadas (a), totalmente (b) e parcialmente (c) irradiadas com radiação gama do ${ }^{60} \mathrm{Co}$ [73].

Para realizar a irradiação parcial, a parte inferior do capilar de vidro contendo o gel dosimétrico (20 $\mathrm{mm}$ de baixo para cima) foi blindada utilizando tijolos de chumbo de $50 \mathrm{~mm}$ de espessura. Para proteger a parte inferior do tubo, um dos tijolos de chumbo foi perfurado a fim de acomodar o capilar de vidro contendo a solução Fricke gel. O arranjo experimental é apresentado na FIG. 9 [73]. 


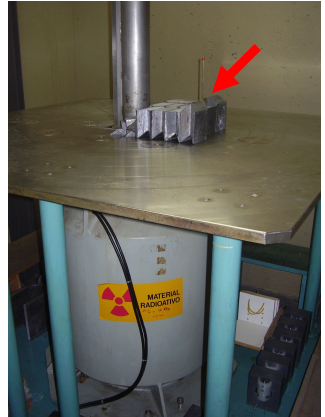

a

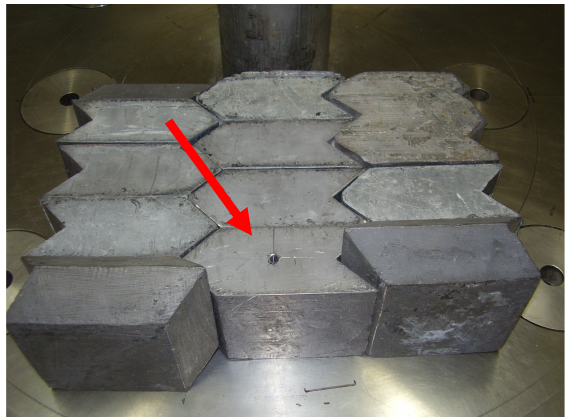

b

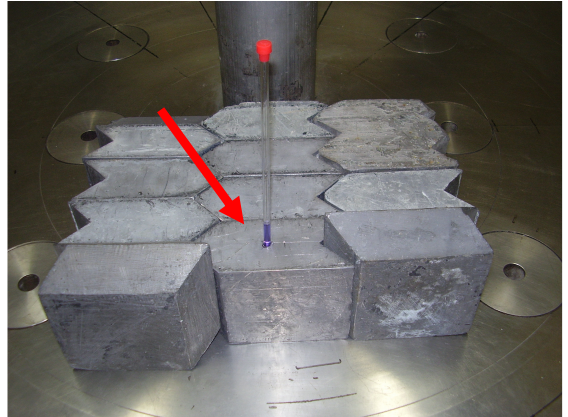

C

FIGURA 9 - Arranjo experimental para a irradiação parcial da amostra da solução Fricke gel $(5 \%$ de gelatina 270 Bloom $)$ na fonte de ${ }^{60} \mathrm{Co}$ Panorâmica (a); tijolo de chumbo perfurado para acomodação do capilar de vidro contendo a solução Fricke gel para a irradiação parcial da amostra (b) e solução Fricke gel parcialmente irradiada (c) [73].

Todas as medições efetuadas empregando as técnicas de IRM, ERM e de tempo de relaxação das amostras das soluções Fricke gel foram realizadas pela equipe do Laboratório de Ressonância Magnética Nuclear (LRMN) do IF-USP.

\subsection{Apresentação dos resultados}

As medições espectrofotométricas e de RM correspondem à média aritmética de três amostras para cada parâmetro analisado (dose, concentração de gelatina, energia efetiva, etc.) e as barras de erro dos pontos apresentados nos gráficos (imperceptíveis em alguns deles), correspondem aos desvios padrões das médias das leituras; incertezas do tipo B não foram consideradas nos testes de desempenho das soluções Fricke gel.

A radiação de fundo foi subtraída de todas as médias aritméticas dos resultados das medições empregando as técnicas de $A O$ e $R M$, exceto das amostras utilizadas para a determinação da estabilidade da reposta espectrofotométrica das soluções dosimétricas preparadas com as diferentes qualidades de gelatina estudadas.

As respostas espectrofotométricas das soluções Fricke gel irradiadas com radiação $X$ para todas as energias estudadas são relativas à resposta da solução irradiada com radiação gama do ${ }^{60} \mathrm{Co}$ e corrigidas para a absorção $\left(e^{-\mu x}\right)$ da parede da cubeta de PMMA. 
As incertezas expandidas das curvas de isodose foram calculadas (APÊNDICE A) considerando um fator de abrangência, $k$, igual a 2, para um nível de confiança aproximado de $95 \%$. 


\section{RESULTADOS E DISCUSSÕES}

\subsection{Padronização do método de obtenção da solução Fricke gel}

Para padronizar o método de obtenção da solução Fricke gel desenvolvida no IPEN [74,75] foram preparadas soluções dosimétricas com gelatinas de diferentes qualidades (270 e 300 Bloom) e diferentes concentrações de gelatina $(1 \%, 5 \%, 10 \%$ e $15 \%)$.

\subsubsection{Influência da concentração da gelatina}

Na FIG. 10 é apresentada a influência da concentração da gelatina na resposta espectrofotométrica das soluções Fricke gel preparadas com concentrações de $1 \%, 5 \%, 10 \%$ e $15 \%$ de gelatina 270 Bloom e irradiadas com radiação gama do ${ }^{60} \mathrm{Co}$ com doses de 5 e $40 \mathrm{~Gy}$.

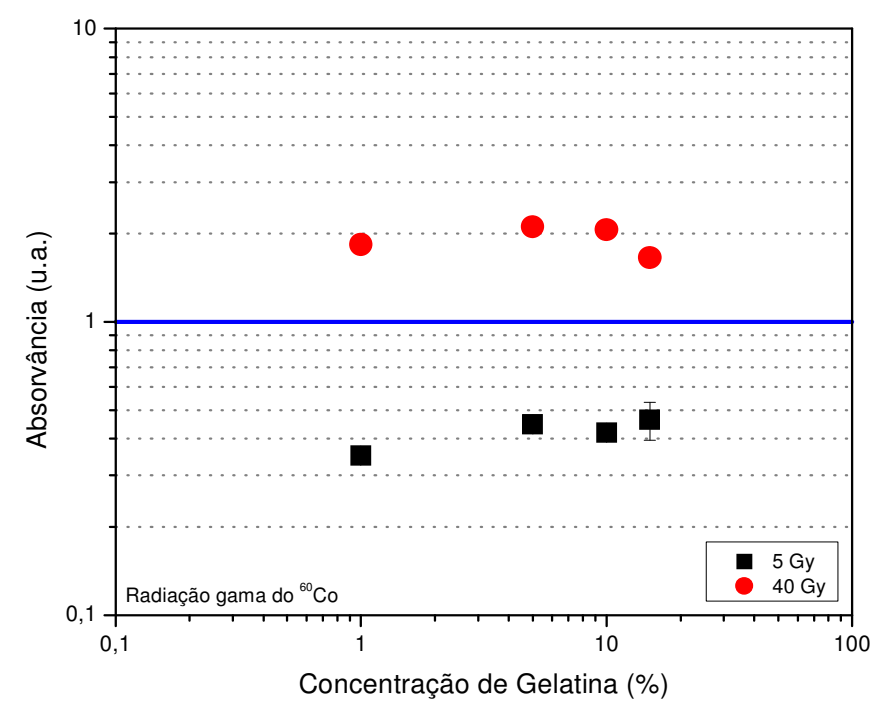

FIGURA 10 - Resposta espectrofotométrica das soluções Fricke gel preparadas com gelatina 270 Bloom em função da concentração da gelatina. 
Os resultados apresentados na FIG. 10 correspondem ao comprimento de onda dosimétrico de $585 \mathrm{~nm}$ [12].

Comparando os resultados apresentados pelas soluções preparadas com diferentes concentrações de gelatina e irradiadas observa-se que a solução preparada com $1 \%$ de gelatina apresenta os menores valores de absorvância para ambas as doses de radiação e as soluções preparadas com $5 \%$ e $10 \%$ de gelatina apresentam comportamento similar para as doses de 5 e 40 Gy. A solução preparada com $15 \%$ de gelatina também apresenta comportamento similar ao das soluções preparadas com $5 \%$ e $10 \%$ de gelatina para a dose de 5 Gy e, o menor valor de absorvância para a dose de $40 G y$, indicando que a resposta espectrofotométrica desta solução satura antes da resposta das demais soluções como consequência da maior concentração de gelatina na solução.

Considerando o comportamento das soluções Fricke gel preparadas com diferentes concentrações de gelatina podem ser feitas as observações seguintes:

- A solução preparada com $1 \%$ de gelatina não apresenta consistência adequada para a determinação da distribuição de dose em três dimensões (3D);

- A solução preparada com $10 \%$ de gelatina apresenta consistência e sensibilidade adequadas para a aplicação dosimétrica, mas sua solidificação ocorre em alguns minutos após a preparação, o que dificulta, por exemplo, o preenchimento das cubetas de leitura com a solução dosimétrica;

- A preparação da solução com $15 \%$ de gelatina é praticamente inviável. A dissolução dessa quantidade de gelatina é extremamente difícil. Depois da total dissolução da gelatina, torna-se impossível a manutenção da solução no estado líquido. Desta forma, faz-se necessário aumentar a agitação da solução, o que gera inúmeras bolhas de ar, que resultam em uma solução não homogênea e que contribuem para o aumento da oxidação natural dos íons $F e^{2+}$;

- A solução preparada com $5 \%$ de gelatina é a que apresenta maior facilidade de preparação e de manuseio. Além disso, apresenta sensibilidade e consistência adequadas para a determinação da distribuição de dose em 3D. Os resultados apresentados na FIG. 10 
indicam semelhança do comportamento desta solução com o da solução preparada com $10 \%$ de gelatina (para 5 e $40 \mathrm{~Gy}$ ) e com o da solução preparada com $15 \%$ de gelatina (para $5 \mathrm{~Gy}$ ), mas além da preparação da solução com $5 \%$ de gelatina ser mais fácil, utiliza-se menor quantidade de gelatina e, portanto, tem-se um consumo menor de agente gelificante na preparação das soluções dosimétricas.

Como conclusão, a concentração de gelatina foi fixada em $5 \%$ para ambos os tipos de gelatina.

\subsubsection{Influência da qualidade da gelatina}

Para fins de comparação entre as soluções Fricke gel preparadas com 5\% de gelatinas 270 e 300 Bloom, para cada solução, foram determinados, empregando a técnica de espectrofotometria de Absorção Óptica (AO), os parâmetros seguintes:

- Cor;

- Consistência;

- $\mathrm{pH}$;

- Espectros de absorção óptica;

- Estabilidade da resposta espectrofotométrica em função do tempo sob duas diferentes condições de armazenagem:

○ Condição 1: sob refrigeração $\left((4 \pm 1)^{\circ} C\right)$ e ao abrigo da luz;

- Condição 2: sob temperatura e luz ambiente;

- Resposta espectrofotométrica em função da dose;

- Limites mínimo e máximo de detecção para radiação gama do ${ }^{60} \mathrm{Co}$.

Não foram preparadas soluções utilizando outras concentrações de gelatina 300 Bloom, além de $5 \%$, e também não foram realizados mais testes de desempenho da solução preparada com esta qualidade de gelatina porque os testes realizados foram suficientes para a comparação do comportamento das soluções preparadas com ambas as qualidades de gelatina estudadas. 


\subsubsection{Cor}

Na FIG. 11 é apresentada a mudança na coloração da solução Fricke gel preparada com 5\% de gelatina 270 Bloom, acondicionada em cubetas de polimetilmetacrilato (PMMA), não irradiada e irradiada com radiação gama do ${ }^{60}$ Co com doses entre 0,5 e 100,0 Gy.

A solução preparada com $5 \%$ de gelatina 270 Bloom e as demais soluções Fricke gel preparadas com diferentes concentrações de gelatina 270 Bloom apresentam cores que variam do amarelo-ouro (solução não irradiada) até o violeta-escuro (solução irradiada com doses de 40 a 100 Gy).

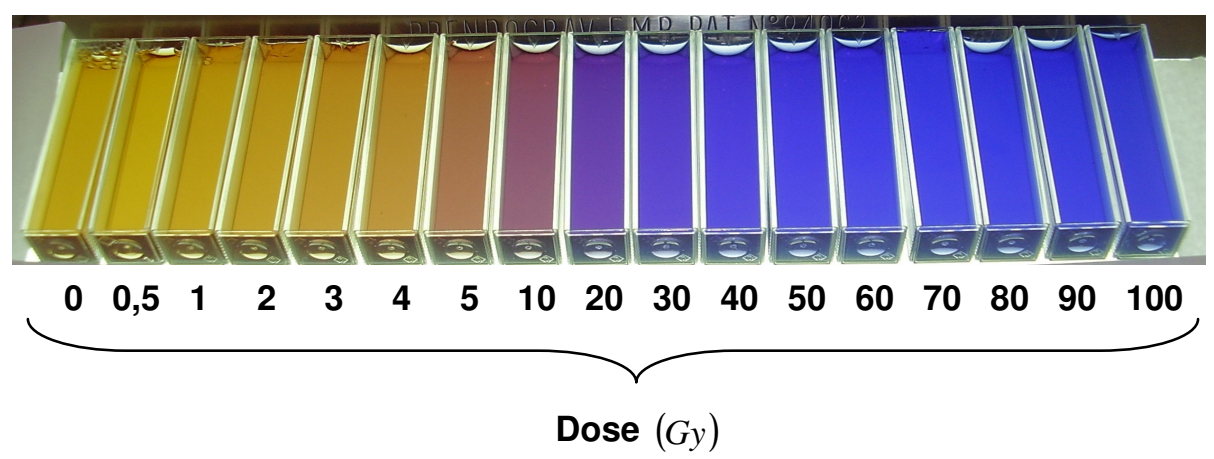

FIGURA 11 - Intervalo de cores apresentado pela solução Fricke gel (5\% de gelatina 270 Bloom ) não irradiada e irradiada com radiação gama do ${ }^{60} \mathrm{Co}$ com doses entre 0,5 e 100,0 Gy.

A solução Fricke gel preparada com $5 \%$ de gelatina 300 Bloom apresenta, para amostras não irradiadas e irradiadas, para uma mesma dose, a mesma coloração que a solução preparada com gelatina 270 Bloom (FIG. 11).

As amostras das soluções Fricke gel preparadas com diferentes qualidades e concentrações de gelatina, apresentam, também, as mesmas cores quando irradiadas nos diferentes sistemas de irradiação, com doses entre 0,5 e 100,0 Gy e taxas de dose entre $9,3 \times 10^{-3}$ e $2,8 k G y \cdot h^{-1}$.

As cores das soluções Fricke gel foram verificadas visualmente e também com o auxílio de negatoscópio.

\subsubsection{Consistência}

As soluções preparadas com $5 \%$ de gelatina 270 Bloom solidificam completamente à temperatura ambiente dentro de 1 hora após a preparação e 
permaneceram consistentes durante todo o tempo em que foram utilizadas (antes e depois das irradiações e durante as medições espectrofotométricas e de RM), nessa mesma temperatura.

A solução Fricke gel preparada com $5 \%$ de gelatina 300 Bloom solidifica à temperatura ambiente dentro de 30 minutos após a sua preparação e também permaneceu consistente durante todo o tempo de utilização (antes e depois das irradiações e durante as medições espectrofotométricas), nessa mesma temperatura.

\subsubsection{Potencial de hidrogênio - pH}

Para medir o $\mathrm{pH}$ das soluções dosimétricas preparadas com diferentes concentrações de gelatina, o eletrodo de medição do $\mathrm{pH}$ era colocado dentro do recipiente que continha a solução não irradiada juntamente com o sensor de temperatura do pH-metro, imediatamente após a preparação de cada solução. Após a estabilização da temperatura (necessária, pois o $\mathrm{pH}$ varia com a variação da temperatura da solução) o valor de pH indicado no equipamento era anotado.

$\mathrm{O} \mathrm{pH}$ das soluções preparadas com gelatina 270 Bloom variou de modo crescente de 1,33 a $27^{\circ} \mathrm{C}$ para $1 \%$ de gelatina até 2,47 a $31^{\circ} \mathrm{C}$ para $15 \%$ de gelatina. As temperaturas apresentadas são diferentes porque as soluções Fricke gel foram preparadas em dias diferentes.

$\mathrm{O}$ pH da solução preparada com $5 \%$ de gelatina 300 Bloom é de 1,43 a $26^{\circ} \mathrm{C}$, semelhante ao observado para a solução preparada com $5 \%$ de gelatina 270 Bloom $\left(1,42\right.$ a $\left.28^{\circ} C\right)$. Não foram preparadas soluções com outras concentrações de gelatina 300 Bloom .

\subsubsection{Espectros de absorção óptica}

Os espectros de absorção óptica foram obtidos para as diferentes soluções (270 e 300 Bloom ) não irradiadas e irradiadas com radiação gama do ${ }^{60} \mathrm{Co}$ com doses entre 0,5 e 100,0 Gy (FIG. 12). 


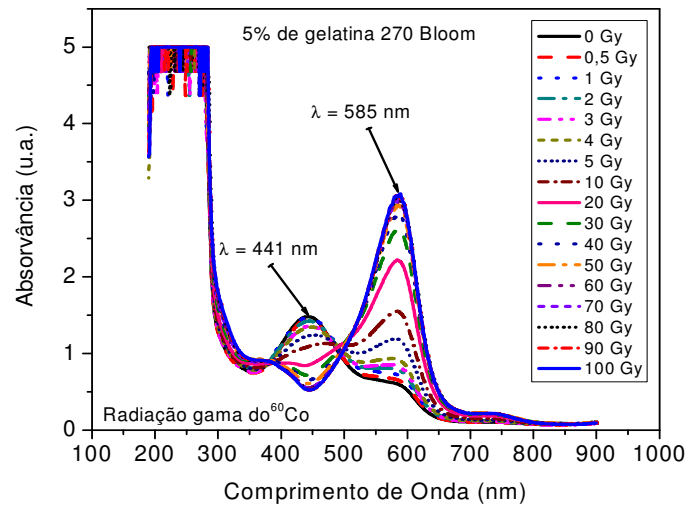

a

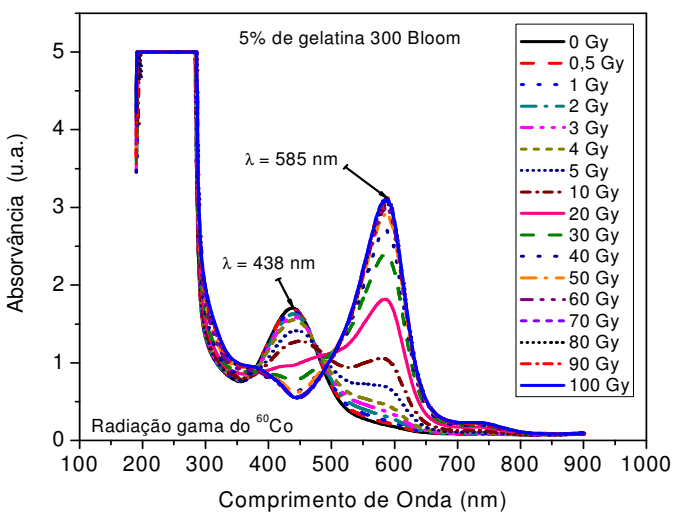

b

FIGURA 12 - Espectros de absorção óptica das soluções Fricke gel preparadas com gelatinas 270 (a) e 300 (b) Bloom não irradiadas e irradiadas com radiação gama do ${ }^{60} \mathrm{Co}$.

A solução preparada com gelatina 270 Bloom apresenta duas bandas de absorção: uma em $441 \mathrm{~nm}$, correspondente aos íons $\mathrm{Fe}^{2+}$ inicialmente presentes nas soluções dosimétricas e outra em $585 \mathrm{~nm}$ correspondente aos íons $\mathrm{Fe}^{3+}$, originados pela oxidação dos íons $\mathrm{Fe}^{2+}$ pela ação da radiação ionizante.

A solução preparada com gelatina 300 Bloom também apresenta duas bandas de absorção: uma em $438 \mathrm{~nm}$, correspondente aos íons $\mathrm{Fe}^{2+}$ e outra em $585 \mathrm{~nm}$ correspondente aos íons $\mathrm{Fe}^{3+}$.

Comparando os espectros das soluções preparadas com diferentes qualidades e concentrações de gelatina, irradiadas, foi fixado o comprimento de onda dosimétrico de $585 \mathrm{~nm}$, o mesmo estabelecido por Bero [12].

Observa-se intensificação dos valores de absorvância da banda de $585 \mathrm{~nm}$ com o aumento da dose de radiação para as soluções preparadas com diferentes qualidades de gelatina. Nota-se também que as bandas de absorção em $438 \mathrm{~nm}$, gelatina 300 Bloom, e em $441 \mathrm{~nm}$, gelatina 270 Bloom, tendem a desaparecer (FIG. 12) em função da dose de radiação.

Como apresentado na FIG. 13, a solução Fricke gel preparada com gelatina 300 Bloom, não irradiada, apresenta somente uma banda de absorção em $438 \mathrm{~nm}$, o que não acontece com a solução dosimétrica preparada com gelatina 270 Bloom, que apresenta uma pequena intensificação da resposta na banda de absorção de $585 \mathrm{~nm}$, indicando a possível presença de íons $\mathrm{Fe}^{3+}$ na solução não 
irradiada, provavelmente proveniente do modo de obtenção dessa qualidade de gelatina.

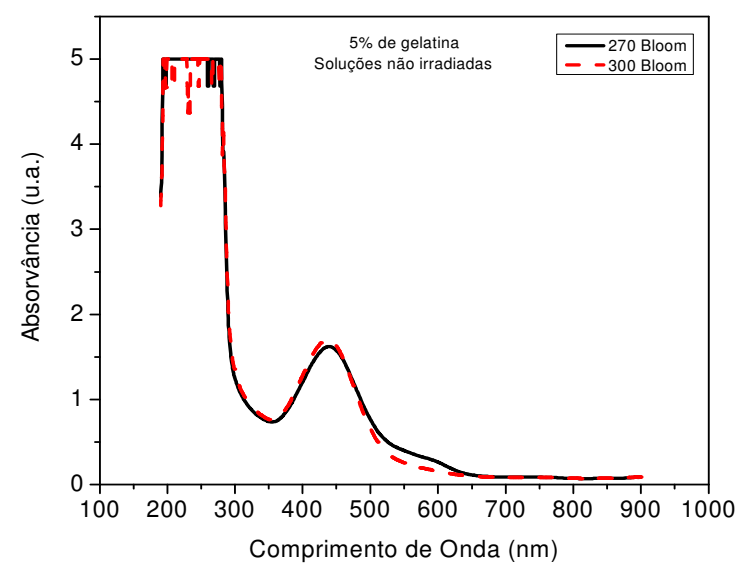

FIGURA 13 - Espectros de absorção óptica das soluções Fricke gel preparadas com gelatinas 270 e 300 Bloom não irradiadas.

Esse resultado comprova a maior pureza da gelatina 300 Bloom, que é de grau analítico, sendo que a de 270 Bloom é de qualidade alimentícia e farmacêutica. No entanto, isto não impede a utilização da gelatina 270 Bloom, basta subtrair a contribuição da concentração de possíveis íons $\mathrm{Fe}^{3+}$ préexistente quando os dosímetros forem irradiados.

\subsubsection{Estabilidade da resposta}

A estabilidade da resposta espectrofotométrica em função do tempo foi estudada para as soluções Fricke gel preparadas com $5 \%$ de gelatinas 270 e 300 Bloom, não irradiadas e irradiadas com radiação gama do ${ }^{60} \mathrm{Co}$ com dose de $10 \mathrm{~Gy}$, sob as duas diferentes condições de armazenagem descritas na subseção 5.1.2, com a finalidade de conhecer a variação da resposta dessas soluções (acondicionadas nas cubetas de leitura), para poder fazer correções caso seja necessário.

As amostras de solução Fricke gel não irradiadas destinadas à condição 1, foram retiradas do refrigerador e permaneceram sob temperatura ambiente e ao abrigo da luz por 30 minutos antes da primeira medição espectrofotométrica (leitura zero). A primeira medição das amostras irradiadas, também destinadas à condição 1, foi realizada 30 minutos após a irradiação; depois foram colocadas sob refrigeração $\left((4 \pm 1)^{\circ} C\right)$. Para a realização das medições seguintes essas 
amostras foram sempre retiradas do refrigerador 30 minutos antes, a fim de alcançar equilíbrio térmico.

Após a preparação, as amostras de solução Fricke gel não irradiadas destinadas à condição 2 permaneceram sob temperatura e luz ambiente durante todo o período de análise (4 dias), inclusive antes da leitura zero. As primeiras medições das amostras irradiadas (condição 2) também foram realizadas 30 minutos após a irradiação e, depois, também permaneceram sob temperatura e luz ambiente para a realização das medições seguintes.

A radiação de fundo não foi subtraída das amostras das diferentes soluções Fricke gel, não irradiadas e irradiadas, destinadas às duas condições de armazenagem.

Todas as amostras foram seladas com filme de policloreto de vinila (PVC) para amenizar a evaporação do solvente da solução.

As medições das soluções preparadas com diferentes qualidades de gelatina, não irradiadas e irradiadas, para ambas as condições de armazenagem, foram repetidas nos intervalos de tempo seguintes:

- De 1 em 1 hora, até as primeiras 24 horas;

- 2 vezes ao dia, no segundo dia de análise;

- De 24 em 24 horas, a partir do terceiro dia de análise.

Ambas as soluções dosimétricas permaneceram sob a forma sólida (temperatura ambiente) e não houve formação de fungos durante os 4 dias de análise.

Nas FIG. 14 e 15 são apresentados os resultados de estabilidade da resposta espectrofotométrica da solução Fricke gel preparada com $5 \%$ de gelatina 270 Bloom, não irradiada e irradiada, respectivamente. 


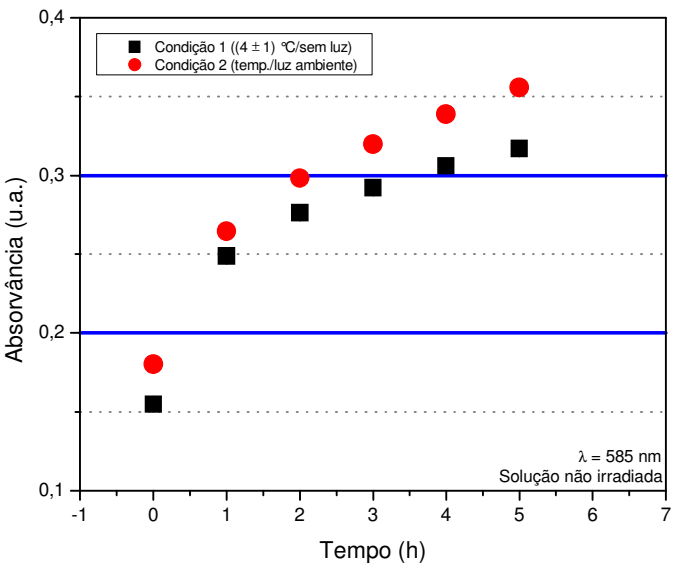

a

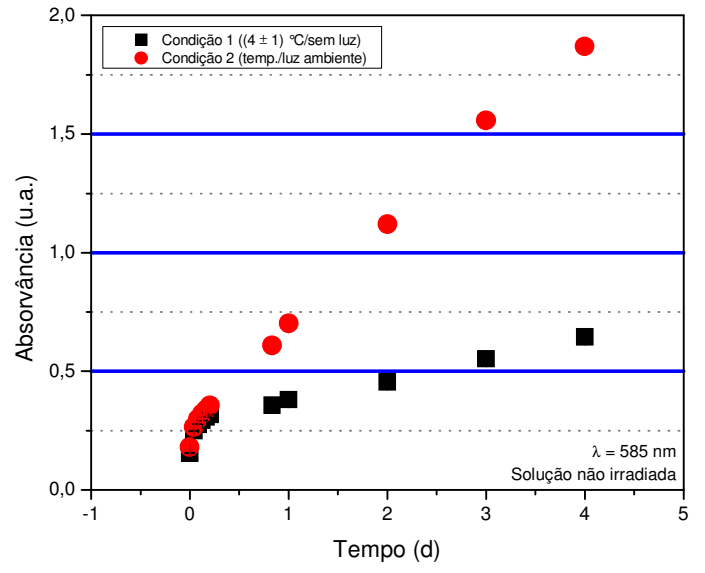

b

FIGURA 14 - Estabilidade da resposta espectrofotométrica da solução Fricke gel preparada com $5 \%$ de gelatina 270 Bloom não irradiada em função do tempo em horas (a) e em dias (b).

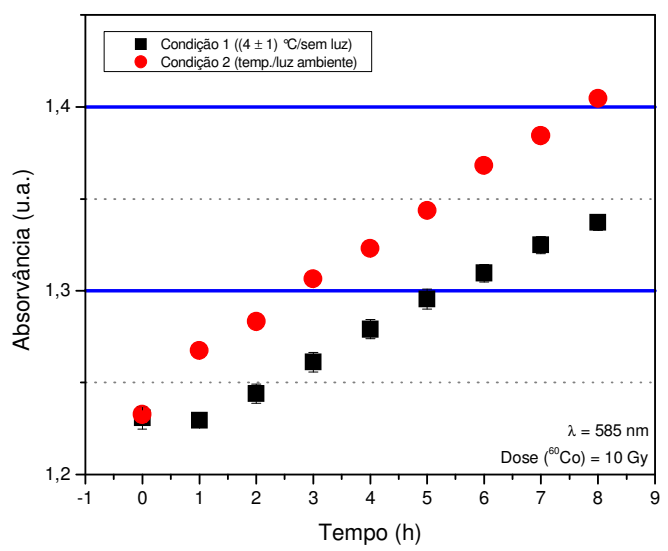

a

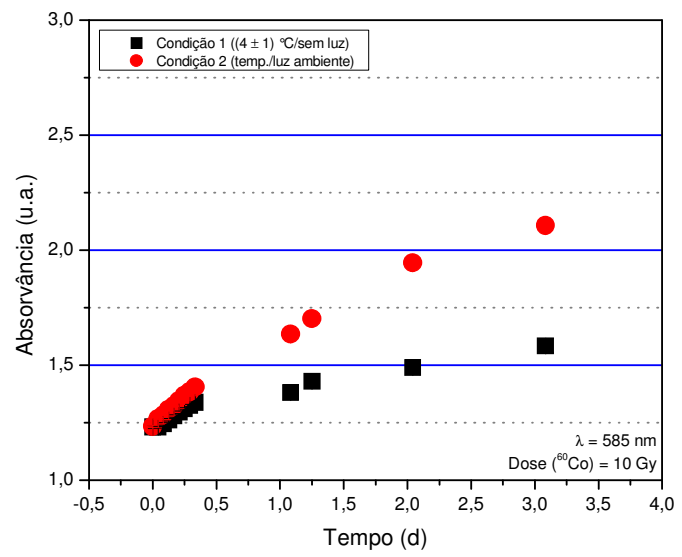

b

FIGURA 15 - Estabilidade da resposta espectrofotométrica da solução Fricke gel preparada com 5\% de gelatina 270 Bloom irradiada com radiação gama do ${ }^{60} \mathrm{Co}$ em função do tempo em horas (a) e em dias (b).

A solução Fricke gel preparada com $5 \%$ de gelatina 270 Bloom não irradiada e irradiada apresenta intensificação significativa dos valores de absorvância nas duas condições de armazenagem estudadas. A variação da resposta entre as medições realizadas de hora em hora diminui, mas os valores de absorvância continuam se intensificando; na condição 2, ocorre maior intensificação dos valores de absorvância que na condição 1.

Esse resultado é explicado pela oxidação natural dos íons $F e^{2+}$ presentes na solução, acelerada em ambos os casos para as amostras mantidas na condição 2. 
Nas FIG. 16 e 17 são apresentados os resultados de estabilidade da resposta espectrofotométrica da solução Fricke gel preparada com $5 \%$ de gelatina 300 Bloom, não irradiada e irradiada, respectivamente.

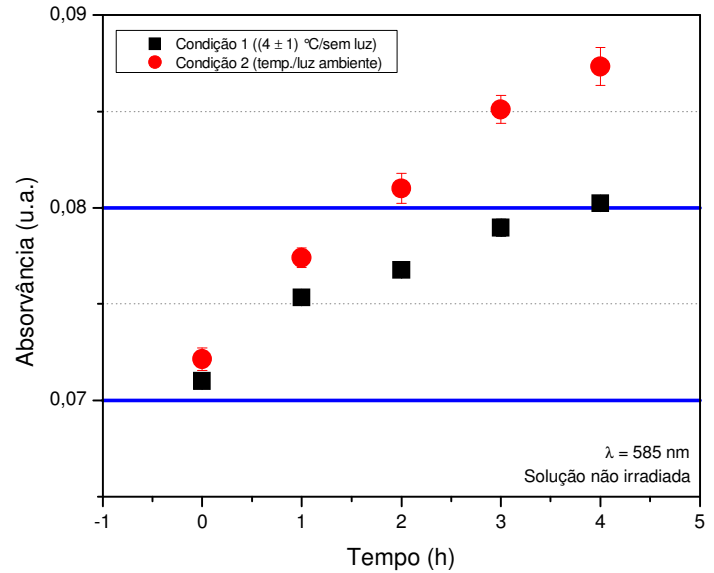

a

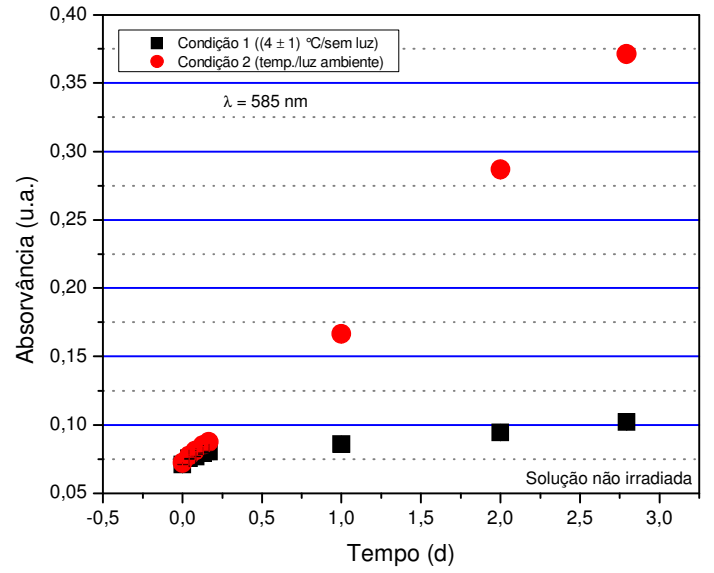

b

FIGURA 16 - Estabilidade da resposta espectrofotométrica da solução Fricke gel preparada com $5 \%$ de gelatina 300 Bloom não irradiada em função do tempo em horas (a) e em dias (b).

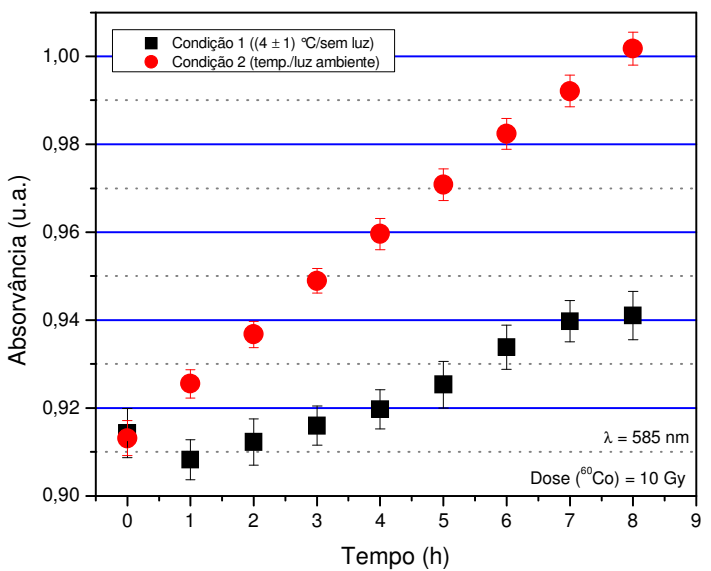

a

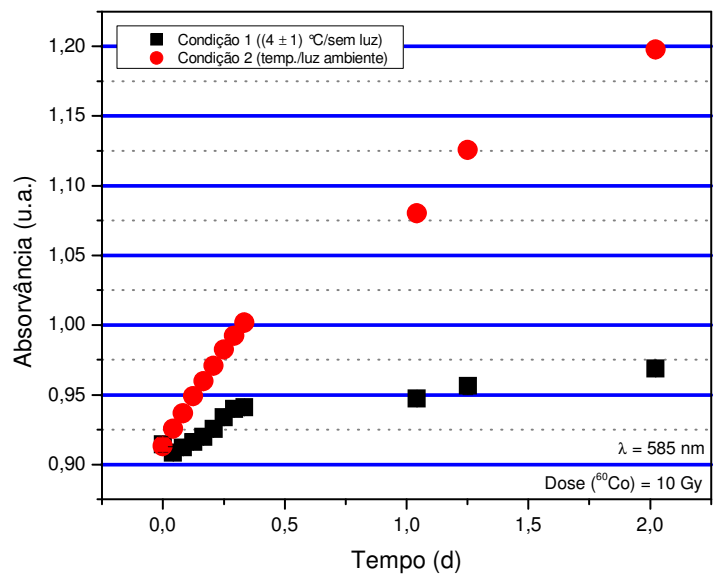

b

FIGURA 17 - Estabilidade da resposta espectrofotométrica da solução Fricke gel preparada com $5 \%$ de gelatina 300 Bloom irradiada com radiação gama do ${ }^{60}$ Co em função do tempo em horas (a) e em dias (b).

É observado um comportamento semelhante ao apresentado pelas amostras preparadas com $5 \%$ de gelatina 270 Bloom (FIG. 14 e 15), porém, a variação entre os valores de absorvância em ambas as condições de armazenagem é menor. 
As amostras preparadas com ambas as qualidades de gelatina estudadas continuaram sendo visualmente observadas por um período total de aproximadamente 70 dias, para verificação de formação de fungos nas soluções dosimétricas. Não foi observada formação de fungos durante todo este período para as amostras preparadas com gelatinas 270 e 300 Bloom, acondicionadas nas cubetas de leitura.

Como conclusão, apesar de haver intensificação significativa da resposta espectrofotométrica das soluções dosimétricas em ambas as condições de armazenagem estudadas, é mais adequado manter as soluções Fricke gel sob refrigeração e ao abrigo da luz, pois a oxidação natural dos íons $F e^{2+}$ é diretamente proporcional à temperatura e à exposição à luz (ultravioleta, principalmente).

\subsubsection{Resposta em função da dose}

Nas FIG. 18 e 19 são apresentadas as curvas de resposta (espectrofotométrica) em função da dose das soluções Fricke gel preparadas com $5 \%$ de gelatinas 270 e 300 Bloom, respectivamente, irradiadas com radiação gama do ${ }^{60}$ Co com doses entre 0,5 e 100,0 Gy.

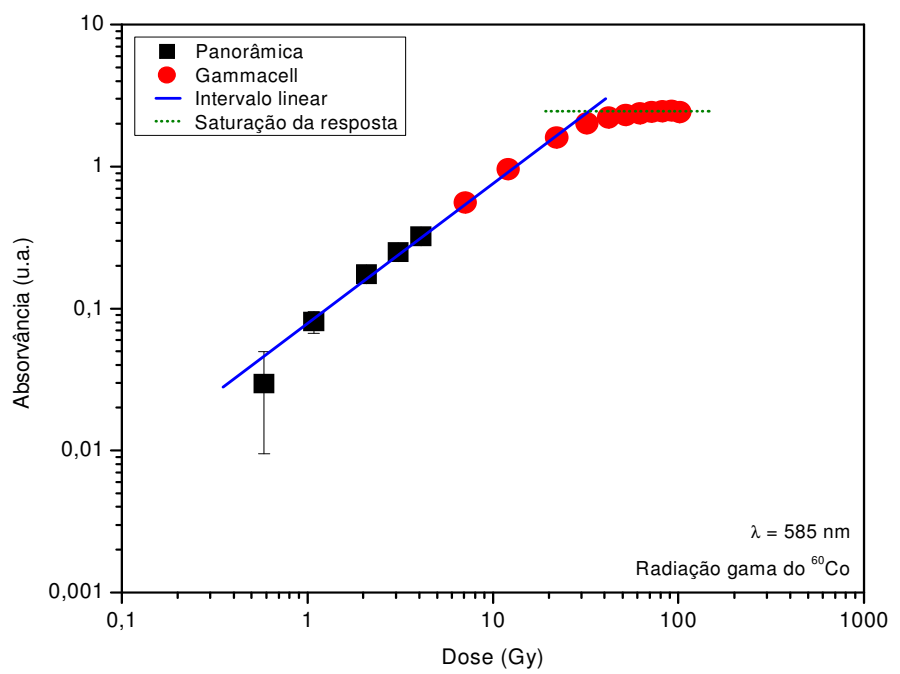

FIGURA 18 - Resposta espectrofotométrica da solução Fricke gel preparada com $5 \%$ de gelatina 270 Bloom em função da dose. 


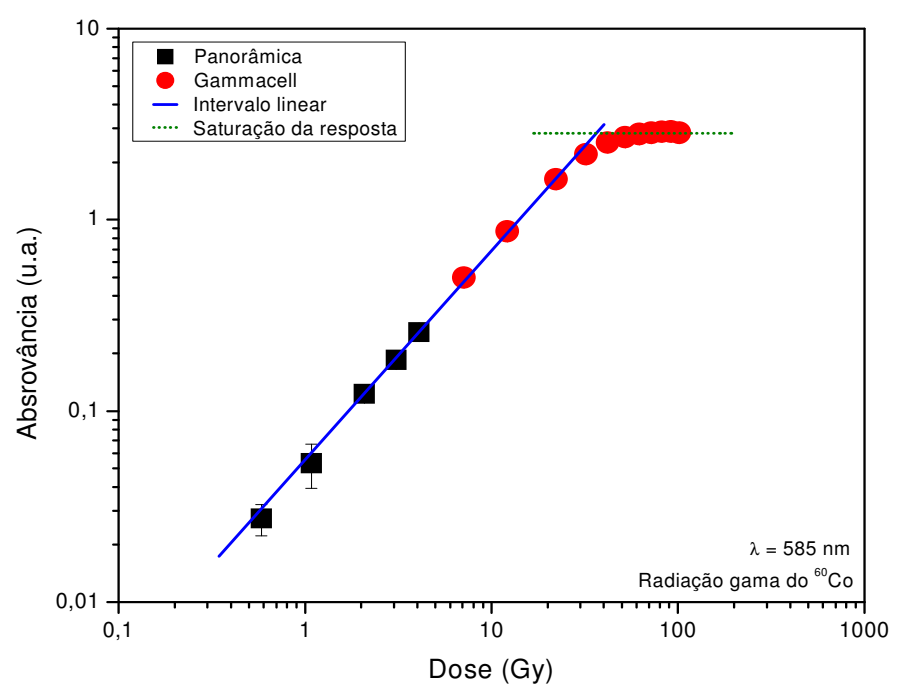

FIGURA 19 - Resposta espectrofotométrica da solução Fricke gel preparada com $5 \%$ de gelatina 300 Bloom em função da dose.

As soluções preparadas com $5 \%$ de gelatinas 270 e 300 Bloom e irradiadas com radiação gama do ${ }^{60} \mathrm{Co}$ apresentam intervalos de dose útil entre 0,5 e 30,0 Gy.

Os pontos correspondentes às doses absorvidas de 0,5 e 1,0 Gy (FIG. 18 e 19, respectivamente) apresentam desvios padrões da média das leituras maiores em virtude da dose de trânsito da fonte de ${ }^{60} \mathrm{Co}$ utilizada (fonte Panorâmica).

Para a obtenção das equações da reta das curvas apresentadas nas FIG. 18 e 19 (EQ. 8 e 9, respectivamente) foi feito um ajuste linear dos pontos correspondentes às doses entre 5 e 20 Gy sem a subtração da leitura da amostra não irradiada.

$$
\begin{aligned}
& y=0,068 \cdot x+0,208 \\
& y=0,075 \cdot x+0,055
\end{aligned}
$$

Na FIG. 20 é apresentada uma comparação das curvas de resposta em função da dose apresentadas nas FIG. 18 e 19, correspondentes às soluções preparadas com as diferentes qualidades de gelatina, 270 e 300 Bloom, respectivamente. 


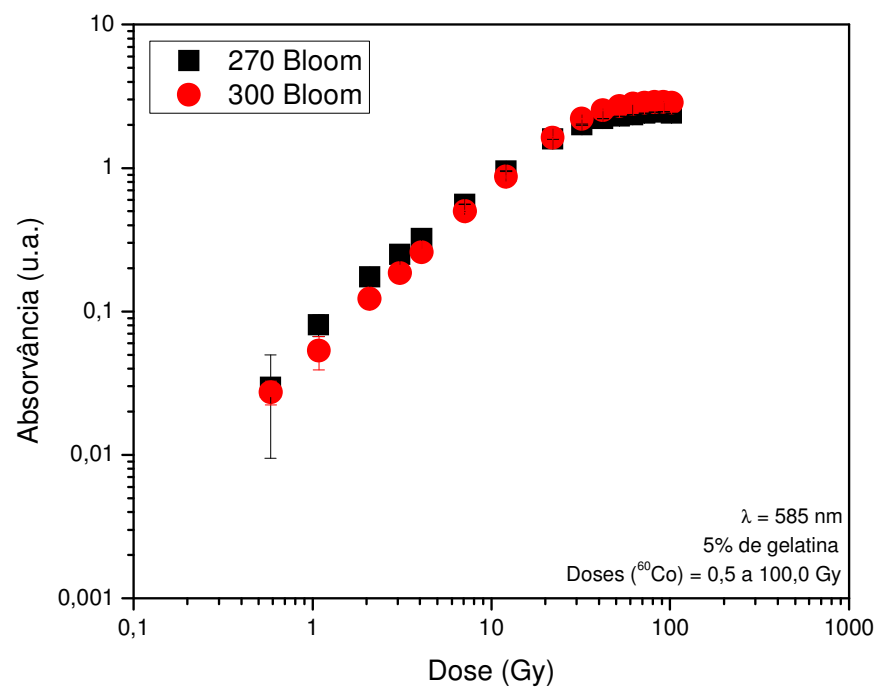

FIGURA 20 - Comparação entre as curvas de resposta com a dose das soluções Fricke gel preparadas com gelatinas 270 e 300 Bloom .

A solução preparada com gelatina 300 Bloom apresenta sensibilidade $20 \%$ maior que a da solução preparada com gelatina 270 Bloom .

\subsubsection{Limites mínimo e máximo de detecção para radiação gama do ${ }^{60} \mathrm{Co}$}

Os limites mínimos das soluções Fricke gel preparadas com $5 \%$ de gelatinas 270 e 300 Bloom, determinados experimentalmente, foram obtidos por meio da irradiação das soluções Fricke gel, preparadas com diferentes qualidades de gelatina, com a menor dose possível $(0,5 \mathrm{~Gy})$ de um dos sistemas de irradiação com fonte de ${ }^{60} \mathrm{Co}$ utilizados (fonte Panorâmica).

Os limites máximos foram obtidos experimentalmente, tomando o ponto em que ocorre a saturação da resposta das soluções irradiadas com radiação gama do ${ }^{60} \mathrm{Co}$ com dose máxima de até 100 Gy (FIG. 18 e 19).

Na TAB. 9 são apresentados os limites mínimos (experimentais) e máximos (adotados) de detecção das soluções preparadas com diferentes qualidades de gelatina, determinados para radiação gama do ${ }^{60} \mathrm{Co}$. 
TABELA 9-Limites mínimos e máximos de detecção das soluções Fricke gel preparadas com gelatinas 270 e 300 Bloom para radiação gama do ${ }^{60} \mathrm{Co}$.

\begin{tabular}{|c|c|c|}
\hline \multicolumn{3}{|c|}{ SOLUÇÃO FRICKE GEL (5 \% DE GELATINA) } \\
\hline $\begin{array}{l}\text { Qualidade de } \\
\text { Gelatina } \\
\text { (Bloom) }\end{array}$ & $\begin{array}{c}\text { Limite Mínimo de } \\
\text { Detecção Experimental } \\
(G y)\end{array}$ & $\begin{array}{c}\text { Limite Máximo de } \\
\text { Detecção Adotado } \\
(G y)\end{array}$ \\
\hline 270 & $0,50 \pm 0,02$ & $30,0 \pm 0,2$ \\
\hline 300 & $0,50 \pm 0,02$ & $30,0 \pm 0,2$ \\
\hline
\end{tabular}

Os limites mínimos de detecção experimentais para radiação gama do ${ }^{60} \mathrm{Co}$ das diferentes soluções dosimétricas foram fixados em $0,5 \mathrm{~Gy}$ (para radiação gama do ${ }^{60} \mathrm{Co}$ ), valor que apresenta três desvios padrões acima da leitura da amostra não irradiada. Os limites máximos de detecção foram fixados em $30,0 \mathrm{~Gy}$, pois a resposta em função da dose para as soluções preparadas com as diferentes qualidades de gelatina estudadas saturam quando as soluções são irradiadas (radiação gama do ${ }^{60} \mathrm{Co}$ ) com doses acima de 30,0 $\mathrm{Gy}$.

Avaliando o desempenho das soluções dosimétricas preparadas com gelatinas 270 e 300 Bloom e, considerando o fato da gelatina 270 Bloom apresentar características semelhantes às de 300 Bloom, citada na literatura [12], e, baseado no seu baixo custo, uma vez que é encontrada no mercado nacional, foi dada continuidade ao estudo das demais propriedades dosimétricas da solução Fricke gel preparada com essa qualidade de gelatina.

\subsection{Caracterização da resposta da solução Fricke gel para diferentes tipos de radiação}

Para caracterizar a resposta da solução Fricke gel preparada com gelatina 270 Bloom para radiação gama do ${ }^{60} \mathrm{Co}$, radiação $\mathrm{X}$ de energias baixas e fótons de $6 \mathrm{MeV}$, empregando as técnicas de espectrofotometria de Absorção Óptica (AO) e Ressonância Magnética (RM), foram realizados os demais testes de desempenho, necessários para caracterizar um material como dosímetro. 


\subsubsection{Espectrofotometria de absorção óptica (AO)}

\subsubsection{Repetitividade e reprodutibilidade}

Para o teste de repetitividade da resposta espectrofotométrica da solução Fricke gel foram utilizadas medições de um mesmo lote de solução preparada com $5 \%$ de gelatina 270 Bloom não irradiada. Foram utilizados 8 conjuntos de 3 amostras e de cada conjunto foram obtidos a média aritmética e o desvio padrão da média das leituras. A maior variação obtida no teste de repetitividade foi de $0,24 \%$.

Para o teste de reprodutibilidade da resposta espectrofotométrica da solução Fricke gel foram utilizadas medições de diferentes lotes de soluções de diferentes volumes $(100,200$ e $400 \mathrm{~mL})$ preparadas com $5 \%$ de gelatina 270 Bloom e sob as mesmas condições experimentais, exceto a temperatura ambiente, que foi diferente em razão das soluções terem sido preparadas em dias diferentes. Foram utilizadas medições de 9 lotes (3 lotes para cada volume preparado) de soluções não irradiadas e 5 lotes (volumes variados) de soluções irradiadas com radiação gama do ${ }^{60} \mathrm{Co}$ com dose de $20 \mathrm{~Gy}$. A reprodutibilidade para diferentes lotes da solução Fricke gel não irradiada e irradiada está dentro de $\pm 5 \%$, conforme apresentado na FIG. 21.

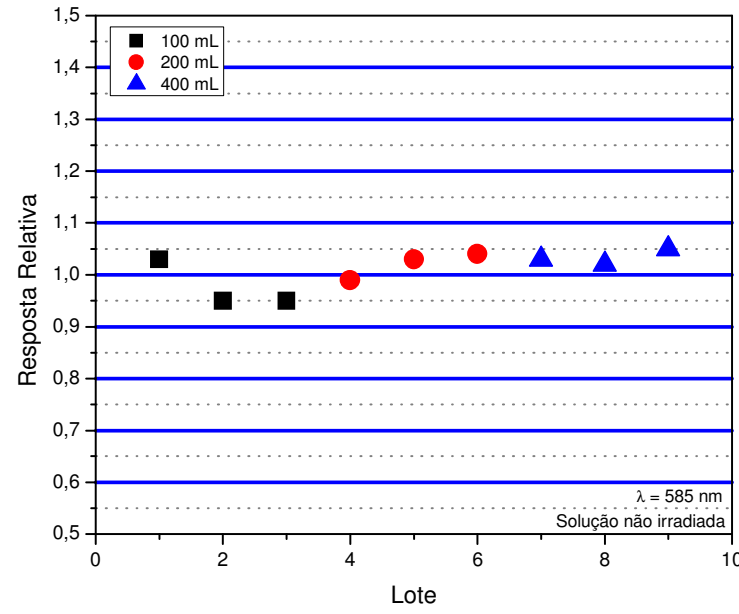

a

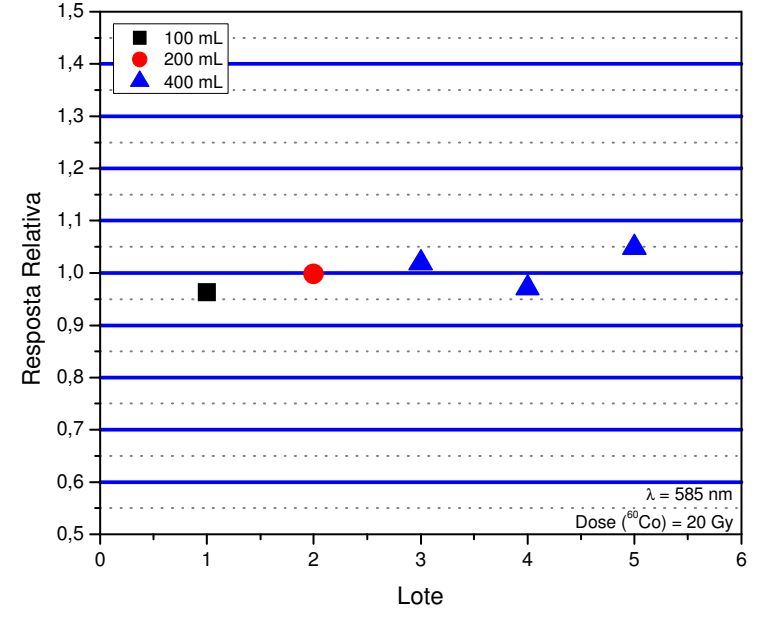

b

FIGURA 21 - Reprodutibilidade da resposta espectrofotométrica da solução Fricke gel preparada com $5 \%$ de gelatina 270 Bloom não irradiada (a) e irradiada (b) em função de diferentes lotes. 
Para uma melhor reprodutibilidade da resposta da solução dosimétrica as amostras devem ser preparadas sempre sob a mesma temperatura ambiente, considerando a influência da temperatura na oxidação natural dos íons $\mathrm{Fe}^{2+}$.

\subsubsection{Resposta para radiação gama do ${ }^{60} \mathrm{Co}$ e fótons de $6 \mathrm{MeV}$}

\subsection{Dependência com a taxa de dose}

Na FIG. 22 é apresentada a dependência com a taxa de dose da resposta espectrofotométrica de diferentes lotes da solução Fricke gel preparados com $5 \%$ de gelatina 270 Bloom e irradiados com dose de $30 \mathrm{~Gy}$ nas diferentes fontes de radiação e com as taxas de dose seguintes:

- Panorâmica:

- Taxas de dose:

- Sem atenuação: $2,2 \times 10^{-1} ; 8,9 \times 10^{-2}$ e $3,1 \times 10^{-2} k G y \cdot h^{-1}$;

- Com $70 \%$ de atenuação: $6,7 \times 10^{-2} ; 2,7 \times 10^{-2}$ e $9,3 \times 10^{-3} k G y \cdot h^{-1}$.

- Gammacell:

- Taxas de dose:

- Sem atenuação: $2,6 k G y \cdot h^{-1}$;

- Com $50 \%, 70 \%$ e $90 \%$ de atenuação, respectivamente: 1,3; $7,6 \times 10^{-1}$ e $2,6 \times 10^{-1} k G y \cdot h^{-1}$.

- Acelerador CLINAC 6EX:

- Taxas de dose: 200, 300, 400, 500 e $600 \mathrm{UM} \cdot \mathrm{min}^{-1}$ ou $1,2 \times 10^{-1}$; $1,8 \times 10^{-1} ; 2,4 \times 10^{-1} ; 3,0 \times 10^{-1}$ e $3,6 \times 10^{-1} k G y \cdot h^{-1}$, respectivamente. 


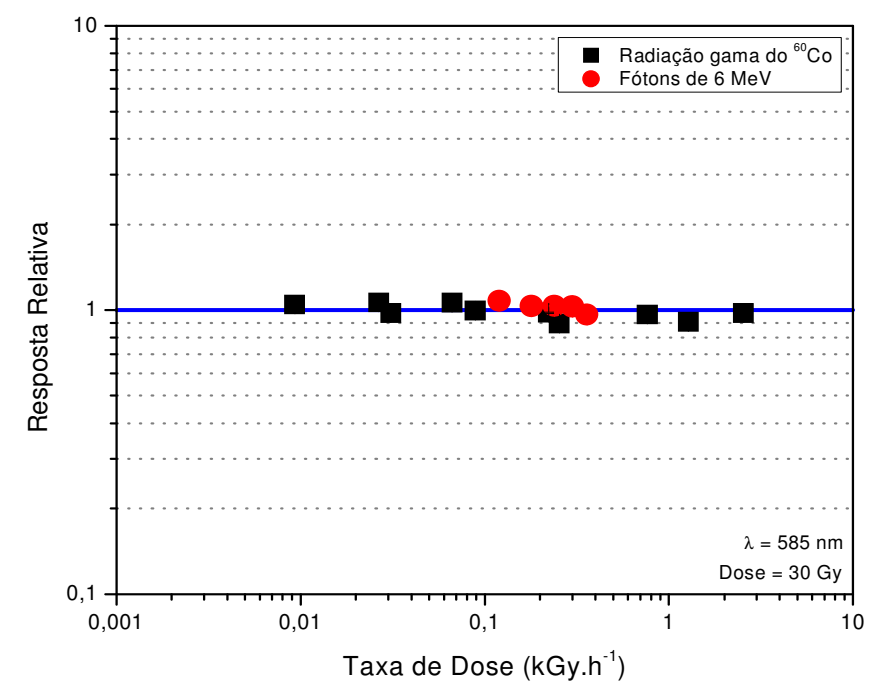

FIGURA 22 - Resposta espectrofotométrica relativa ao valor de absorvância médio das soluções Fricke gel preparadas com $5 \%$ de gelatina 270 Bloom e irradiadas com diferentes taxas de dose nas fontes de radiação gama do ${ }^{60} \mathrm{Co}$ Panorâmica e Gammacell e no acelerador CLINAC 6EX.

A variação máxima da resposta espectrofotométrica da solução em função da taxa de dose é de $\pm 10 \%$ para os diferentes sistemas de irradiação e melhor que $\pm 8 \%$ para fótons de $6 \mathrm{MeV}$.

Considerando os resultados obtidos para os sistemas de irradiação utilizados, as amostras de solução Fricke gel devem ser calibradas sempre com a mesma taxa de dose utilizada na irradiação da solução.

\subsection{Estabilidade da resposta para fótons de $6 \mathrm{MeV}$}

Para o estudo da estabilidade da resposta espectrofotométrica da solução Fricke gel irradiada com fótons de $6 \mathrm{MeV}$ (acelerador CLINAC 6EX) foi preparada uma solução com $5 \%$ de gelatina 270 Bloom. Após a irradiação, as amostras foram mantidas sob as condições descritas na subseção 5.1 .1 e foi adotado o mesmo procedimento descrito na subseção 5.1.2.5. As medições foram realizadas nos intervalos de tempo seguintes:

- De 1 em 1 hora, até as primeiras 24 horas;

- De 24 em 24 horas, do segundo ao último dia de análise.

$\mathrm{Na}$ FIG. 23 são apresentados os resultados de estabilidade da resposta espectrofotométrica da solução Fricke gel irradiada com fótons de $6 \mathrm{MeV}$ com 
dose de $5 \mathrm{~Gy}$. A radiação de fundo não foi subtraída das amostras não irradiadas e irradiadas destinadas às duas condições de armazenagem.

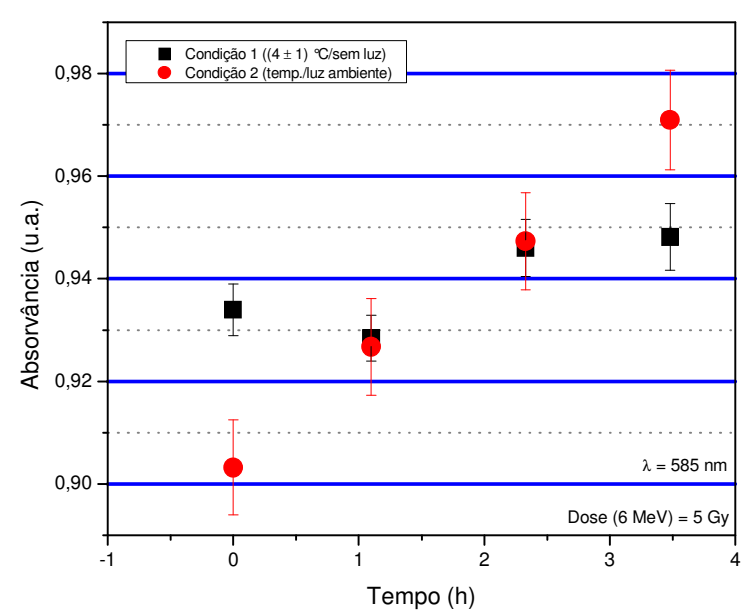

a

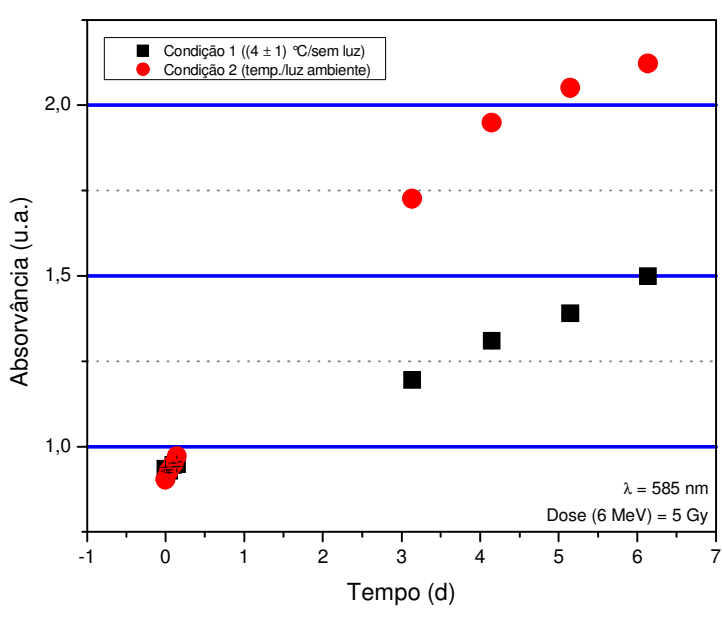

b

FIGURA 23 - Estabilidade da resposta espectrofotométrica da solução Fricke gel preparada com $5 \%$ de gelatina 270 Bloom irradiada com fótons de $6 \mathrm{MeV}$ em função do tempo em horas (a) e em dias (b).

A solução apresenta intensificação mais significativa dos valores de absorvância na condição 2 (FIG. 23a e 23b). O comportamento da solução Fricke gel irradiada com fótons de $6 \mathrm{MeV}$ (5 $\mathrm{Gy}$ ) em função do tempo e de diferentes condições de armazenagem é similar ao comportamento da solução preparada com a mesma concentração e qualidade de gelatina e irradiada com radiação gama do ${ }^{60} \mathrm{Co}(10 \mathrm{~Gy})$. No entanto, os valores de absorvância da solução irradiada no acelerador CLINAC 6EX são menores, possivelmente em virtude da dose de radiação ter sido menor.

Não houve formação de fungos durante todo o período de análise (6 dias) e a solução dosimétrica permaneceu sob a forma sólida à temperatura ambiente.

\subsection{Resposta em função da dose para fótons de $6 \mathrm{MeV}$}

$\mathrm{Na}$ FIG. 24 é apresentada a curva da resposta espectrofotométrica da solução Fricke gel preparada com $5 \%$ de gelatina 270 Bloom e irradiada com fótons de $6 \mathrm{MeV}$ com doses entre 0,4 e 40,0 $\mathrm{Gy}$ em função da dose. No acelerador CLINAC 6EX foi possível irradiar a solução com dose menor que 0,5 Gy. 


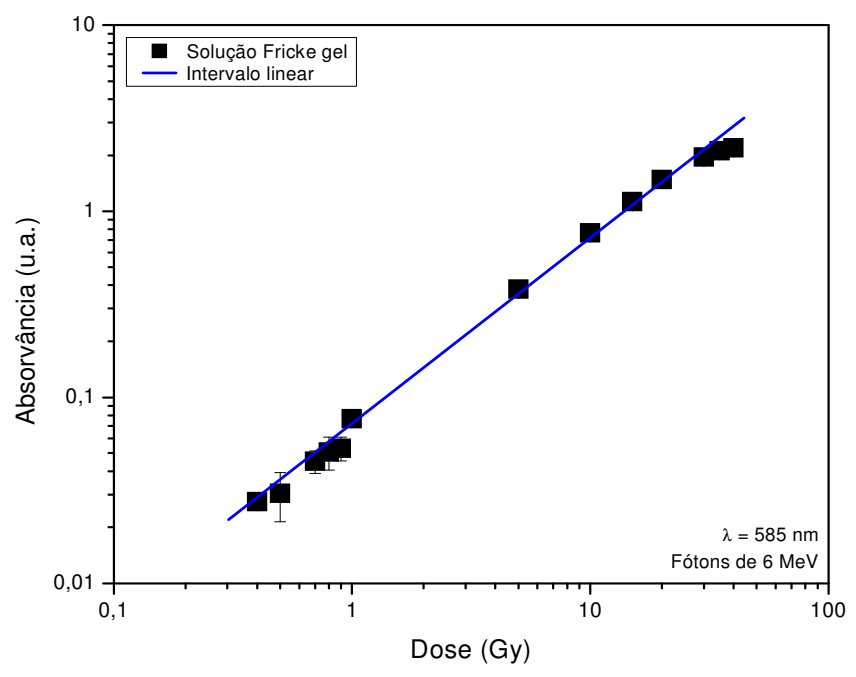

FIGURA 24 - Resposta espectrofotométrica da solução Fricke gel preparada com $5 \%$ de gelatina 270 Bloom em função da dose.

A solução irradiada com fótons de $6 \mathrm{MeV}$ apresenta comportamento linear da resposta entre 0,4 e 30,0 Gy; comportamento similar ao da solução irradiada com radiação gama do ${ }^{60} \mathrm{Co}$.

\subsubsection{Resposta para radiação X de energias entre 13,93 e 40,75 keV}

\subsection{Dependência energética da resposta}

Na FIG. 25 é apresentada a curva da dependência energética da resposta espectrofotométrica de diferentes lotes da solução Fricke gel preparada com 5\% de gelatina 270 Bloom e irradiados com dose de 1 Gy e com diferentes energias, nos sistemas de radiação X (PANTAK-SEIFERT ${ }^{\circledR}$ ) (energias apresentadas na TAB. 5), radiação gama do ${ }^{60} \mathrm{Co}$ (energia média de $1,25 \mathrm{MeV}$ ) e fótons de $6 \mathrm{MeV}$. 


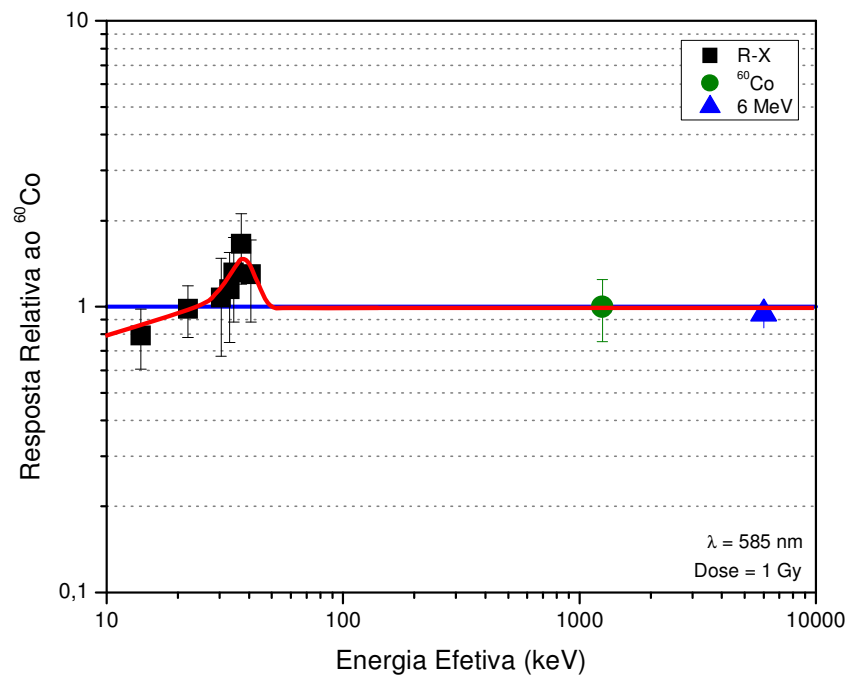

FIGURA 25 - Dependência energética da resposta espectrofotométrica da solução Fricke gel preparada com $5 \%$ de gelatina 270 Bloom .

A resposta espectrofotométrica da solução Fricke gel apresenta dependência máxima de $30 \%$ para energia efetiva de $37,05 \mathrm{keV}$ (região de predominância do efeito fotoelétrico) no intervalo de energia estudado. Esse resultado é justificado considerando que o número atômico efetivo $\left(Z_{\text {eff }}\right)$ da solução Fricke gel (5\% de gelatina 270 Bloom), determinado por Galante [76,77], é 7,42 .

Para energias maiores que $\cong 50 \mathrm{keV}$, não se verifica dependência energética da resposta espectrofotométrica da solução Fricke gel no intervalo de energia estudado.

\subsection{Dependência angular da resposta}

Para o estudo da dependência angular da resposta espectrofotométrica da solução Fricke gel foi preparada uma solução com $5 \%$ de gelatina 270 Bloom que foi irradiada no sistema RIGAKU-DENKI ${ }^{\circledR}$ com dose de $10 \mathrm{~Gy}$, energia efetiva de $17,70 \mathrm{keV}$ e nos ângulos de irradiação seguintes:

- $0^{\circ}, 45^{\circ}, 90^{\circ}, 135^{\circ}$ e $180^{\circ}$.

Para realizar as irradiações nesses diferentes ângulos, as cubetas contendo a solução Fricke gel foram sendo giradas em sentido horário em relação à face da cubeta que ficou perpendicular ao feixe de radiação $X$, inicialmente. Trinta 
minutos após a irradiação, as duas faces ópticas de cada cubeta foram lidas no espectrofotômetro.

Na FIG. 26 é apresentada a curva da dependência angular relativa da resposta espectrofotométrica da solução Fricke gel. Os valores de absorvância apresentados são relativos à resposta da solução irradiada com radiação gama do ${ }^{60}$ Co $(10 G y)$.

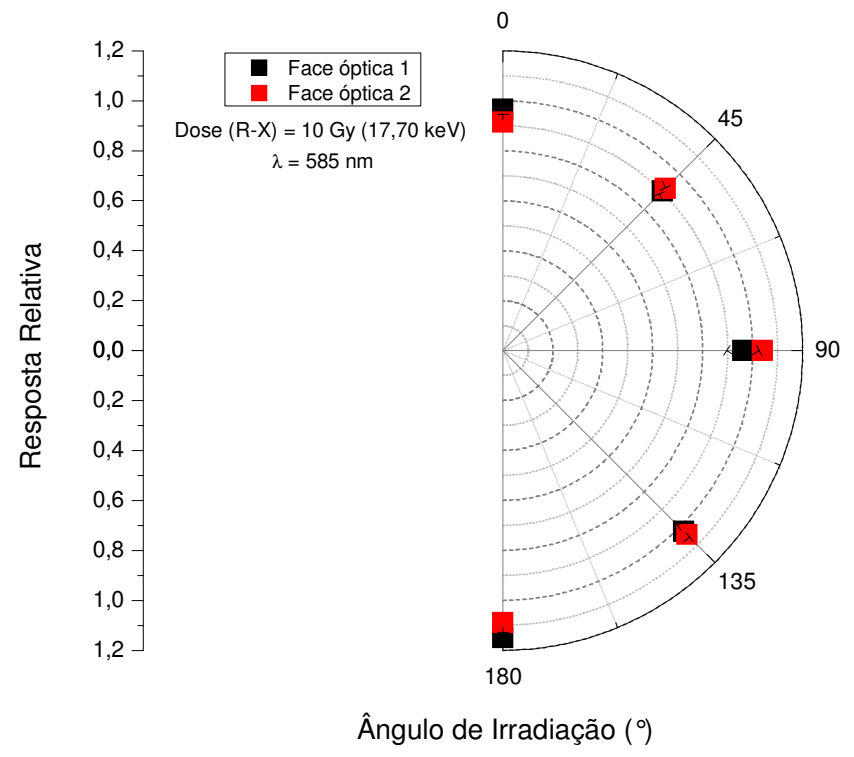

FIGURA 26 - Dependência angular relativa da resposta espectrofotométrica da solução Fricke gel preparada com $5 \%$ de gelatina 270 Bloom .

A dependência angular máxima da resposta espectrofotométrica da solução para a energia de $17,70 \mathrm{keV}$ está dentro de $\pm 10 \%$ para as leituras das duas faces ópticas das cubetas de PMMA em que estavam contidas as amostras dosimétricas. Nenhuma dependência foi encontrada para amostras irradiadas com radiação gama do ${ }^{60} \mathrm{Co}$.

\subsection{Resposta em função da dose para radiação $X$}

Diferentes lotes de soluções dosimétricas foram preparados com $5 \%$ de gelatina 270 Bloom para a obtenção da resposta espectrofotométrica em função da dose para radiação $X$ de energias baixas, a fim de verificar a possível aplicação da solução dosimétrica em outras áreas da medicina, além da radioterapia, como por exemplo, mamografia e radioesterilização de bolsas de sangue. 
Um dos lotes foi irradiado no sistema RIGAKU-DENKI ${ }^{\circledR}$ com doses de 5 e $10 \mathrm{~Gy}$ com energia efetiva de $17,70 \mathrm{keV}$. O outro lote foi irradiado no sistema PANTAK-SEIFERT $^{\circledR}$ com doses entre 1 e 5 Gy com energia efetiva de 13,93 keV . As irradiações foram realizadas ininterruptamente para cada dose dos intervalos de dose estudados.

Na FIG. 27 é apresentada a curva de resposta em função da dose obtida. Os valores de absorvância das amostras irradiadas com energia de $17,70 \mathrm{keV}$ foram corrigidos, utilizando os dados apresentados na FIG. 25, para a energia de $13,93 \mathrm{keV}$.

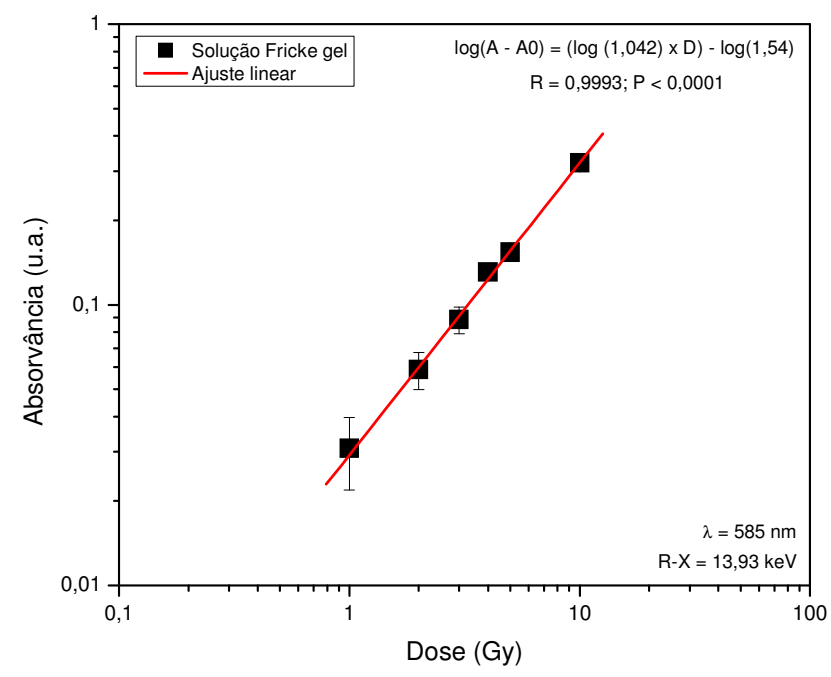

FIGURA 27 - Resposta espectrofotométrica da solução Fricke gel preparada com $5 \%$ de gelatina 270 Bloom em função da dose para radiação X.

Em razão das limitações dos sistemas de radiação $X$ utilizados, tal como superaquecimento dos tubos de radiação $X$ quando estes são utilizados por um prolongado período de tempo (requerido para irradiação contínua com doses maiores que $10 G y$ ), a solução Fricke gel foi irradiada com doses de até $10 G y$. De forma análoga à solução irradiada com os outros tipos de radiação estudados, essa solução apresenta linearidade da resposta espectrofotométrica no intervalo de doses entre 1 e 10 Gy. 


\subsubsection{Resposta da solução Fricke gel avaliada por imageamento por RM e tempo de relaxação}

\subsubsection{Influência da concentração da gelatina}

Para a determinação da influência da concentração da gelatina na resposta da solução Fricke gel avaliada pela intensidade de sinal de RM foram utilizadas amostras dos mesmos lotes de soluções preparadas para a avaliação da influência da concentração da gelatina na resposta espectrofotométrica da solução dosimétrica.

Na FIG. 28 é apresentada a intensidade de sinal de RM das soluções preparadas com concentrações de $1 \%, 5 \%, 10 \%$ e $15 \%$ de gelatina 270 Bloom irradiada com radiação gama do ${ }^{60} \mathrm{Co}$ com dose de $5 \mathrm{~Gy}$.

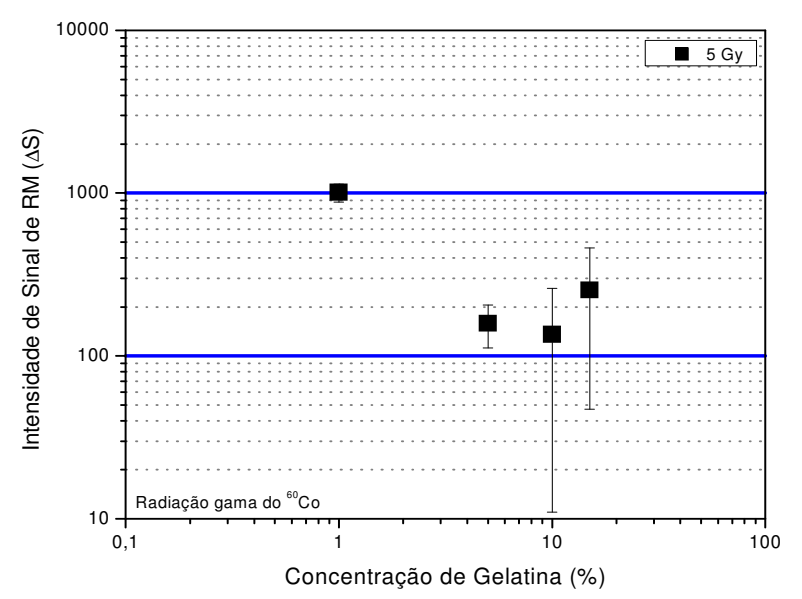

FIGURA 28 - Intensidade de sinal de RM das soluções Fricke gel preparadas com gelatina 270 Bloom em função da concentração de gelatina.

De forma análoga aos resultados obtidos pela técnica de espectrofotometria de $A O$ (FIG. 10), as soluções preparadas com $5 \%$ e $10 \%$ de gelatina apresentam comportamento similar (ocorre variação não significativa em relação aos valores de absorvância e desvios padrões da média das leituras grandes, possivelmente em virtude de artefatos da imagem de RM obtida das amostras) e o valor de intensidade de sinal de RM da solução preparada com $15 \%$ de gelatina, comparado com os valores das soluções preparadas com as concentrações de $5 \%$ e $10 \%$ de gelatina, é maior, indicando que apresenta maior quantidade de íons férricos $\left(\mathrm{Fe}^{3+}\right)$ originados em virtude da maior quantidade de gelatina 
empregada na sua preparação, já que o gel contribui na oxidação dos íons ferrosos $\left(\mathrm{Fe}^{2+}\right)$ durante a irradiação [39].

Para a solução preparada com $1 \%$ de gelatina ocorre comportamento oposto ao da solução avaliada pela técnica espectrofotométrica, ou seja, os valores de intensidade do sinal de RM dessa solução são mais intensos que os valores das soluções preparadas com as outras concentrações de gelatina.

\subsubsection{Difusão de íons férricos $\left(F e^{3+}\right)$ na solução Fricke gel}

Por meio do estudo da difusão de íons $F e^{3+}$ na solução Fricke gel preparada com $5 \%$ de gelatina 270 Bloom estabeleceu-se o tempo máximo ideal após a irradiação para as medições de RM de um objeto simulador constituído dessa solução dosimétrica.

Nas FIG. 29a e 29b são apresentados os perfis espectrais da evolução da distribuição de íons $\mathrm{Fe}^{3+}$ e $\mathrm{Fe}^{2+}$ ao longo do eixo $z$, respectivamente, em função do tempo. Por meio destes perfis é possível estudar a difusão dos íons $\mathrm{Fe}^{3+}$ e a oxidação dos íons $\mathrm{Fe}^{2+}$ nas amostras e determinar o coeficiente de difusão dos íons $\mathrm{Fe}^{3+}[73]$.

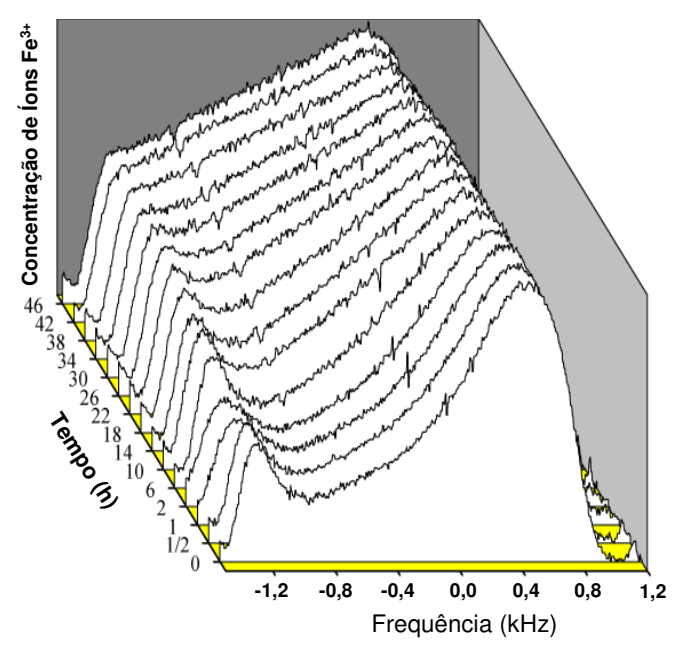

a

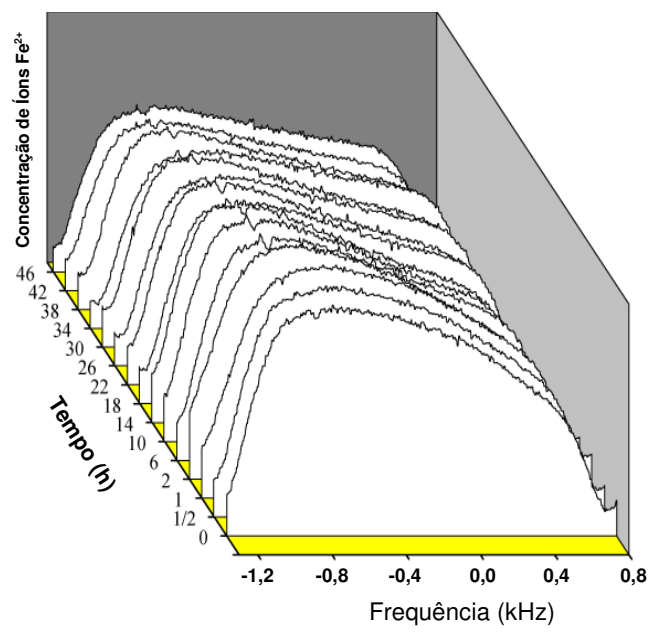

b

FIGURA 29 - Perfis espectrais da evolução dos íons $F e^{3+}$ (a) e $F e^{2+}$ (b) na solução Fricke gel preparada com $5 \%$ de gelatina 270 Bloom parcialmente irradiada com radiação gama do ${ }^{60} \mathrm{Co}$, em função do tempo [73]. 
Cada espectro apresentado corresponde à distribuição dos íons $\mathrm{Fe}^{2+}$ e $\mathrm{Fe}^{3+}$ ao longo do capilar de vidro, depois de um determinado intervalo de tempo. valor do tempo de inversão das sequências de pulso IR para a amostra parcialmente irradiada, $\tau$, igual a $760 \mathrm{~ms}$, produz a distribuição de íons $\mathrm{Fe}^{3+}$ longitudinal, o de $\tau=310 \mathrm{~ms}$ produz a distribuição de íons $F e^{2+}$ correspondente e o de $\tau=5000 \mathrm{~ms}$ produz o perfil típico total, sendo adquirido para normalizar e corrigir possíveis deslocamentos em frequência destes perfis.

O primeiro espectro de $\mathrm{RM}$ da solução parcialmente irradiada, $t=0$ (FIG. 29a), foi obtido 30 minutos depois da irradiação correspondendo à distribuição inicial esperada de íons $F e^{3+}$ no capilar de vidro, a qual é menor na parte inferior (região blindada) e maior na parte superior (região não blindada) da amostra. A evolução da difusão dos íons foi registrada repetindo as medições por 1 hora, 2 horas e então, a cada 2 horas aproximadamente, por 2 dias.

Conforme apresentado na FIG. 29a, na região de frequência baixa (parte inferior da amostra parcialmente irradiada), a intensidade do sinal aumenta com o tempo enquanto a intensidade do sinal diminui na região de frequência alta (parte superior da amostra parcialmente irradiada). Isto indica que a concentração de íons $\mathrm{Fe}^{3+}$ está aumentando com o tempo na parte inferior da amostra parcialmente irradiada em virtude dos processos de difusão dos íons $\mathrm{Fe}^{3+} \mathrm{e}$ oxidação dos íons $\mathrm{Fe}^{2+}$ que estão ocorrendo simultaneamente.

Observando-se os perfis do tempo de evolução dos íons $F e^{2+}$ (FIG. 29b), as mudanças nos espectros de RM sucessivos têm de algum modo, um comportamento oposto ao observado para os íons $\mathrm{Fe}^{3+}$. Este comportamento é atribuído à oxidação contínua e natural dos íons $F e^{2+}$ [73].

Para a determinação do coeficiente de difusão aparente, $D$, foi adotado o modelo de difusão unidimensional (EQ. 10) [78], pois as dimensões transversais do capilar de vidro são desprezíveis quando comparadas à dimensão longitudinal.

$$
\frac{\partial c(z, t)}{\partial t}-D \frac{\partial^{2} c(z, t)}{\partial z^{2}}=0, \text { para } z \in(0,1), t>0
$$

onde $c(z, t)$ é a concentração de íons $F e^{3+}$. 
Por meio do ajuste dos perfis espectrais totais foi determinada a posição da amostra em relação à bobina de radiofrequência do espectrômetro de RM. Cada perfil de íons $\mathrm{Fe}^{3+}$ foi ajustado utilizando a EQ. 10, com a finalidade de obter os valores de $D$ em função do tempo.

O valor do coeficiente de difusão aparente foi obtido para cada medição separadamente, apresentando inicialmente um comportamento transiente durante as primeiras 6 horas, aproximadamente, e, em seguida, permanecendo constante até o final dos 2 dias de análise. Desprezando o comportamento transiente inicial, o valor médio do coeficiente de difusão aparente obtido para a solução preparada com $5 \%$ de gelatina 270 Bloom e $50 \mathrm{mM}$ de ácido sulfúrico é de $(1,8 \pm 0,2) \times 10^{-2} \mathrm{~cm}^{2} \cdot h^{-1}$ [73], que está de acordo com o valor obtido por Schulz [78].

Os quatro primeiros espectros de RM apresentados na FIG. 29a (2,5 horas, aproximadamente) são semelhantes, pois as mudanças nos perfis dos íons $\mathrm{Fe}^{3+}$ são pequenas. Portanto, até aproximadamente duas horas e trinta minutos após a irradiação, um simulador produzido com solução Fricke gel preparada com $5 \%$ de gelatina 270 Bloom pode ser utilizado para a obtenção da distribuição de dose em 3D empregando a técnica de IRM, com boa precisão e nitidez dentro deste intervalo de tempo [73].

\subsubsection{Dependência com a taxa de dose}

Para a determinação da influência da taxa de dose na resposta da solução Fricke gel avaliada pela taxa do tempo de relaxação $T_{1}\left(\frac{1}{T_{1}}\right)$, representada por $R_{1}$, foram utilizadas amostras do mesmo lote de solução preparada para a avaliação da influência da taxa de dose na resposta espectrofotométrica da solução dosimétrica. Na FIG. 30 é apresentada a taxa de relaxação $T_{1}$ da solução preparada com $5 \%$ de gelatina 270 Bloom e irradiada com radiação gama do

${ }^{60}$ Co com dose de $30 G y$ e taxas de dose de $2,6 k G y \cdot h^{-1}$ (sem atenuação), 1,3 $k G y \cdot h^{-1}$ (atenuação de $50 \%$ ), 7,6 $\times 10^{-1} k G y \cdot h^{-1}$ (atenuação de $70 \%$ ) e $2,6 \times 10^{-1} k G y \cdot h^{-1}$ (atenuação de $90 \%$ ). 


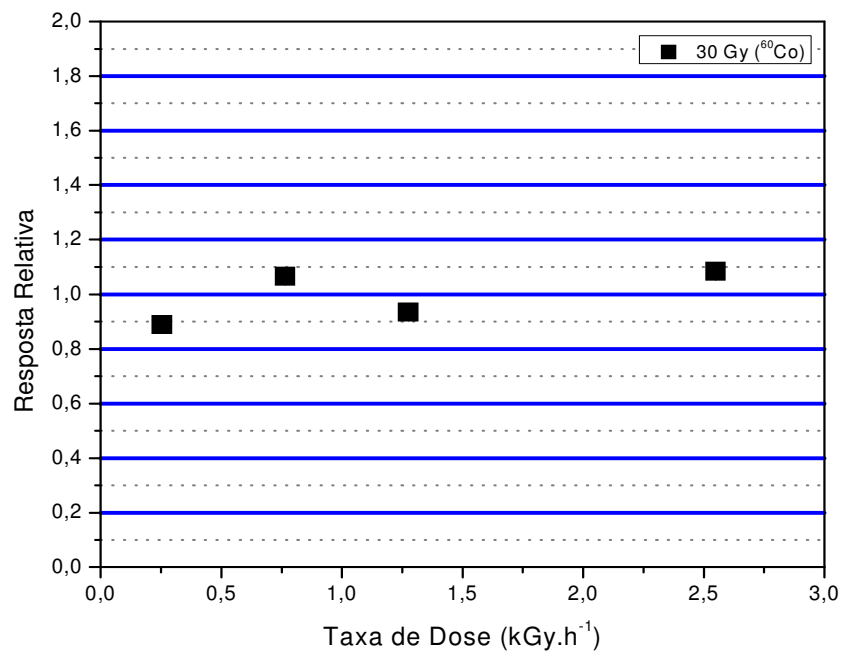

FIGURA 30 - Resposta relativa ao valor médio de $R_{1}$ da solução Fricke gel preparada com $5 \%$ de gelatina 270 Bloom e irradiada com radiação gama do ${ }^{60} \mathrm{Co}$ em função da taxa de dose.

A maior variação de $R_{1}$ da solução com a taxa de dose para radiação gama do ${ }^{60}$ Co é de $\pm 11 \%$ e é semelhante aos resultados apresentados para a técnica de espectrofotometria de AO (subseção 5.2.1.2.1).

Assim como para os resultados obtidos pela técnica espectrofotométrica, deve ser utilizada, para a calibração das amostras, a mesma taxa de dose utilizada na irradiação.

\subsubsection{Estabilidade da resposta}

Para a determinação da estabilidade da resposta da solução Fricke gel avaliada pela taxa de relaxação $T_{1}\left(R_{1}\right)$ em função do tempo foram utilizadas amostras do mesmo lote de solução preparada para a avaliação da estabilidade da resposta espectrofotométrica da solução dosimétrica. Na FIG.31 é apresentada a estabilidade da taxa de relaxação $R_{1}$ da solução Fricke gel preparada com $5 \%$ de gelatina 270 Bloom não irradiada e irradiada com radiação gama do ${ }^{60} \mathrm{Co}$ com dose de $10 \mathrm{~Gy}$, sob as duas diferentes condições de armazenagem descritas na subseção 5.1.2. A radiação de fundo não foi subtraída das amostras não irradiadas e irradiadas destinadas às condições 1 e 2. 


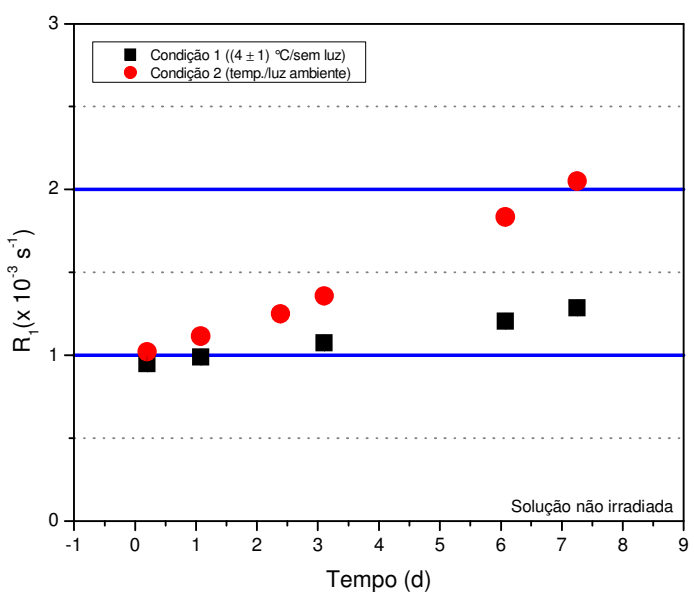

a

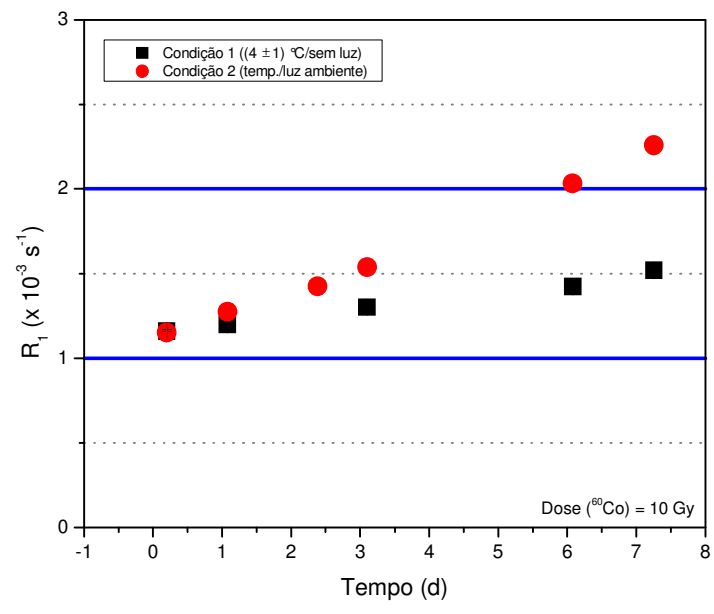

b

FIGURA 31 - Estabilidade da taxa de relaxação $T_{1}\left(R_{1}\right)$ da solução Fricke gel preparada com 5\% de gelatina 270 Bloom não irradiada (a) e irradiada (b) em função do tempo.

Observa-se intensificação significativa dos valores de $\mathrm{R}_{1}$ das amostras não irradiadas e irradiadas nas duas condições de armazenagem, sendo mais significativa na condição 2 , de modo análogo ao observado empregando a técnica de espectrofotometria de AO.

A solução dosimétrica permaneceu sob a forma sólida (temperatura ambiente) e não houve formação de fungos durante todo o período de análise (7 dias).

Embora, como determinado na subseção 5.2.2.2, o tempo ideal para a avaliação da solução Fricke gel é $\leq 2,5$ horas.

\subsection{Irradiação do simulador esférico no sistema Leksell Gamma Knife ${ }^{\circledast}$}

\subsubsection{Resposta em função da imagem}

Na FIG. 32 são apresentadas as imagens, em escala de cinza, das cubetas de PMMA (duas cubetas para cada dose estudada) contendo a solução Fricke gel preparada com $5 \%$ de gelatina 270 Bloom não irradiada e irradiada com radiação gama do ${ }^{60} \mathrm{Co}$ com doses entre 0,5 e 100,0 Gy, obtidas por meio da técnica de IRM. Estas imagens foram obtidas com a finalidade de associar a intensidade média dos pixels à dose absorvida. 


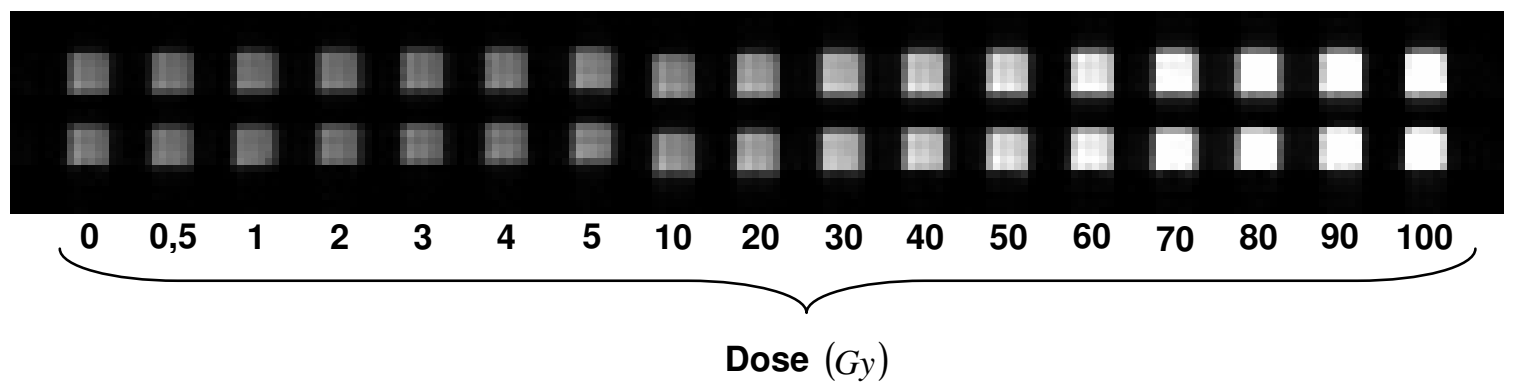

FIGURA 32 - Imagens por RM das cubetas de PMMA contendo a solução Fricke gel (5\% de gelatina 270 Bloom) não irradiada e irradiada com radiação gama do ${ }^{60} \mathrm{Co}$.

A intensidade média dos pixels é diretamente proporcional à concentração de íons $\mathrm{Fe}^{3+} \mathrm{e}$, portanto, diretamente proporcional à dose absorvida. Por isso, quanto maior a dose de radiação, mais intenso é o brilho da imagem ou mais claros são os tons de cinza em virtude da maior quantidade de íons $\mathrm{Fe}^{3+}$ presentes nas amostras irradiadas com doses mais altas.

Por meio das imagens apresentadas na FIG. 32, puderam ser obtidas as curvas de intensidade de sinal de RM e de taxa de relaxação $T_{1}\left(R_{1}\right)$ da solução Fricke gel em função da dose, apresentadas nas FIG. 33 e 34, respectivamente [49]. Se um outro tomógrafo de RM for utilizado, essas curvas devem ser obtidas novamente.

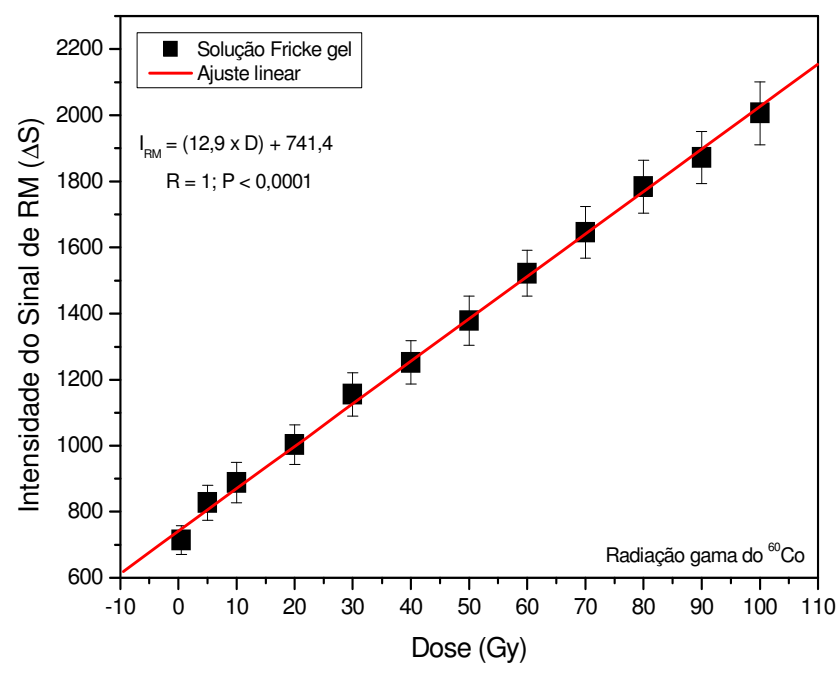

FIGURA 33 - Intensidade de sinal de RM da solução Fricke gel preparada com $5 \%$ de gelatina 270 Bloom e irradiada com radiação gama do ${ }^{60} \mathrm{Co}$ em função da dose [49]. 


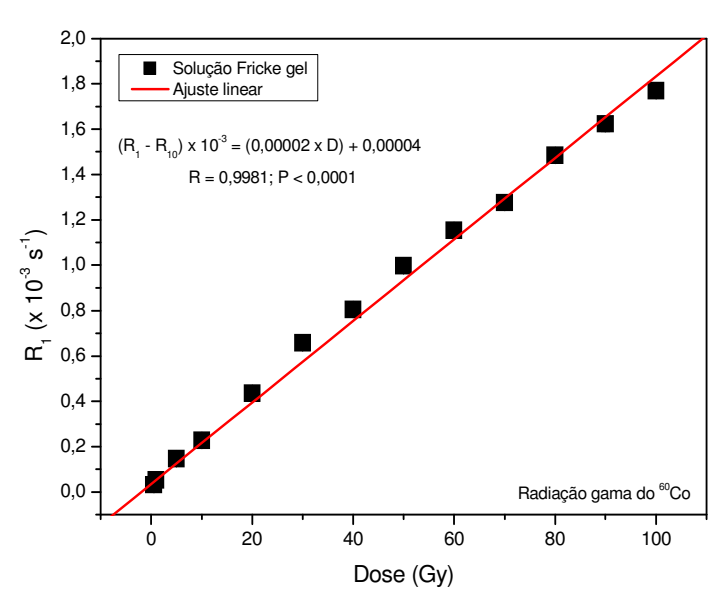

a

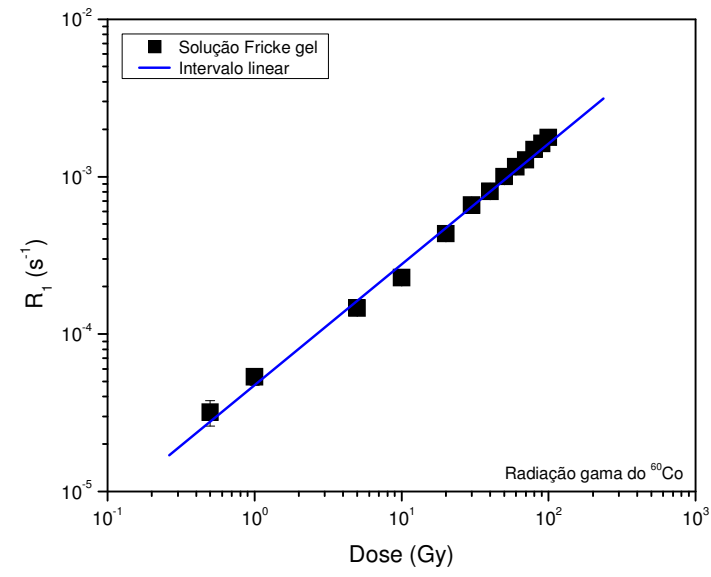

b

FIGURA 34 - Taxa de relaxação $\left(R_{1}\right)$ da solução Fricke gel preparada com $5 \%$ de gelatina 270 Bloom e irradiada com radiação gama do ${ }^{60} \mathrm{Co}$ em função da dose [49]. A curva em escala logarítmica (b) é apresentada para melhor visualização dos valores de $R_{1}$ correspondentes às doses de 0,5 e 1,0 Gy.

O intervalo de dose útil da solução avaliada pela técnica de RM está entre 0,5 e 100,0 $\mathrm{Gy}$, para radiação gama do ${ }^{60} \mathrm{Co}$.

As curvas apresentadas nas FIG. 33 e 34 foram utilizadas como referência para a leitura da distribuição de dose no simulador esférico [49].

\subsubsection{Imagens dos cortes do simulador esférico}

Na FIG. 35 são apresentadas imagens dos cortes do simulador esférico produzido com a solução Fricke gel preparada com $5 \%$ de gelatina 270 Bloom e irradiado com radiação gama do ${ }^{60} \mathrm{Co}$ (dose de $80 \mathrm{~Gy}$ no centro do alvo e isodose prescrita de $50 \%$ ) no sistema Leksell Gamma Knife ${ }^{\circledR}$ obtidas pela técnica de IRM. 


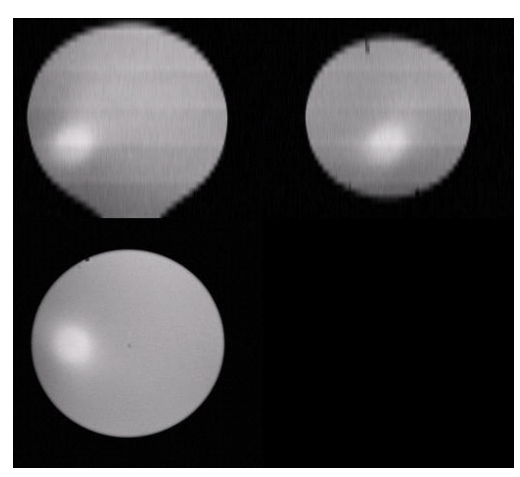

a

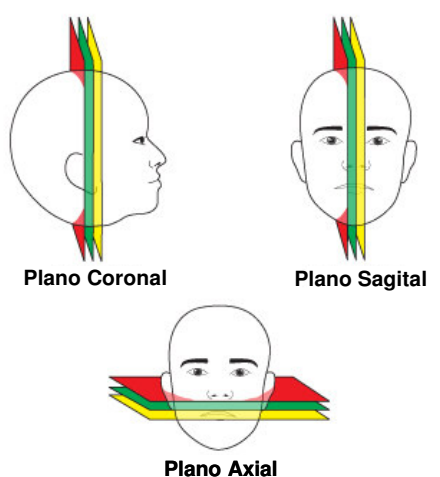

b

FIGURA 35 - Imagens dos cortes do simulador esférico produzido com solução Fricke gel (5\% de gelatina 270 Bloom) e irradiado no sistema Leksell Gamma Knife ${ }^{\circledR}$ obtidas pela técnica de IRM (a); ilustração para auxílio da orientação das imagens: coronal, sagital e axial (b) [79].

Vários outros cortes da imagem do simulador não irradiado e irradiado, ponderados no tempo de relaxação $T_{1}$, foram obtidos. Cortes na orientação padrão, $z$, foram utilizados na aquisição das fatias selecionadas (imagens da seção transaxial) apresentadas na FIG. 36.

Cerca de trinta e três fatias obtidas por IRM (fatias em $z$ apresentadas na FIG. 36) foram processadas no programa MATLAB ${ }^{\circledR}$. A representação do simulador esférico em 3D é apresentada na FIG. 37.

A escala colorida de dose apresentada nas FIG. 36 e 37 foi relatada como porcentagem de Dose Prescrita (\% DP) [49]. 


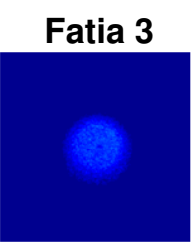

Fatia 12

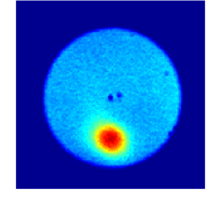

Fatia 18

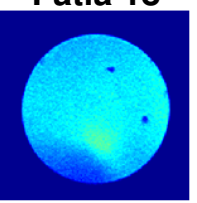

Fatia 8

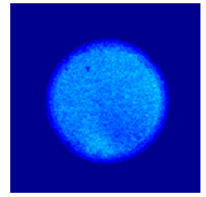

Fatia 14

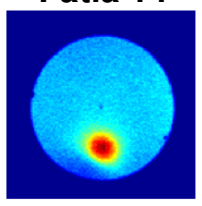

Fatia 25

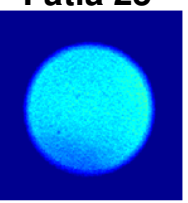

Fatia 10

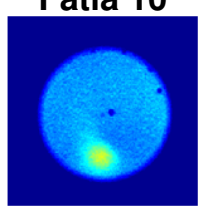

Fatia 16

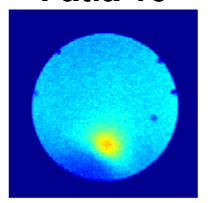

Fatia 30

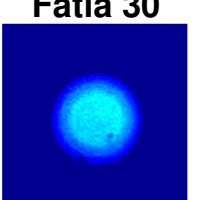

$$
\% \text { (DP) }
$$
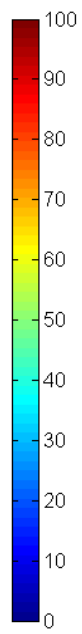

FIGURA 36 - Fatias em $z$ da imagem do simulador esférico irradiado, selecionadas, obtidas pela técnica de IRM [49].

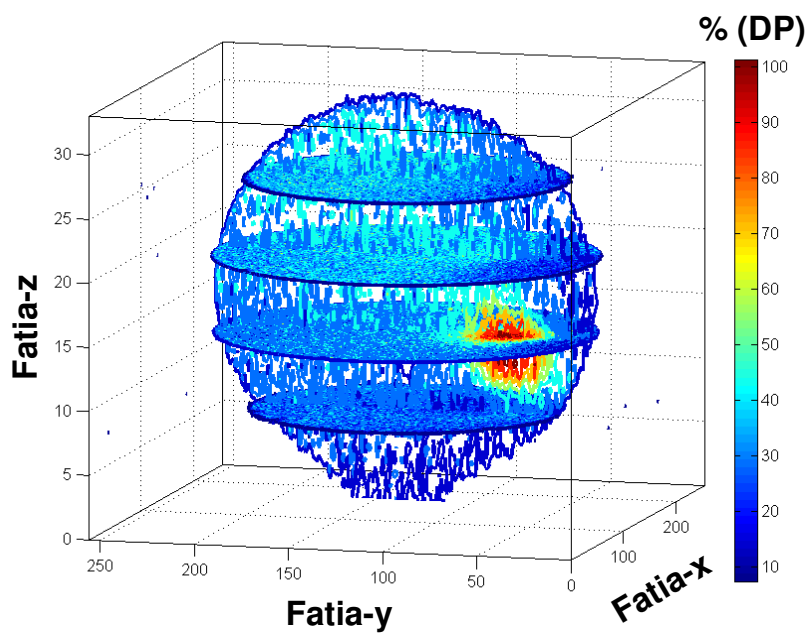

FIGURA 37 - Representação do simulador esférico em 3D com a orientação das fatias obtidas pela técnica de IRM. Corte na fatia $x=130$ [49].

\subsubsection{Reconstrução da imagem em 3D}

Utilizando o programa MATLAB ${ }^{\circledR}$, os valores de $T_{1}$ dos pixels foram calculados e a distribuição de dose tridimensional do simulador irradiado foi reconstruída [49].

Nas FIG. 38 e 39 são apresentadas reconstruções das imagens do simulador esférico em 3D. 


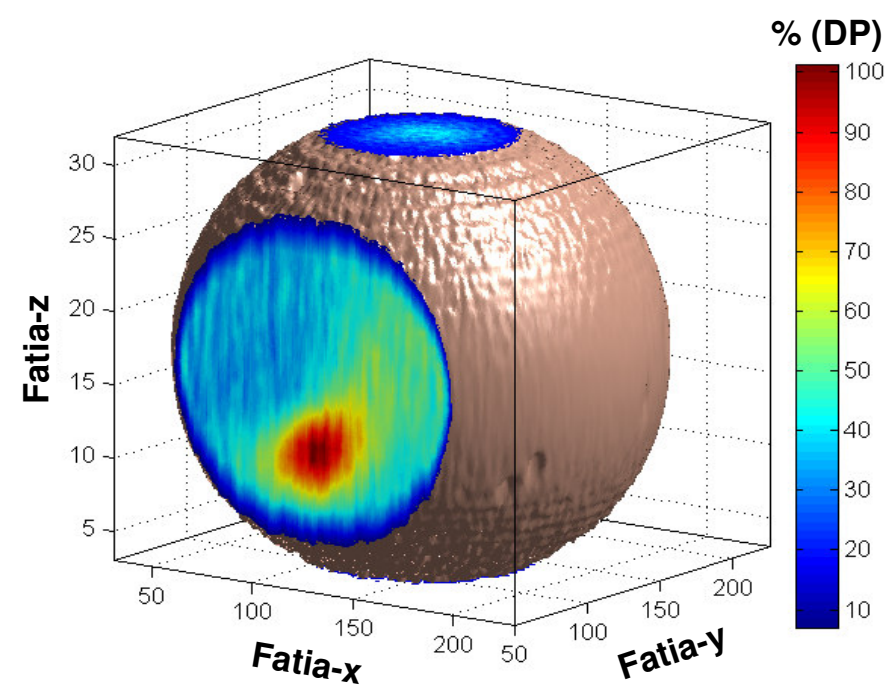

FIGURA 38 - Reconstrução da imagem do simulador esférico em 3D. Corte na fatia $y=50$ para destacar o centro do volume irradiado [49].

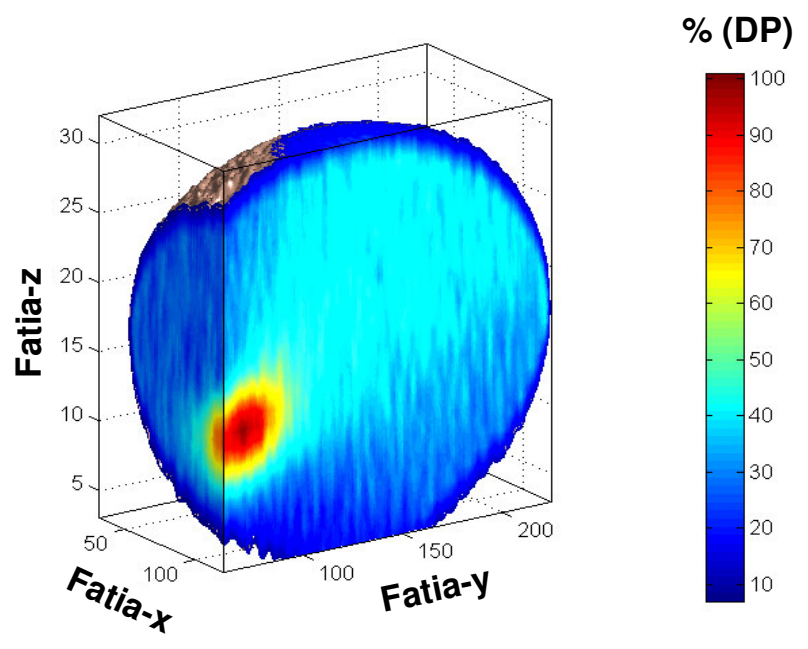

FIGURA 39 - Reconstrução da imagem do simulador esférico em 3D. Cortes nas fatias $y=60$ e $x=120$ mostrando a projeção do cone irradiado [49].

Nota-se, observando as FIG. 38 e 39, que o centro do alvo irradiado apresenta a maior porcentagem de dose prescrita $(100 \%)$ e que essa porcentagem vai sendo reduzida do centro para a periferia do alvo irradiado. 0 simulador constituído de solução Fricke gel também é sensível às menores porcentagens de dose prescrita, tornando possível a visualização (nas reconstruções em 3D) da projeção do cone de menor porcentagem de dose prescrita (FIG. 39) que se forma ao longo do seu volume. Por isso, é importante que, em radiocirurgia, a porcentagem de dose de radiação seja prescrita com 
precisão para que tecidos sadios adjacentes ao tumor, em um paciente, não sejam danificados por essa projeção de dose.

\subsubsection{Determinação das curvas de isodose}

Empregando a técnica de Espectroscopia Localizada (EL), os valores de $T_{1}$ foram medidos em dois voxels $\left(10 \times 10 \times 10 \mathrm{~cm}^{3}\right)$, um no volume irradiado e um distante dele (FIG. 40), a fim de correlacionar a intensidade média dos pixels com a dose de radiação em diferentes partes do simulador esférico [49]. O voxel distante do volume irradiado foi tomado como uma média dos pixels que preenchem o volume do simulador.

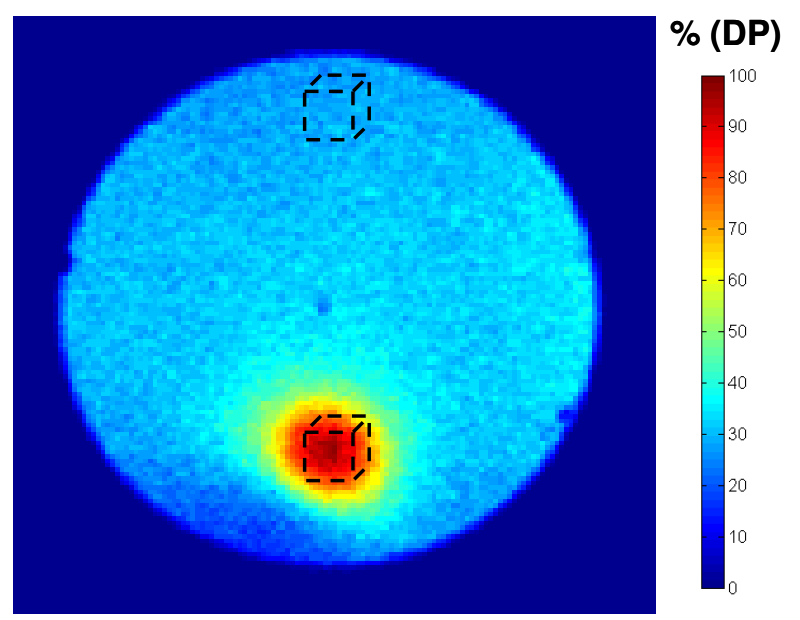

FIGURA 40 - Representação dos dois voxels dos quais foram obtidos os valores de $\mathrm{T}_{1}$ utilizados para a determinação das curvas de isodose. Imagem da fatia 14, apresentada na FIG. 36.

A intensidade média dos pixels da imagem é correlacionada ao tempo de relaxação $\mathrm{T}_{1}$ e consequentemente, à dose de radiação.

As curvas de isodose correspondentes à distribuição de dose obtida com 0 simulador esférico desenvolvido são apresentadas na FIG. 41. Para a determinação destas curvas foram utilizadas as curvas de resposta em função da dose absorvida apresentadas nas FIG. 33 e 34. 
$\%$ (DP)

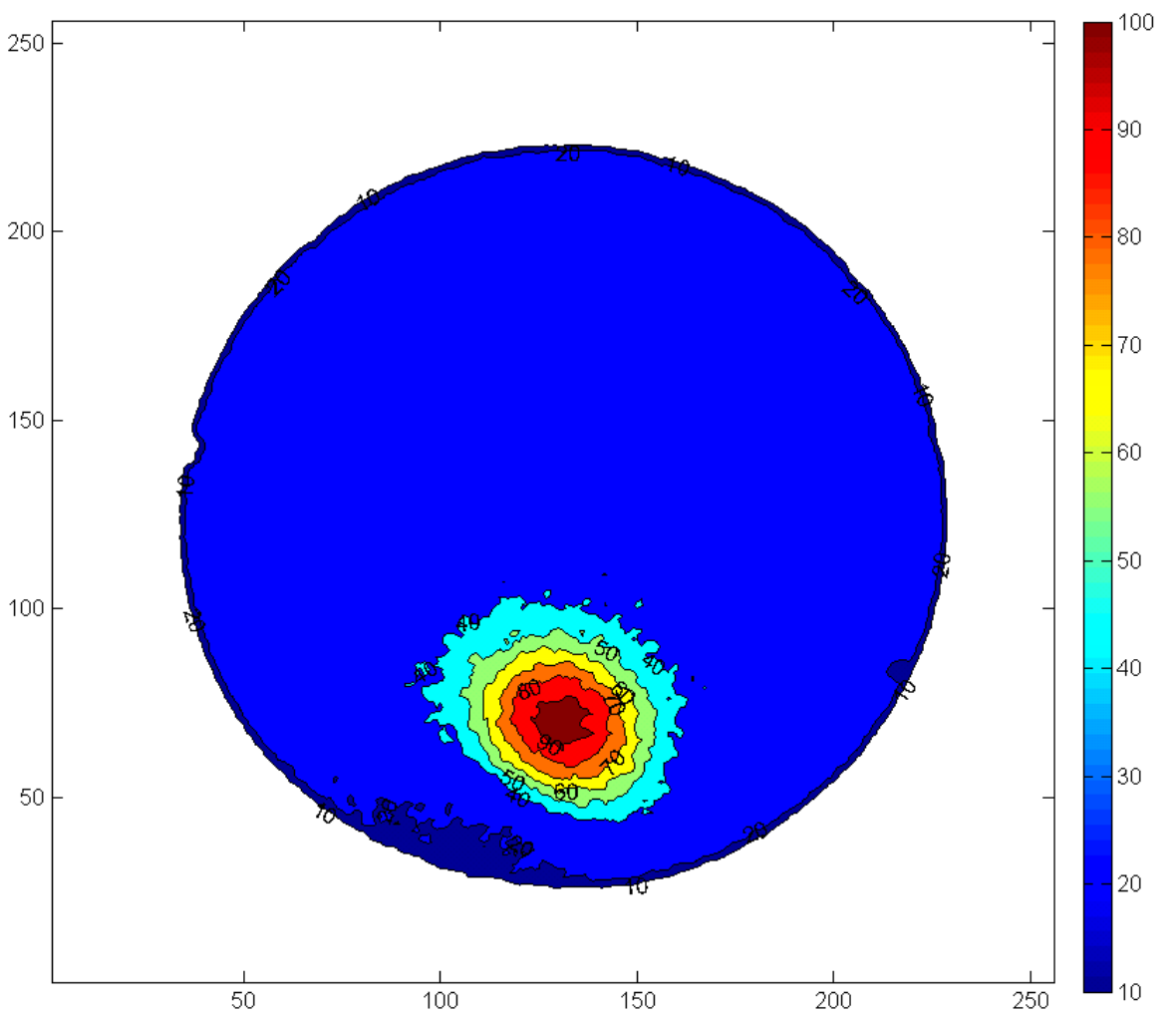

FIGURA 41 - Porcentagem de distribuição de dose absorvida na fatia 14 (FIG. 36) baseada nas curvas apresentadas nas FIG. 33 e 34.

As doses prescritas no centro do alvo $(80 G y)$ e de $50 \%$ na isolinha $(40 \mathrm{~Gy})$, apresentam incertezas expandidas melhores que $\pm 4 \%$ com um nível de confiança de $95 \%$. 


\section{CONCLUSÕES}

- As soluções preparadas com gelatinas 270 e 300 Bloom apresentam respostas equivalentes para os diferentes parâmetros estudados empregando a técnica de espectrofotometria de absorção óptica e radiação gama do ${ }^{60} \mathrm{Co}$;

- A concentração ótima de gelatina para a preparação da solução Fricke gel foi fixada em $5 \%$ para os diferentes tipos de gelatina estudados, 270 e 300 Bloom;

- A gelatina 270 Bloom é de baixo custo, sendo cerca de 45 vezes mais barata que a gelatina 300 Bloom, é de fabricação nacional, de fácil aquisição no mercado e de fácil manipulação;

- A solução Fricke gel preparada com 5\% de gelatina 270 Bloom apresenta as características seguintes:

- A reprodutibilidade da resposta espectrofotométrica é melhor que $\pm 5 \%$;

- É de fácil manuseio, pode ser obtida dentro de 3 horas, aproximadamente, e deve ser produzida cada vez que for utilizada;

- Os intervalos de dose útil para radiação gama do ${ }^{60} \mathrm{Co}$ e fótons de $6 \mathrm{MeV}$ estão entre 0,4 e 30,0 Gy, empregando a técnica de espectrofotometria de absorção óptica e entre 0,5 e 100,0 Gy, empregando a técnica de imageamento por ressonância magnética;

- A calibração das respostas espectrofotométrica e de imageamento por ressonância magnética da solução deve ser feita sempre com a mesma taxa de dose utilizada na irradiação das amostras nos sistemas de irradiação utilizados;

- Não apresenta dependência energética da resposta espectrofotométrica para energias acima de aproximadamente $50 \mathrm{keV}$;

- Apresenta dependência angular da resposta espectrofotométrica para radiação $X$ de energias baixas, mas não apresenta nenhuma dependência para radiação gama do ${ }^{60} \mathrm{Co}$; 
- O tempo estabelecido para a realização de medições de ressonância magnética é de até 2,5 horas após a irradiação, considerando a difusão de íons férricos na solução Fricke gel;

- O simulador esférico preparado com gelatina 270 Bloom apresenta consistência e integridade apropriadas à temperatura ambiente durante a irradiação e o imageamento por ressonância magnética;

- As isolinhas de dose podem ser obtidas com boa precisão, melhor que $\pm 4 \%$, empregando a técnica de espectroscopia localizada e utilizando curvas de respostas em função da dose avaliadas empregando a técnica de imageamento por ressonância magnética e a taxa de relaxação spinrede.

Os resultados obtidos indicam que a gelatina 270 Bloom pode substituir com vantagem a gelatina 300 Bloom, importada, e que o simulador de cérebro preparado com essa qualidade de gelatina satisfaz os requerimentos para ser utilizado no controle de qualidade em radiocirurgia estereotáxica utilizando a técnica de Gamma Knife ${ }^{\circledast}$ e pode constituir mais uma opção de dosímetro em radioterapia.

A dose distribuída em qualquer ponto no simulador de cérebro pode ser medida, a distribuição de dose pode ser mapeada em extensões tridimensionais em qualquer corte para qualquer orientação (coronal, sagital ou axial), as curvas de isodose podem ser facilmente obtidas e as doses podem ser determinadas com boa precisão dependendo da curva de calibração.

Todos os resultados obtidos qualificam a aplicabilidade do dosímetro Fricke gel na dosimetria tridimensional pela técnica de IRM. 


\section{APÊNDICE A - Avaliação de incertezas de medições.}

\section{A.1 INCERTEZAS PADRÕES}

\section{A.1.1 Tipo A}

Se uma medição de uma grandeza dosimétrica, $x$, é repetida $n$ vezes, então a melhor estimativa para $x$ é $\bar{x}$. O valor da média aritmética $(\bar{x})$ de todas as medições $x_{i}$ é dado pela EQ. 11 [24]:

$$
\bar{x}=\frac{\sum_{i=1}^{n} x_{i}}{n}
$$

O desvio padrão amostral, $s_{x}$, caracteriza a incerteza média para um resultado individual, $x_{i}$, e é dado pela EQ. 12 [24]:

$$
s_{x}=\sqrt{\frac{\sum_{i=1}^{n}\left(x_{i}-\bar{x}\right)^{2}}{n-1}}
$$

O desvio padrão do valor médio é dado pela EQ. 13 [24]:

$$
\sigma_{\bar{x}}=\frac{s_{x}}{\sqrt{n}}=\sqrt{\frac{\sum_{i=1}^{n}\left(x_{i}-\bar{x}\right)^{2}}{n(n-1)}}
$$

A incerteza padrão do tipo A, denotada $u_{A}$, é definida como o desvio padrão do valor médio, $u_{A}=\sigma_{\bar{x}}$. Esta incerteza é obtida por uma análise estatística de medições repetidas e, em princípio, pode ser reduzida pelo aumento do número de medições [24]. 


\section{A.1.2 Tipo B}

As incertezas padrões tipo $\mathrm{B}, u_{B}$, não podem ser estimadas por medições repetidas; mais propriamente, elas são suposições inteligentes ou opiniões científicas de incertezas não estatísticas associadas à medição. Elas incluem influências sobre o processo de medição, aplicação de fatores de correção ou dados físicos capturados da literatura.

É frequentemente assumido que as incertezas padrões tipo B tem uma distribuição de probabilidade, tal como distribuição normal (Gaussiana), $t$ de Student ou retangular [24].

\section{A.1.3 Incertezas combinadas e expandidas}

A incerteza padrão combinada, $u_{C}$, é a incerteza padrão do resultado de uma medição, quando esse resultado é obtido dos valores de outras grandezas (EQ. 14). Dependerá das incertezas tipo $\mathrm{A}\left(u_{A}\right)$ e tipo $\mathrm{B}\left(u_{B}\right)$ das outras grandezas envolvidas [24,80].

$$
u_{C}=\sqrt{\sum_{i=1}^{n}\left(\frac{\partial f}{\partial x_{i}}\right)^{2} u^{2}\left(x_{i}\right)}
$$

Tipicamente, a incerteza combinada $\left(u_{C}\right)$ corresponde a $68 \%$ da distribuição normal e é multiplicada por um fator de abrangência, denotado por $k$, para obter a incerteza expandida $U=k \cdot u_{C}$.

A incerteza expandida, $U$, define o intervalo em torno do resultado da medição, dentro do qual estão os valores que poderão ser razoavelmente atribuídos à grandeza, com um determinado nível de confiança. Em química, normalmente trabalha-se com o fator de abrangência, $k=2$, correspondente a $95 \%$ de nível de confiança [24,80,81].

Associado ao fator de abrangência, tem-se o número de graus de liberdade efetivo $\left(v_{\text {eff }}\right)$, por meio do qual é estimada a combinação dos graus de liberdade associados a cada incerteza padrão, com uma ponderação pelas respectivas incertezas padrões. $\mathrm{O} v_{\text {eff }}$ é dado pela equação de Welch-Satterthwaite: 


$$
v_{e f f}=\frac{\boldsymbol{u}_{c}^{4}}{\sum_{i=1}^{n} \frac{\boldsymbol{u}_{i}^{4}}{\boldsymbol{v}_{i}}}
$$

onde $u_{i}$ e $v_{i}$ são a incerteza padrão combinada e os graus de liberdade associados à i-ésima fonte de incerteza, respectivamente [81,82].

O resultado da medição de uma grandeza, $Q$, é então expresso por $(Q \pm U)$ e sua respectiva unidade, com um determinado nível de confiança que deve ser especificado $[24,80]$. 
APÊNDICE B - Equipamentos de medição e sistema radiocirúrgico Leksell Gamma Knife ${ }^{\circledR}$.

\section{B.1 EQUIPAMENTOS DE MEDIÇÃO}

B.1.1 Medições espectrofotométricas

- Espectrofotômetro (FIG. 42):

- Marca: SHIMADZU ${ }^{\circledR}$;

○ Modelo: UV-2101PC.

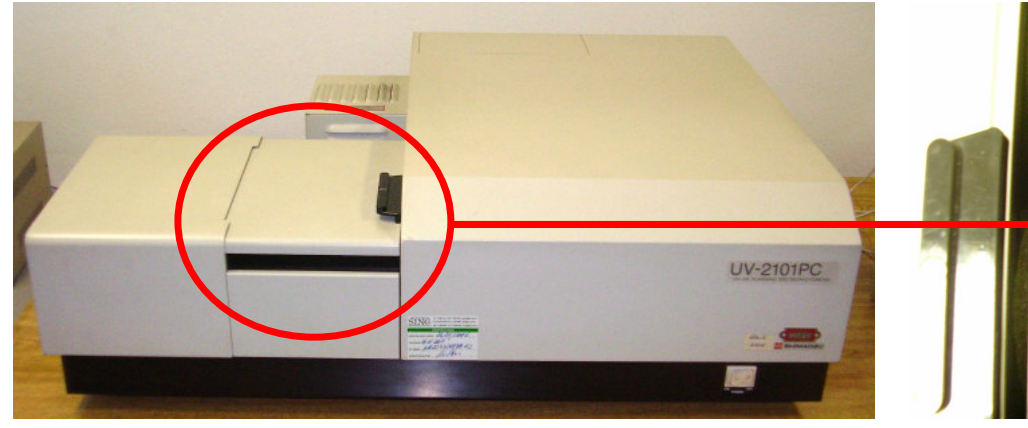

a

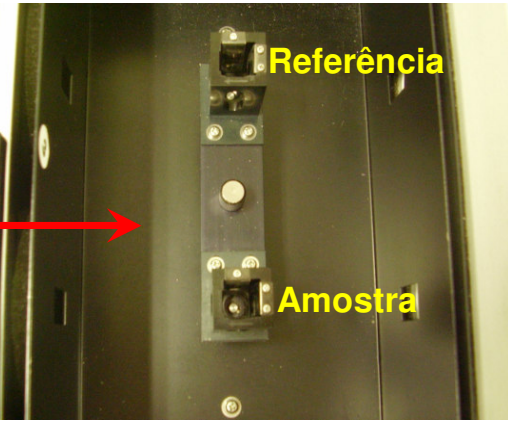

b

FIGURA 42 - Espectrofotômetro marca SHIMADZU ${ }^{\circledR}$ (a) e seus compartimentos de referência e amostra (b). 
B.1.2 Medições de ressonância magnética (RM)

- Tomógrafo de Corpo Inteiro - TCI (FIG. 43):

- Marca: PHILIPS ${ }^{\circledR}$;

- Modelo: GYROSCAN S15/ACS-II.

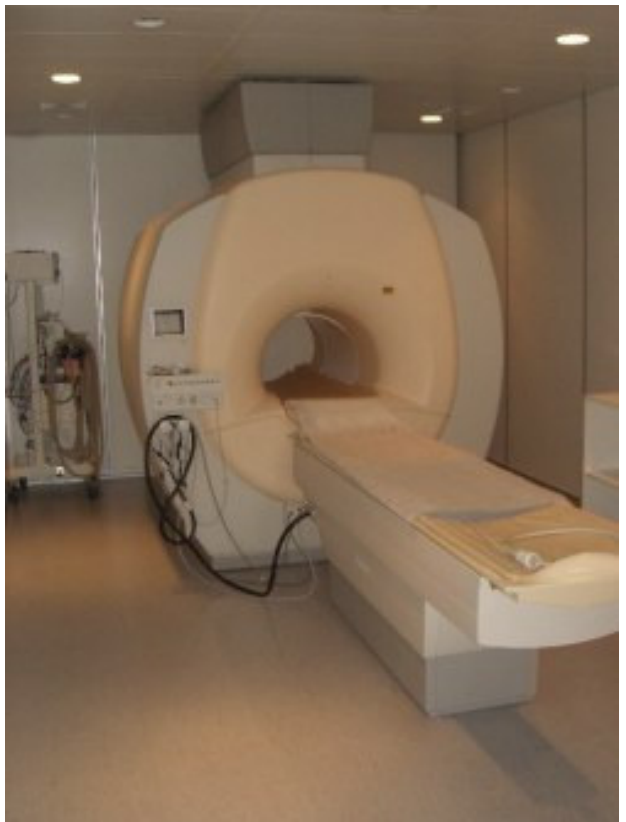

FIGURA 43 - Tomógrafo de corpo inteiro marca PHILIPS ${ }^{\circledR}$ [83].

- Espectrômetro de RM de alta resolução (FIG. 44):

- Marca: VARIAN ${ }^{\circledR}$;

○ Modelo: GEMINI 2000.

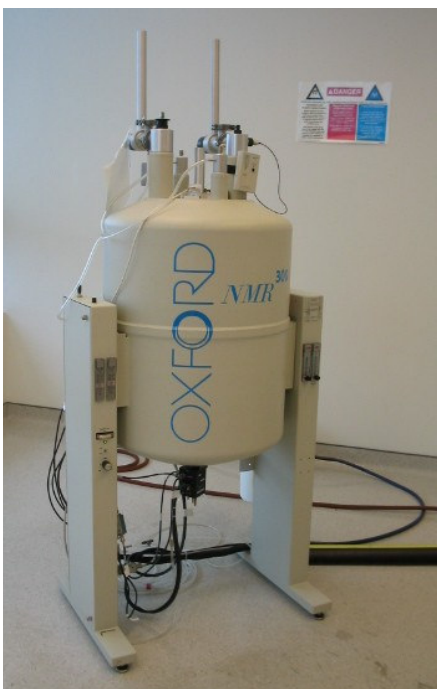

FIGURA 44 - Espectrômetro de RM de alta resolução marca VARIAN ${ }^{\circledR}$ [84]. 


\section{B.2 SISTEMA RADIOCIRÚRGICO LEKSELL GAMMA KNIFE ${ }^{\circledR}$}

- Marca: Elekta ${ }^{\circledR}$ (FIG. 45);

- Modelo: B.

Os principais componentes de uma unidade gama são:

- Uma unidade de radiação com blindagem no hemisfério superior e na parte central da unidade;

- Uma mesa de operação e um berço móvel;

- Um conjunto de quatro capacetes colimadores com o qual podem ser obtidos feixes circulares com diâmetros de 4, 8, 14 e $18 \mathrm{~mm}$ no isocentro; e

- Uma unidade de controle [62].

Na FIG. 45 é apresentada uma instalação Gamma Knife ${ }^{\circledR}$ típica com a parte principal da máquina, a mesa de tratamento e o capacete colimador. 


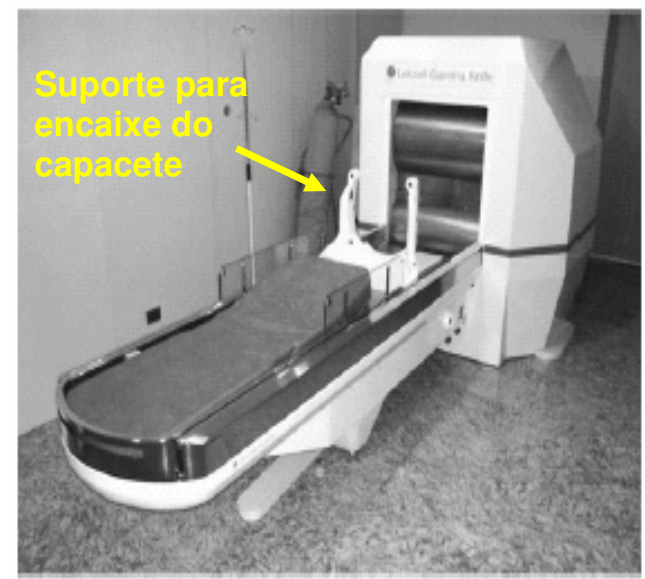

a

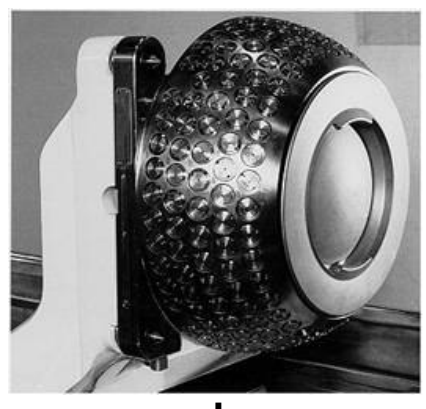

b

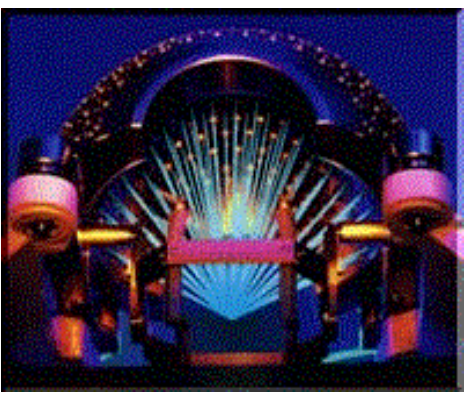

C

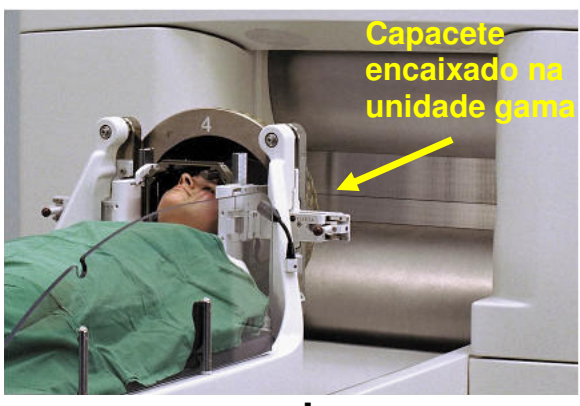

d

FIGURA 45 - Sistema Leksell Gamma Knife ${ }^{\circledR}$ marca Elekta ${ }^{\circledR}$ modelo B (Instituto de Radiocirurgia Neurológica - Hospital Santa Paula) (a); vista da parte posterior do capacete colimador de feixes de radiação gama do ${ }^{60} \mathrm{Co}$ (b); simulação dos feixes (em azul) colimados (c) e demonstração do capacete colimador encaixado na unidade Gamma Knife $^{\circledR}(\mathrm{d})[63,85,86]$.

Na FIG. 46 é apresentado o dispositivo estereotáxico utilizado para posicionar a cabeça do paciente dentro do capacete colimador.

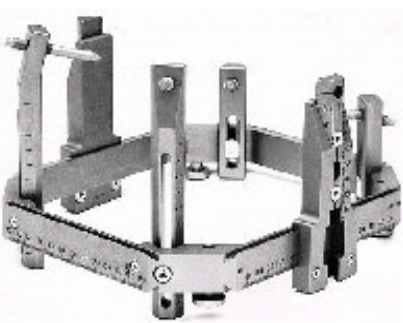

a

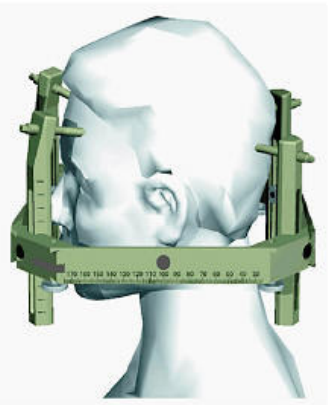

b

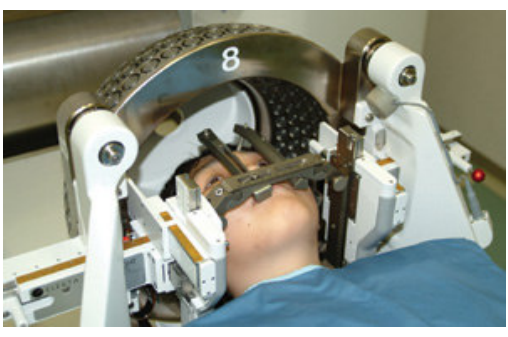

C

FIGURA 46 - Dispositivo estereotáxico (a), encaixado na cabeça de um paciente (b) e, então, encaixado dentro do capacete colimador (c) $[63,86,87]$. 


\section{APÊNDICE C - Parâmetros utilizados para a avaliação da resposta da solução Fricke gel por IRM e tempo de relaxação.}

TABELA 10 - Parâmetros operacionais utilizados para a avaliação da influência da concentração da gelatina na resposta da solução Fricke gel por IRM.

\begin{tabular}{|c|c|c|}
\hline $\begin{array}{c}\text { CONCENTRAÇÁO DA GELATINA } \\
(\%)\end{array}$ & DESCRIÇÃO & PARÂMETROS \\
\hline \multirow[t]{11}{*}{1} & Sequência de pulso & IR-TSE \\
\hline & Espessura da fatia & $9 \mathrm{~mm}$ \\
\hline & (Slice Thickness, THK) & \\
\hline & Campo de visão & $130 \mathrm{~mm}$ \\
\hline & (Field of View, FOV) & \\
\hline & TR & $1800 \mathrm{~ms}$ \\
\hline & Tempo de inversão (TI) & $714 \mathrm{~ms}$ \\
\hline & TE & $18 \mathrm{~ms}$ \\
\hline & Número médio de sinais & 4 \\
\hline & (Number of Signals Averaged, NSA) & \\
\hline & $\begin{array}{l}\text { Tamanho da matriz } \\
\text { (Matrix Size, MS) }\end{array}$ & $256 \times 256$ pixels \\
\hline \multirow[t]{9}{*}{5} & Sequência de pulso & $\mathrm{T}_{1}$-TFE \\
\hline & THK & $9 \mathrm{~mm}$ \\
\hline & Fov & $180 \mathrm{~mm}$ \\
\hline & Intensificação do contraste & Ponderado em $T_{1}$ \\
\hline & Pré-pulso do TI & $714 \mathrm{~ms}$ \\
\hline & TR & $18 \mathrm{~ms}$ \\
\hline & TE & $9 \mathrm{~ms}$ \\
\hline & NSA & 32 \\
\hline & MS & $256 \times 256$ pixels \\
\hline \multirow[t]{9}{*}{10} & Sequência de pulso & $\overline{T_{1}-\mathrm{TFE}}$ \\
\hline & THK & $9 \mathrm{~mm}$ \\
\hline & FOV & $150 \mathrm{~mm}$ \\
\hline & Intensificação do contraste & Ponderado em $T_{1}$ \\
\hline & Pré-pulso do TI & $714 \mathrm{~ms}$ \\
\hline & TR & $18 \mathrm{~ms}$ \\
\hline & TE & $9 \mathrm{~ms}$ \\
\hline & NSA & 32 \\
\hline & MS & $256 \times 256$ pixels \\
\hline \multirow[t]{9}{*}{15} & Sequência de pulso & $\mathrm{T}_{1}$-TFE \\
\hline & THK & $9 \mathrm{~mm}$ \\
\hline & Fov & $190 \mathrm{~mm}$ \\
\hline & Intensificação do contraste & Ponderado em $T_{1}$ \\
\hline & Pré-pulso do TI & $714 \mathrm{~ms}$ \\
\hline & TR & $15 \mathrm{~ms}$ \\
\hline & TE & $7,5 \mathrm{~ms}$ \\
\hline & NSA & 32 \\
\hline & MS & $256 \times 256$ pixels \\
\hline
\end{tabular}


TABELA 11 - Parâmetros operacionais utilizados para a avaliação da influência da taxa de dose na resposta da solução Fricke gel por tempo de relaxação.

\begin{tabular}{cc}
\hline DESCRIÇÃO & PARÂMETROS \\
\hline Sequência de pulso & $\mathrm{T}_{1}$-TFE \\
THK & $9 \mathrm{~mm}$ \\
FOV & $130 \mathrm{~mm}$ \\
Intensificação do contraste & Ponderado em $\mathrm{T}_{1}$ \\
Pré-pulso do TI & $800 \mathrm{~ms}$ \\
TR & $12 \mathrm{~ms}$ \\
TE & $5,9 \mathrm{~ms}$ \\
NSA & 32 \\
MS & $128 \times 128$ pixels \\
\hline
\end{tabular}


TABELA 12 - Parâmetros operacionais utilizados para a avaliação da estabilidade da resposta da solução Fricke gel por tempo de relaxação.

\begin{tabular}{|c|c|c|}
\hline DIA DE ANÁLISE & DESCRIÇÃO & PARÂMETROS \\
\hline \multirow[t]{8}{*}{$11^{\circ}$} & Sequência de pulso & $\mathrm{IR}$ \\
\hline & THK & $9 \mathrm{~mm}$ \\
\hline & FOV & $120 \mathrm{~mm}$ \\
\hline & $\mathrm{TI}$ & $816 \mathrm{~ms}$ \\
\hline & TR & $1500 \mathrm{~ms}$ \\
\hline & TE & $20 \mathrm{~ms}$ \\
\hline & NSA & 2 \\
\hline & MS & $256 \times 256$ pixels \\
\hline \multirow[t]{8}{*}{$2^{\circ} ., 3^{\circ}$. e 4ㅇ. } & Sequência de pulso & IR \\
\hline & THK & $9 \mathrm{~mm}$ \\
\hline & FOV & $130 \mathrm{~mm}$ \\
\hline & TI & $816 \mathrm{~ms}$ \\
\hline & TR & $1750 \mathrm{~ms}$ \\
\hline & TE & $20 \mathrm{~ms}$ \\
\hline & NSA & 1 \\
\hline & MS & $256 \times 256$ pixels \\
\hline \multirow[t]{8}{*}{5 . } & Sequência de pulso & IR \\
\hline & THK & $9 \mathrm{~mm}$ \\
\hline & FOV & $120 \mathrm{~mm}$ \\
\hline & $\mathrm{TI}$ & $816 \mathrm{~ms}$ \\
\hline & TR & $1750 \mathrm{~ms}$ \\
\hline & TE & $20 \mathrm{~ms}$ \\
\hline & NSA & 1 \\
\hline & MS & $256 \times 256$ pixels \\
\hline \multirow[t]{8}{*}{60.} & Sequência de pulso & $\mathrm{IR}$ \\
\hline & THK & $9 \mathrm{~mm}$ \\
\hline & FOV & $130 \mathrm{~mm}$ \\
\hline & $\mathrm{TI}$ & $710 \mathrm{~ms}$ \\
\hline & TR & $1500 \mathrm{~ms}$ \\
\hline & TE & $25 \mathrm{~ms}$ \\
\hline & NSA & 2 \\
\hline & MS & $256 \times 256$ pixels \\
\hline
\end{tabular}


TABELA 13 - Parâmetros operacionais utilizados para a avaliação da resposta em função da imagem da solução Fricke gel por IRM.

\begin{tabular}{cc}
\hline DESCRIÇÃO & PARÂMETROS \\
\hline Sequência de pulso & $\mathrm{T}_{1}$-TFE \\
THK & $10 \mathrm{~mm}$ \\
FOV & $220 \mathrm{~mm}$ \\
Intensificação do contraste & Ponderado em $\mathrm{T}_{1}$ \\
Pré-pulso do TI & $730 \mathrm{~ms}$ \\
TR & $9 \mathrm{~ms}$ \\
TE & $4,4 \mathrm{~ms}$ \\
NSA & 32 \\
MS & $128 \times 128$ pixels \\
\hline
\end{tabular}

TABELA 14 - Parâmetros operacionais utilizados para a avaliação das imagens do simulador esférico por IRM.

\begin{tabular}{cc}
\hline DESCRIÇÃO & PARÂMETROS \\
\hline Sequência de pulso & IR-TSE \\
THK & $4 \mathrm{~mm}$ \\
FOV & $160 \mathrm{~mm}$ \\
TR & $700 \mathrm{~ms}$ \\
TE & $11 \mathrm{~ms}$ \\
NSA & 4 \\
MS & $256 \times 256$ pixels \\
\hline
\end{tabular}


ANEXO A - Certificados de análise das gelatinas 270 e 300 Bloom.

\section{A.1 GELATINA 270 Bloom}

- Produto: gelatina alimentícia de origem suína;

- Descrição: é um produto proteico de coloração amarelo claro, obtido pela extração do colágeno parcialmente hidrolisado, derivado de tecido animal, com sabor e odor característicos;

- Armazenagem: sob armazenamento em local fresco e seco, a gelatina mantém suas propriedades por um período de 5 anos.

\section{A.1.1 Certificado 1}

$\mathrm{Na}$ TAB. 15 são apresentadas as especificações da gelatina alimentícia de origem suína - 270P Bloom / 8 mesh emitidas no dia 19 de dezembro de 2003 e registradas no certificado versão 00 da Gelita ${ }^{\circledR}$. 
TABELA 15 - Especificações da gelatina alimentícia suína - 270P/8.

\begin{tabular}{|c|c|c|c|c|c|}
\hline \multicolumn{6}{|c|}{ GELATINA ALIMENTÍCIA DE ORIGEM SUÍNA - 270P/8 } \\
\hline \multicolumn{6}{|c|}{$\begin{array}{l}\text { Especificações } \\
\end{array}$} \\
\hline $\begin{array}{c}\text { FísICO } \\
\text { QuíMICO } \\
\text { (FQ) }\end{array}$ & LIMITES & MÉTODOS & $\begin{array}{c}\text { MICROBIOLÓGICO } \\
\text { (MB) }\end{array}$ & LIMITES & MÉTODOS \\
\hline $\begin{array}{c}\text { Bloom } \\
(6,66 \%)\end{array}$ & $\begin{array}{c}260-280 \\
g\end{array}$ & FQ. 01/01 & Contagem Total & $\leq 1000 / 1 g$ & MB. 02/01 \\
\hline $\begin{array}{c}\text { Viscosidade } \\
\begin{array}{c}(6,66 \% \\
\left.60^{\circ} \mathrm{C}\right)\end{array}\end{array}$ & $\begin{array}{c}40-51 \\
m P s\end{array}$ & FQ. 02/01 & Coliformes Fecais & Negativo/10 $g$ & MB. 03/01 \\
\hline Umidade & $\begin{array}{c}8,0- \\
13,0 \%\end{array}$ & FQ. 05/01 & $\begin{array}{c}\text { Esporos Sulfito } \\
\text { Redutor }\end{array}$ & $\leq 10 / 1 \mathrm{~g}$ & MB. 05/01 \\
\hline Cinzas & $\leq 1,5 \%$ & FQ. 17/01 & Salmonella sp. & Negativo/25 $g$ & MB. $10 / 01$ \\
\hline $\begin{array}{c}\mathrm{pH} \\
(6,67 \%)\end{array}$ & $4,5-5,8$ & FQ. 09/01 & & & \\
\hline Cromo & $\leq 2 \mathrm{ppm}$ & FQ. 26/01 & & & \\
\hline Arsênico & $\begin{array}{l}\leq 1,0 \\
\text { ppm }\end{array}$ & $\begin{array}{c}\text { Ab. } \\
\text { Atômica }\end{array}$ & & & \\
\hline Nitrogênio & $\geq 15,0 \%$ & KJELDAHL & & & \\
\hline $\mathrm{SO}_{2}$ AFNOR & $\begin{array}{l}\leq 40 \\
\text { ppm }\end{array}$ & FQ. 24/01 & & & \\
\hline Peróxido de & $\leq 10$ & FQ. 23/01 & & & \\
\hline Hidrogênio & ppm & & & & \\
\hline Metais & $\leq 20$ & FQ. 34/01 & & & \\
\hline Pesados & ppm & & & & \\
\hline Chumbo & $\begin{array}{l}\leq 1,5 \\
\text { ppm }\end{array}$ & $\begin{array}{c}\text { Ab. } \\
\text { Atômica }\end{array}$ & & & \\
\hline Granulometria & 8 mesh & FQ. 06/01 & & & \\
\hline
\end{tabular}




\section{A.1.2 Certificado 2}

$\mathrm{Na}$ TAB. 16 são apresentadas as especificações da gelatina alimentícia de origem suína - 273P Bloom / 8 mesh emitidas no dia 19 de abril de 2005 e registradas no certificado da Gelita ${ }^{\circledR}$.

TABELA 16 - Especificações da gelatina alimentícia suína - 273P/8.

\begin{tabular}{|c|c|c|c|c|c|}
\hline \multicolumn{6}{|c|}{ GELATINA ALIMENTÍCIA DE ORIGEM SUÍNA - 273P/8 } \\
\hline \multicolumn{6}{|c|}{ Especificações } \\
\hline $\begin{array}{l}\text { FÍSICO } \\
\text { QUíMICO } \\
\text { (FQ) }\end{array}$ & LIMITES & MÉTODOS & $\begin{array}{c}\text { MICROBIOLÓGICO } \\
\text { (MB) }\end{array}$ & LIMITES & MÉTODOS \\
\hline $\begin{array}{c}\text { Bloom } \\
(6,66 \%)\end{array}$ & $260-280 \mathrm{~g}$ & FQ. 01/01 & Contagem Total & $\begin{array}{c}\leq 1000 / 1 \\
g\end{array}$ & MB. $02 / 01$ \\
\hline $\begin{array}{c}\text { Viscosidade } \\
\begin{array}{c}(6,66 \%- \\
\left.60^{\circ} \mathrm{C}\right)\end{array}\end{array}$ & 40-51 mPs & FQ. 02/01 & Coliformes Fecais & $\mathrm{A} / 10 \mathrm{~g}$ & MB. 03/01 \\
\hline Umidade & $8,0-13,0 \%$ & FQ. 05/01 & $\begin{array}{c}\text { Esporos Sulfito } \\
\text { Redutor }\end{array}$ & $\leq 10 / 1 \mathrm{~g}$ & MB. 05/01 \\
\hline Cinzas & $\leq 1,5 \%$ & FQ. 17/01 & Salmonella sp. & $\mathrm{A} / 25 g$ & MB. $10 / 01$ \\
\hline $\begin{array}{c}\mathrm{pH} \\
(6,67 \%)\end{array}$ & $4,5-5,8$ & FQ. 09/01 & & & \\
\hline Cromo & $\leq 2 \mathrm{ppm}$ & FQ. 26/01 & & & \\
\hline Arsênico & $\leq 1,0 \mathrm{ppm}$ & $\begin{array}{c}\text { Ab. } \\
\text { Atômica }\end{array}$ & & & \\
\hline Nitrogênio & $\geq 15,0 \%$ & KJELDAHL & & & \\
\hline $\mathrm{SO}_{2}$ AFNOR & $\leq 40 \mathrm{ppm}$ & FQ. 24/01 & & & \\
\hline $\begin{array}{l}\text { Peróxido de } \\
\text { Hidrogênio }\end{array}$ & $\leq 10 \mathrm{ppm}$ & FQ. 23/01 & & & \\
\hline $\begin{array}{l}\text { Metais } \\
\text { Pesados }\end{array}$ & $\leq 20 \mathrm{ppm}$ & FQ. 34/01 & & & \\
\hline Chumbo & $\leq 1,5 \mathrm{ppm}$ & $\begin{array}{c}\text { Ab. } \\
\text { Atômica }\end{array}$ & & & \\
\hline Granulometria & 8 mesh & FQ. 06/01 & & & \\
\hline
\end{tabular}




\section{A.2 GELATINA 300 Bloom}

- Produto: gelatina de pele suína, Tipo A;

- Número: G2500;

- Marca: Sigma-Aldrich ${ }^{\circledR}$;

- Número CAS: 9000-70-8.

Na TAB. 17 são apresentadas as especificações da gelatina pró-análise de origem suína -300 Bloom registradas no certificado da Sigma-Aldrich ${ }^{\circledR}$.

TABELA 17 - Especificações da gelatina pró-análise suína - 300 Bloom .

\begin{tabular}{|c|c|c|}
\hline TESTE & ESPECIFICAÇÃO & $\begin{array}{c}\text { RESULTADOS DO LOTE } \\
\text { 036K0144 }\end{array}$ \\
\hline Aparência & $\begin{array}{c}\text { Pó branco-sujo a } \\
\text { amarelo }\end{array}$ & Branco-sujo \\
\hline Solubilidade & $\begin{array}{c}\text { Solução clara a } \\
\text { amarela pálida } \\
\text { enevoada à } \\
50 \mathrm{mg} \cdot \mathrm{mL}^{-1} \text { em água }\end{array}$ & $\begin{array}{c}\text { Levemente amarela pálida } \\
\text { enevoada }\end{array}$ \\
\hline Proteína por biureto & 70 a $90 \%$ & $81 \%$ \\
\hline Número Bloom & $\cong 300$ Bloom & $\begin{array}{c}306 \text { Bloom } \\
\text { (informação do fornecedor) }\end{array}$ \\
\hline Período de validade & 5 anos & abril/2006 à abril/2011 \\
\hline
\end{tabular}




\section{REFERÊNCIAS BIBLIOGRÁFICAS}

1 SABOL, J.; WENG, P.S. Introduction to radiation protection dosimetry. Singapore: World Scientific, 1995.

2 MARTINS, J.B. História da energia nuclear. Rio de Janeiro: Comissão Nacional de Energia Nuclear (RJ). Disponível em: $<$ http://www.cnen.gov.br/ensino/apostilas/historia.pdf>. Acesso em: 22 jun. 2009.

3 SHUNG, K.K.; SMITH, M.B.; TSUI, B.M.W. Principles of medical imaging. San Diego, CA: Academic, 1992. cap. 1, x-ray. p. 1-77.

4 HENDEE, W.R.; RITENOUR, E.R. Medical imaging physics. 4.ed. New York, NY: Wiley-Liss, 2002.

5 SANTOS, C.A. O Indiana Jones do núcleo atômico: colunista revê legado de Ernest Rutherford, que há cem anos recebeu o Nobel de Química. Ci. Hoje, São Paulo, jun. 2008. Seção Do Laboratório para a Fábrica. Disponível em: <http://cienciahoje.uol.com.br/122576>. Acesso em: 22 jun. 2009.

6 FACULDADE DE CIÊNCIAS FARMACÊUTICAS DA UNIVERSIDADE DE SÃO PAULO. Atomística. São Paulo: Universidade de São Paulo, 2004. Disponível em: <http://www.fcf.usp.br/Ensino/Graduacao/Disciplinas/LinkAula/MyFiles/Atomistica.htm>. Acesso em: 22 jun. 2009.

7 PODGORSAK, E.B. Radiation oncology physics: a handbook for teachers and students. Vienna: International Atomic Energy Agency, 2005. cap. 1, basic radiation physics. p. 1-43.

8 SHANI, G. Radiation dosimetry: instrumentation and methods. Boca Raton, FL: CRC, 1991. cap. 1, the theory of radiation dosimetry. p. 1-16.

9 SCHABERLE, F.A.; SILVA, N.C. Introdução à física da radioterapia. Santa Catarina: Universidade Federal de Santa Catarina, 2000. Disponível em: $<$ http://www.fsc.ufsc.br/ canzian/intrort/planejamento>. Acesso em: 22 jun. 2009.

10 MCLAUGHLIN, W.L.; BOYD, A.W.; CHADWICK, K.H.; MCDONALD, J.C.; MILLER, A. Dosimetry for radiation processing. London: Taylor \& Francis, 1989. 
11 GORE, J.C.; KANG, Y.S.; SCHULZ, R.J. Measurement of radiation dose distributions by nuclear magnetic resonance (NMR) imaging. Phys. Med. Biol., v. 29, n. 10, p. 1189-1197, 1984.

12 BERO, M.A.; GILBOY, W.B.; GLOVER, P.M. Radiochromic gel dosemeter for three-dimensional dosimetry. Radiat. Phys. Chem., v. 61, p. 433-435, 2001.

13 SEHESTED, K. The Fricke dosimeter. In: HOLM, N.W.; BERRY, R.J. (Ed.). Manual on radiation dosimetry. New York, NY: Marcel Dekker, 1970. p. 313317.

14 IBBOTT, G.S. Applications of gel dosimetry. J. Phys. Conf. Ser., v. 3, p. 58$77,2004$.

15 NETO, L.Q. Seus olhos: pterígio. Disponível em:

$<$ http://www.drqueirozneto.com.br/patologias/pterigio/tratamento.htm>. Acesso em: 22 jun. 2009.

16 MASCARENHAS, F.; COSTA, M.S.; ORTIZ, M.; ALMEIDA, A.; CARVALHO, H.; FERREIRA, A.G.; CATTONI, M.B. A radiocirurgia estereotáxica em tumores benignos e malignos do sistema nervoso central. Acta. Med. Port., Lisboa, v. 18, p. 45-60, 2005. Disponível em: $<$ http://www.actamedicaportuguesa.com/pdf/2005-18/1/045-060.pdf>. Acesso em: 22 jun. 2009.

17 TAUHATA, L.; SALATI, I.P.A.; DI PRINZIO, R.; DI PRINZIO, M.A.R.R. Radioproteção e dosimetria: fundamentos. 5 rev. ed. Rio de Janeiro: Instituto de Radioproteção e Dosimetria, 2003.

18 MEDEIROS, R.B. Produção e propriedade dos raios X. In: BITELLI, T. (Ed.). Física e dosimetria das radiações. 2. ed. São Paulo: Atheneu, 2006. p. 129167.

19 BERRY, R.J.; HOLM, N.W. Introduction to basic concepts and principles in radiation dosimetry. In: HOLM, N.W.; BERRY, R.J. (Ed.) Manual on radiation dosimetry. New York, N.Y.: Marcel Dekker, 1970. p. 3-9.

20 GREENING, J.R. Fundamentals of radiation dosimetry. 2. ed. England: Adam Hilger, 1985. cap. 2, interactions of ionising radiations with matter. p. 634.

21 PECEQUILO, B.R.S. Parte I: interação da radiação com a matéria. São Paulo: Instituto de Pesquisas Energéticas e Nucleares, 2007. Apostila da disciplina de pós-graduação TNA-5733: tópicos avançados de medidas nucleares. 
22 KIRCHER, J.F. Basic concepts of radiation effects. In: KIRCHER, J.F.; BOWMAN, R.E. (Ed.). Effects of radiation on materials and components. New York, N.Y.: Reinhold, 1964. p. 11-48.

23 ATTIX, F.H. Introduction to radiological physics and radiation dosimetry. New York, NY: John Wiley \& Sons, 1986. cap. 11, dosimetry fundamentals. p. 264-291.

24 IZEWSKA, J.; RAJAN, G. Radiation dosimeters. In: PODGORSAK, E.B. (Ed.). Radiation oncology physics: a handbook for teachers and students. Vienna: International Atomic Energy Agency, 2005. p. 71-99.

25 GALANTE, A.M.S. Pesquisa, desenvolvimento e caracterização de materiais dosimétricos para monitoramento em processos de irradiação com doses altas. 2003. Tese (Doutorado) - Instituto de Pesquisas Energéticas e Nucleares, São Paulo.

26 RADAK, B.; MARKOVIC, V. Calorimetry. In: HOLM, N.W.; BERRY, R.J (Ed.). Manual on radiation dosimetry. New York, NY: Marcel Dekker, 1970. p. 4581.

27 CAMERON, J.R. Radiophotoluminescent and thermoluminescent dosimetry. In: HOLM, N.W.; BERRY, R.J. (Ed.). Manual on radiation dosimetry. New York, NY: Marcel Dekker, 1970. p. 105-127.

28 SEHESTED, K. The Fricke dosimeter. In: HOLM, N.W.; BERRY, R.J. (Ed.). Manual on radiation dosimetry. New York, N.Y.: Marcel Dekker, 1970. p. 313-317.

29 INTERNATIONAL ATOMIC ENERGY AGENCY. Dosimetry for food irradiation. Vienna, 2002. (Technical Report Series, 409).

30 AMERICAN SOCIETY FOR TESTING AND MATERIALS. Standard guide for selection and application of dosimetry systems for radiation processing of food. July. 29, 1988. (ASTM E 1261).

31 CHUNG, W.H. Chemical dosimetry. In: MAHESH, K.; VIJ, D.R. (Ed.). Techniques of radiation dosimetry. Índia: Wiley Eastern, 1985. p. 372-400.

32 FIELDEN, E.M.; HOLM, N.W. Dosimetry in accelerator research and processing. In: HOLM, N.W.; BERRY, R.J. (Ed.). Manual on radiation dosimetry. New York, N.Y.: Marcel Dekker, 1970. p. 261-309. 
33 FRICKE, H.; HART, E.J. Chemical dosimetry. In: ATTIX, F.H.; ROESCH, W.C. (Ed.). Radiation dosimetry. 2. ed. New York, NY: Academic, 1966. p. 167-239.

34 SCHREINER, L.J. Review of Fricke gel dosimeters. J. Phys. Conf. Ser., v. 3, p. 9-21, 2004.

35 Gelatins. Saint Louis, MO: Sigma-Aldrich ${ }^{\circledR}, 2005$. Product information sheet.

36 GELITA $^{\circledR}$. Propriedades. Disponível em: <http://www.gelita.com/DGFportuguese/index.html>. Acesso em: 22 jun. 2009.

37 BALDOCK, C. Historical overview of gel dosimetry. J. Phys. Conf. Ser., v. 3, p. 1-3, 2004.

38 AUDET, C.; SCHREINER, L.J. Multiple-site fast exchange model for spinlattice relaxation in the Fricke-gelatin dosimeter. Med. Phys., v. 24, n. 2, p. 201-209, 1997.

$39 \mathrm{CHU}$, W.C. Radiation dosimetry using Fricke-infused gels and magnetic resonance imaging. Proc. Natl. Sci. Counc. $\operatorname{ROC}(B)$, v. 25, n. 1, p. 1-11, 2001.

40 OLSSON, L.E.; PETERSSON, S.; AHLGREN, L.; MATTSSON, S. Ferrous sulphate gels for determination of absorbed dose distributions using MRI technique: basic studies. Phys. Med. Biol., v. 34, n. 1, p. 43-52, 1989.

41 HEALY, B.J.; ZAHMATKESH, M.H.; NITSCHKE, K.N.; BALDOCK, C. Effect of saccharide additives on response of ferrous-agarose-xylenol orange radiotherapy gel dosimeters. Med. Phys., v. 30, n. 9, p. 2282-2291, 2003.

42 BERO, M.A.; KHARITA, M.H. Effects of ambient temperature on the FXG radiochromic gels used for 3-D dosimetry. J. Phys. Conf. Ser., v. 3, p. 236239, 2004.

43 BERO, M.A. Dosimetric properties of a radiochromic gel detector for diagnostic X-rays. Nucl. Instrum. Methods A, v. 580, p. 186-189, 2007.

44 HEALY, B.; BRINDHA, S.; ZAHMATKESH, M.; BALDOCK, C. Characterisation of the ferrous-xylenol orange-gelatin (FXG) gel dosimeter. J. Phys. Conf. Ser., v. 3, p. 142-145, 2004. 
45 BERO, M.A.; GILBOY, W.B.; GLOVER, P.M.; EL-MASRI, H.M. Tissueequivalent gel for non-invasive spatial radiation dose measurements. Nucl. Instrum. Methods B, v. 166-167, p. 820-825, 2000.

46 GALANTE, A.M.S.; CERVANTES, H.J.; CAVINATO, C.C.; CAMPOS, L.L.; RABBANI, S.R. MRI study of radiation effect on Fricke gel solutions. Radiat. Meas., v. 43, p. 550-553, 2008.

47 BALCOM, B.J.; LEES, T.J.; SHARP, A.R.; KULKARNI, N.S.; WAGNER, G.S. Diffusion in $\mathrm{Fe}(\mathrm{II} / \mathrm{III})$ radiation dosimetry gels measured by magnetic resonance imaging. Phys. Med. Biol., v. 40, p. 1665-1676, 1995.

48 HARRIS, P.J.; PIERCY, A.; BALDOCK, C. A method for determining the diffusion coefficient in $\mathrm{Fe}(\mathrm{II} / \mathrm{III})$ radiation dosimetry gels using finite elements. Phys. Med. Biol., v. 41, p. 1745-1753, 1996.

49 CAVINATO, C.C.; RODRIGUES JUNIOR, O.; CERVANTES, H.J.; RABBANI, S.R.; CAMPOS, L.L. A dosimetric evaluation of tissue equivalent phantom prepared using 270 Bloom gelatin for absorbed dose imaging in Gamma Knife radiosurgery. In: INTERNATIONAL CONFERENCE ON RADIOTHERAPY GEL DOSIMETRY, 5., September 29 - October 3, 2008, Hersonissos. Preliminary Proceedings... Hersonissos: University of Crete, 2008. p. 80-84.

50 CHAN, M.F.; AYYANGAR, K. Verification of water equivalence of FeMRI gels using Monte Carlo simulation. Med. Phys., v. 22, n. 4, p. 475-478, 1995.

51 INTERNATIONAL COMMISSION ON RADIATION UNITS AND MEASUREMENTS. Phantoms and computational models in therapy, diagnosis and protection. Bethesda, MD, 1992. (ICRU Report 48).

52 SCAFF, L.A.M. Física da radioterapia. São Paulo: Sarvier, 1997.

53 PARKER, W.; PATROCINIO, H. Clinical treatment planning in external photon beam radiotherapy. In: PODGORSAK, E.B. (Ed.). Radiation oncology physics: a handbook for teachers and students. Vienna: International Atomic Energy Agency, 2005. p. 219-272.

54 JOHNS, H.E. Use of $X$ and $\gamma$ rays in radiotherapy. In: ATTIX, F.H.; TOCHILIN, E. Radiation dosimetry. 2. ed. New York, N.Y.: Academic, 1969. v. 3. p. 677741.

55 HENEINE, I.F. Biofísica básica. São Paulo: Atheneu, 1999. cap. 11, soluções - métodos biofísicos de estudo. p. 175-187. 
56 OHLWEILER, O.A. Química analítica quantitativa. Rio de Janeiro: Livros técnicos e científicos, 1974. v. 3. cap. 22, métodos fotométricos, p. 647-701.

57 AMARO JUNIOR, E.; YAMASHITA, H. Aspectos básicos de tomografia computadorizada e ressonância magnética. R. Bras. Psiquiatr., São Paulo, maio 2001. Disponível em: <http://www.scielo.br/scielo.php?script=sci_arttext\&pid=S1516$44462001000500002>$. Acesso em: 22 jun. 2009.

58 AIRD, E.G.A. Basic physics for medical imaging. Oxford: ButterworthHeinemann, 1998. cap. 8, nuclear magnetic resonance - imaging and spectroscopy. p. 166-181.

59 CONOLLY, S.; MACOVSKI, A.; PAULY, J.; SCHENCK, J.; KWONG, K.K.; CHESLER, D.A.; HU, X.; CHEN, W.; PATEL, M.; UGURBIL, K. Magnetic resonance imaging. In: MUDRY, K.M.; PLONSEY, R.; BRONZINO, J.D. Biomedical imaging. Boca Raton, FL: CRC, 2003. p. 1-40.

60 CONTRERAS, L.F.G. Imagens por ressonância magnética nuclear (RMN): princípios e aplicações em medicina. In: SEMANA DA FÍSICA, 5., 2005, Londrina. Anais eletrônicos... Londrina: UEL, 2005. Disponível em: <http://www.fisica.uel.br/sefis/xsefis/IRMN.pdf>. Acesso em: 22 jun. 2009.

61 CARDOSO, E.M. Apostila educativa: aplicações da energia nuclear. Rio de Janeiro: Comissão Nacional de Energia Nuclear (RJ). Disponível em: <http://www.cnen.gov.br/ensino/apostilas/aplica.pdf>. Acesso em: 22 jun. 2009.

62 PODGORSAK, E.B.; PODGORSAK, M.B. Special procedures and techniques in radiotherapy. In: PODGORSAK, E.B. (Ed.). Radiation oncology physics: a handbook for teachers and students. Vienna: International Atomic Energy Agency, 2005. p. 505-548.

63 MONTAGNO, E.A.; SABBATINI, R.M.E. Radiocirurgia. Cérebro \& Mente, Campinas, n. 2, p. 1-5, jun./ago. 1997. Seção Tecnologia. Disponível em: <http://www.cerebromente.org.br/n02/tecnologia/radiocirurg.htm>. Acesso em: 22 jun. 2009.

64 AMERICAN SOCIETY FOR TESTING AND MATERIALS. Reagent water. Mar., 1977. (ASTM D 1193-77).

65 TRINDADE, D.F; PUGLIESI, M. Química básica teórica. São Paulo: Ícone, 1992. 
66 GALANTE, A.M.S. Caracterização de compostos químicos para dosimetria das radiações em processos industriais. 1999. Dissertação (Mestrado) Instituto de Pesquisas Energéticas e Nucleares, São Paulo.

67 BESSA, A.C.M. Intercomparação de câmaras de ionização em feixes padrões de raios $X$, níveis radioterapia, radiodiagnóstico e radioproteção. 2006. Dissertação (Mestrado) - Instituto de Pesquisas Energéticas e Nucleares, São Paulo.

68 MAIA, A.F. Padronização de feixes e metodologia dosimétrica em tomografia computadorizada. 2005. Tese (Doutorado) - Instituto de Pesquisas Energéticas e Nucleares, São Paulo.

69 INTERNATIONAL ATOMIC ENERGY AGENCY. Absorbed dose determination in external beam radiotherapy: an international code of practice for dosimetry based on standards of absorbed dose to water. Vienna, 2004. (Technical Report Series, 398).

70 INTERNATIONAL COMMISSION ON RADIATION UNITS AND MEASUREMENTS. Prescribing, recording, and reporting photon beam therapy. Bethesda, MD, 1993. (ICRU Report 50).

71 INTERNATIONAL COMMISSION ON RADIATION UNITS AND MEASUREMENTS. Prescribing, recording, and reporting photon beam therapy. Bethesda, MD, 1999. (ICRU Report 62).

72 BETTI, F. Desenvolvimento e implantação de um programa de controle e aquisição de dados na calibração de instrumentos em radiodiagnóstico. 2007. Dissertação (Mestrado) - Instituto de Pesquisas Energéticas e Nucleares, São Paulo.

73 CERVANTES, H.R.; BLOISE, A.C.; CAVINATO, C.C.; CAMPOS, L.L.; RABBANI, S.R. NMR study of $\mathrm{Fe}^{3+}$ ions diffusion in gamma irradiated Fricke gel. Appl. Radiat. Isot., 2008. Submetido.

74 GALANTE, A.M.S.; CAMPOS, L.L. Investigations of the Fricke gel (FXG) dosimeter developed at IPEN irradiated with ${ }^{60} \mathrm{Co}$ gamma rays. In:

INTERNATIONAL NUCLEAR ATLANTIC CONFERENCE, 2007, Santos.

Anais eletrônicos... Santos: Associação Brasileira de Energia Nuclear, 2007. Disponível em: <http://www.inac2007.com.br/dvd/pdf_dvd/E02_816.pdf>.

Acesso em: 22 jun. 2009. 
75 GALANTE, A.M.S.; CAMPOS, L.L. Chemical dosimeters development at IPEN for the radiation processes quality control. In: CAMILLERI, A.N. (Ed.).

Radiation physics research progress. New York, NY: Nova Science, 2008. p. 355-384.

76 GALANTE, A.M.S.; CAMPOS, L.L. Characterization of a Fricke gel solution to be applied in 3D dosimetry of radiotherapy treatment planning systems. 2006. Trabalho apresentado ao $10^{\text {th }}$ International Symposium on Radiation Physics, Coimbra, 2006. Não publicado.

77 GALANTE, A.M.S.; CAMPOS, L.L. Spectrophotometric analysis of Fricke gel dosimeters irradiated using a gelatin breast phantom. 2006. Trabalho apresentado ao $10^{\text {th }}$ International Symposium on Radiation Physics, Coimbra, 2006. Não publicado.

78 SCHULZ, R.J.; DE GUZMAN, A.F.; NGUYEN, D.B.; GORE, J.C. Doseresponse curves for Fricke-infused agarose gels as obtained by nuclear magnetic resonance. Phys. Med. Biol., v. 35, n. 12, p. 1611-1622, 1990.

79 GARIB, D.G.; RAYMUNDO JUNIOR, R.; RAIMUNDO, M.V.; RAYMUNDO, D.V.; FERREIRA, S.N. Tomografia computadorizada de feixe cônico (cone beam): entendendo este novo método de diagnóstico por imagem com promissora aplicabilidade na ortodontia. R. Dent. Press. Ortodon. Ortop. Facial, Maringá, v. 12, n. 2, mar./abr. 2007. Disponível em: <http://www.scielo.br/img/revistas/dpress/v12n2/18f11.jpg >. Acesso em: 22 jun. 2009.

80 INSTITUTO SUPERIOR DE ENGENHARIA DO PORTO. Departamento de física: aula 4. Disponível em:

<http://www.defi.isep.ipp.pt/ ndg/site/docs/Aula4.pdf>. Acesso em: 22 jun. 2009.

81 LEITE, F. Validação em análise química. 5 ed. Campinas: Átomo, 2008.

82 INCERPI, P.H.; NORONHA, J.L.; BARCA, L.F. Incerteza de medição simplificada na análise da conformidade do produto. In: ENCONTRO NACIONAL DE ENGENHARIA DE PRODUÇÃO, 25., 2005, Porto Alegre. Anais eletrônicos... Porto Alegre: Associação Brasileira de Engenharia de Produção, 2005. Disponível em:

<http://www.abepro.org.br/biblioteca/ENEGEP2005_Enegep0205_0930.pdf>. Acesso em: 22 jun. 2009.

83 VÁVROVÁ, M. Radiodiagnostika. Ostrava: Městská Nemocnice Ostrava Příspěvková Organizace. Disponível em:

<http://www.mnof.cz/oddeleni/rdg.php?print=1>. Acesso em: 22 jun. 2009. 
84 A.R. SMITH DEPARTMENT OF CHEMISTRY. Facilities - equipment. Disponível em:

<http://www.chemistry.appstate.edu/facilities/equipment/equipment.htm>. Acesso em: 22 jun. 2009.

85 CANTERAS, M.M. Radiocirurgia. R. Neurociências, São Paulo, v. 13, n. 4, p. 190-195, out./dez. 2005. Disponível em:

<http://www.revistaneurociencias.com.br/edicoes/2005/RN\%2013\%2004/Page s\%20from\%20RN\%2013\%2004-4.pdf>. Acesso em: 22 jun. 2009.

86 KRAUS BACK AND NECK INSTITUTE. Gamma Knife. Disponível em: <http://www.lowback-pain.com/gamma\%20knife.htm>. Acesso em: 22 jun. 2009.

87 YAMAMOTO, M.; BARFOD, B.E. Gamma Knife radiosurgery for arteriovenous malformations: past hope and present reality. J. Korean Neurosurg. Soc., Japan, v. 39, p. 1-10, 2006. Disponível em:

<http://www.jkns.or.kr/htm/pdfdown.asp?pn=0042006001>. Acesso em: 22 jun. 2009. 